\title{
Development of an inorganic and organic aerosol model (CHIMERE $2017 \beta$ v1.0): seasonal and spatial evaluation over Europe
}

\author{
Florian Couvidat $^{1}$, Bertrand Bessagnet ${ }^{1}$, Marta Garcia-Vivanco ${ }^{2}$, Elsa Real ${ }^{1}$, Laurent Menut ${ }^{3}$, and Augustin Colette ${ }^{1}$ \\ ${ }^{1}$ Institut National de l'Environnement Industriel et des Risques (INERIS), Verneuil-en-Halatte, France \\ ${ }^{2}$ Centro de Investigaciones Energéticas, Medioambientales y Tecnológicas (CIEMAT), Departamento de Medio Ambiente, \\ Av. Complutense 22, Madrid, Spain \\ ${ }^{3}$ Laboratoire de Métérologie Dynamique (LMD), IPSL, CNRS, UMR8539, Palaiseau CEDEX, France
}

Correspondence: Florian Couvidat (florian.couvidat@ineris.fr)

Received: 16 May 2017 - Discussion started: 6 July 2017

Revised: 26 October 2017 - Accepted: 17 November 2017 - Published: 15 January 2018

\begin{abstract}
A new aerosol module was developed and integrated in the air quality model CHIMERE. Developments include the use of the Model of Emissions and Gases and Aerosols from Nature (MEGAN) 2.1 for biogenic emissions, the implementation of the inorganic thermodynamic model ISORROPIA 2.1, revision of wet deposition processes and of the algorithms of condensation/evaporation and coagulation and the implementation of the secondary organic aerosol (SOA) mechanism $\mathrm{H}^{2} \mathrm{O}$ and the thermodynamic model SOAP.

Concentrations of particles over Europe were simulated by the model for the year 2013. Model concentrations were compared to the European Monitoring and Evaluation Programme (EMEP) observations and other observations available in the EBAS database to evaluate the performance of the model. Performances were determined for several components of particles (sea salt, sulfate, ammonium, nitrate, organic aerosol) with a seasonal and regional analysis of results.

The model gives satisfactory performance in general. For sea salt, the model succeeds in reproducing the seasonal evolution of concentrations for western and central Europe. For sulfate, except for an overestimation of sulfate in northern Europe, modeled concentrations are close to observations and the model succeeds in reproducing the seasonal evolution of concentrations. For organic aerosol, the model reproduces with satisfactory results concentrations for stations with strong modeled biogenic SOA concentrations.

However, the model strongly overestimates ammonium nitrate concentrations during late autumn (possibly due
\end{abstract}

to problems in the temporal evolution of emissions) and strongly underestimates summer organic aerosol concentrations over most of the stations (especially in the northern half of Europe). This underestimation could be due to a lack of anthropogenic SOA or biogenic emissions in northern Europe.

A list of recommended tests and developments to improve the model is also given.

\section{Introduction}

Atmospheric particulate matter (PM) contributes to adverse effects on health and ecosystems. The development of models is necessary to estimate exposure in order to produce air quality forecasting (Rouil et al., 2009), to evaluate the efficiency of air pollution mitigation strategies (Schucht et al., 2015) and to study the impact of emission sources on air quality. However, developing models with enough precision is quite challenging due to the complexity and variety of phenomena and the great number of chemical species involved. Numerous air quality models have been developed to simulate PM concentrations (Emmons et al., 2010; Pozzoli et al., 2011; Zhang et al., 2010; Simpson et al., 2012; Carlton et al., 2010; Menut et al., 2013; Sartelet et al., 2007).

PM consists of various chemical species: organic matter $(\mathrm{OM})$, elemental carbon (EC) mainly originating from anthropogenic sources, major inorganic components (ammonium, nitrate and sulfate), sea salt, mineral dust and other crustal compounds. These species originate from numer- 
ous emission sources which can be natural (biogenic emissions from vegetation, sea-salt emissions, dust emissions) or anthropogenic (for example, emissions from residential biomass burning, road traffic, agriculture, industrial sources). Particles can be primarily emitted in the atmosphere or secondarily formed from chemical reactions.

OM typically represents between 20 and $60 \%$ (Kanakidou et al., 2005; Yu et al., 2007; Zhang et al., 2007) of the fine particulate mass $\left(\mathrm{NH}_{3}\right)$ and is formed via the partitioning of semi-volatile organic compounds (SVOCs) between the gas and particle phases. These SVOCs can be primary in origin but $\mathrm{OM}$ is often considered to be mainly constituted of secondary organic compounds formed via the oxidation in the atmosphere of volatile organic compounds (VOCs) which can be biogenic (like isoprene, monoterpenes and sesquiterpenes) or anthropogenic (for example, long-chain alkanes, toluene and other aromatics). The oxidation (in the gas phase or in the aqueous phase) of sulfur dioxide $\left(\mathrm{SO}_{2}\right)$ produces sulfuric acid $\left(\mathrm{H}_{2} \mathrm{SO}_{4}\right)$ which leads to sulfate formation via condensation or nucleation processes. If ammonia $\left(\mathrm{NH}_{3}\right)$ is present in the atmosphere, it will neutralize sulfate and form ammonium. If there is still $\mathrm{NH}_{3}$ available in the gas phase, it can lead to the formation of ammonium nitrate in the presence of nitric acid $\left(\mathrm{HNO}_{3}\right)$ (formed via the oxidation of nitrogen oxides, $\mathrm{NO}_{x}$ ). Sea salt and natural dust are primary natural particles and can interact with atmospheric pollutants. For example, $\mathrm{HNO}_{3}$ can condense onto sea salt and lead to sodium nitrate and then to the volatilization of chloride acid $(\mathrm{HCl})$. Similarly, $\mathrm{HNO}_{3}$ can condense onto dust particles and lead to the formation of calcium nitrate. As dust and sea salt are mainly coarse particles, these two processes can lead to the formation of coarse nitrate, whereas ammonium nitrate will mainly remain in fine particles.

To simulate PM concentrations, models have to take into account the microphysics of particles (condensation/evaporation, coagulation, nucleation), chemical mechanisms for the gas-phase chemistry, aerosol thermodynamics, emissions and deposition processes. In the scope of this study, a new aerosol module has been developed in a modified version of the CHIMERE model. This new model version is referred to hereafter as CHIMERE 2017 $\beta$. The results of the model were evaluated by comparison to measurements of $\mathrm{PM}_{2.5}$ and $\mathrm{PM}_{10}$ concentrations but also of composition $\left(\mathrm{Cl}, \mathrm{Na}^{+}, \mathrm{SO}_{4}^{2-}, \mathrm{NO}_{3}^{-}, \mathrm{NH}_{4}^{+}\right.$, organic carbon).

The aerosol module include the following processes:

- Biogenic emissions are computed with the Model of Emissions and Gases and Aerosols from Nature (MEGAN) 2.1 algorithm (Guenther et al., 2012) with high-resolution emission factors and leaf area index (LAI) data.

- Below-cloud scavenging is represented as in Henzing et al. (2006) with a polydispersed distribution of cloud droplets (providing a distribution of droplet diameter as a function of rainfall). In-cloud scavenging is represented with the algorithm of Croft et al. (2010).

- Evaporation/condensation of semi-volatile species is represented with the algorithm of Pandis et al. (1993) using thermodynamic equilibria. Coagulation of particles is represented as in Debry et al. (2007). Thermodynamic equilibria are computed with the ISORROPIA II model (Fountoukis and Nenes, 2007) for inorganic compounds and with the Secondary Organic Aerosol Processor (SOAP) (Couvidat and Sartelet, 2015) for organic compounds. $\mathrm{H}_{2} \mathrm{SO}_{4}$ nucleation based on Kulmala and Pirjola (1998) for sulfuric acid nucleation is used.

- The SOA formation mechanism of Couvidat et al. (2012) is used for toluene, xylene and biogenic VOCs.

- The amount of water in particles is calculated as a function of humidity and the composition of particles using ISORROPIA. This amount is used to calculate the wet density of particles (with water) and the wet diameter of particles which are used to compute the kinetics of absorption, coagulation and deposition.

The aerosol module is described in the part "model development" of the paper. The second part focuses on the comparison of modeled concentrations with observations for $\mathrm{Cl}^{-}, \mathrm{Na}^{+}, \mathrm{SO}_{4}^{2-}, \mathrm{NO}_{3}^{-}, \mathrm{NH}_{4}^{+}$, organic carbon, $\mathrm{PM}_{2.5}$ and $\mathrm{PM}_{10}$ with a regional and seasonal analysis of results.

\section{Method}

The CHIMERE $2017 \beta$ is based on the CHIMERE 2013 version (Menut et al., 2013) which is modified by implementing the new aerosol module and chemical mechanisms. Table S1 in the Supplement provides a comparison of algorithms between CHIMERE $2017 \beta$ with CHIMERE 2013 to illustrate the differences between the two versions. CHIMERE $2017 \beta$ was then evaluated for the simulation of PM concentration and composition over Europe in 2013.

The model uses a sectional approach where particles are separated into several diameter bins. In this study, particles were separated into 10 bins from $10 \mathrm{~nm}$ to $10 \mu \mathrm{m}$.

\subsection{Model development}

\subsubsection{Chemical mechanisms}

A simple aqueous-phase chemical mechanism is used for sulfate formation from the oxidation of $\mathrm{SO}_{2}$ in clouds. This mechanism assumes that the aqueous-phase concentrations of $\mathrm{SO}_{2}, \mathrm{H}_{2} \mathrm{O}_{2}$ and $\mathrm{O}_{3}$ are at equilibrium with the gas phase with partitioning being a function of $\mathrm{pH}$ for $\mathrm{SO}_{2}$. The $\mathrm{pH}$ of clouds is computed by taking into account the absorption and dissociation of various acids $\left(\mathrm{H}_{2} \mathrm{SO}_{4}, \mathrm{HCl}, \mathrm{HNO}_{3}\right.$ and $\mathrm{H}_{2} \mathrm{CO}_{3}$ ) and the formation of $\mathrm{NH}_{4}^{+}$. The effect of dust on 
$\mathrm{pH}$ is not taken into account as composition of dust is not represented within CHIMERE. The electroneutrality equation is solved with the Newton-Raphson method. Henry's law constants and equilibrium constants are taken from Seinfeld and Pandis (1998). The following reactions are taken into account:

$$
\begin{aligned}
& \mathrm{SO}_{2}^{\mathrm{aq}}+\mathrm{O}_{3}^{\mathrm{aq}} \rightarrow \mathrm{SO}_{4}^{2-} \quad k=2.4 \times 10^{4} \\
& \mathrm{HSO}_{3}^{-}+\mathrm{O}_{3}^{\mathrm{aq}} \rightarrow \mathrm{SO}_{4}^{2-} \\
& k=3.7 \times 10^{5} \times \exp \left(-5530 \times\left(\frac{1}{T}-\frac{1}{298}\right)\right) \\
& \mathrm{SO}_{3}^{2-}+\mathrm{O}_{3}^{\mathrm{aq}} \rightarrow \mathrm{SO}_{4}^{2-} \\
& k=1.5 \times 10^{9} \times \exp \left(-5280 \times\left(\frac{1}{T}-\frac{1}{298}\right)\right) \\
& \mathrm{S}(\mathrm{IV})^{\mathrm{aq}}+\mathrm{H}_{2} \mathrm{O}_{2}^{\mathrm{aq}} \rightarrow \mathrm{SO}_{4}^{2-} \\
& k=7.5 \times 10^{7} \times \exp \left(-4430 \times\left(\frac{1}{T}-\frac{1}{298}\right)\right),
\end{aligned}
$$

with $\mathrm{O}_{3}^{\text {aq }}$ the concentration of $\mathrm{O}_{3}$ in the aqueous phase, $\mathrm{H}_{2} \mathrm{O}_{2}^{\text {aq }}$ the concentration of $\mathrm{H}_{2} \mathrm{O}_{2}$ in the aqueous phase, $\mathrm{SO}_{2}^{\mathrm{aq}}$ the concentration of $\mathrm{SO}_{2}$ in the aqueous phase, $\mathrm{HSO}_{3}^{-}$and $\mathrm{SO}_{3}^{2-}$, respectively, the concentration of the bisulfite and sulfite ions (at equilibrium with $\mathrm{SO}_{2}^{\mathrm{aq}}$ ), $\mathrm{S}(\mathrm{IV})^{\mathrm{aq}}$ corresponding to the total $\mathrm{SO}_{2}^{\mathrm{aq}}, \mathrm{HSO}_{3}^{-}$and $\mathrm{SO}_{3}^{2-}, T$ the temperature and the kinetic rate parameter in $\mathrm{M}^{-1} \mathrm{~s}^{-1}$.

For SVOC formation that leads to the formation of SOA compounds after partitioning, the mechanism of Couvidat et al. (2012) is used. The mechanism is shown in Table 1. It takes into account the formation of SVOC from biogenic (isoprene, monoterpenes, sesquiterpenes) and anthropogenic precursors (toluene, xylenes) under high- $\mathrm{NO}_{x}$ and low- $\mathrm{NO}_{x}$ conditions.

Following Couvidat et al. (2012), primary organic aerosols (POAs) are assumed to be SVOCs and are split into three compounds: POAIP $\left(K p=1.1 \mathrm{~m}^{3} \mu \mathrm{g}^{-1}\right)$, POAmP $(K p=$ $\left.0.0116 \mathrm{~m}^{3} \mu \mathrm{g}^{-1}\right)$ and POAhP $\left(K p=0.00031 \mathrm{~m}^{3} \mu \mathrm{g}^{-1}\right)$ having, respectively, a low, medium and high volatility to follow the dilution curve of POA in Robinson et al. (2007). The aging of these compounds is also taken into account with a reaction with $\mathrm{OH}$ which leads to less volatile compounds (SOAIP, SOAmP and SOAhP) via the following reactions:

$$
\begin{aligned}
& \mathrm{POAlP}+\mathrm{OH} \stackrel{k}{\rightarrow} \mathrm{SOAlP}+\mathrm{OH} \\
& \mathrm{POAmP}+\mathrm{OH} \stackrel{k}{\rightarrow} \mathrm{SOAmP}+\mathrm{OH} \\
& \mathrm{POAhP}+\mathrm{OH} \stackrel{k}{\rightarrow} \mathrm{SOAhP}+\mathrm{OH},
\end{aligned}
$$

with $k$ the kinetic rate constant equal to $2 \times$ $10^{-11}$ molecules ${ }^{-1} \mathrm{~cm}^{3} \mathrm{~s}^{-1}$. Oxidants are present as both reactants and products so that a reaction added to the mechanism will not affect the original photochemical oxidant concentrations. Following Grieshop et al. (2009), aging is assumed to lead to a decrease of volatility by a factor of 100 (SOAIP, SOAmP and SOAhP are, respectively, less volatile by a factor of 100 than POAIP, POAmP and POAhP). Properties of these species are summarized in Table 3.

\subsubsection{Biogenic emissions}

Biogenic emissions are computed with the MEGAN 2.1 algorithm (Guenther et al., 2012), which is implemented in CHIMERE. It uses meteorological conditions (temperature, solar radiation and soil moisture), the leaf area index and the plant functional type (PFT) to compute biogenic emissions. In this study, the above-canopy model is used. The effects of soil moisture on isoprene emissions are not taken into account because no wilting point (i.e., the soil moisture level below which plants cannot extract water from soil) database is available over Europe. Therefore, isoprene emissions may be overestimated during dry periods.

High spatiotemporal data ( 30 arcsec every 8 days) generated from MODIS (Yuan et al., 2011) are used for LAI inputs. The 30 arcsec USGS (US Geophysical Survey) land-use database is used to provide information on the plant functional type. The PFT is then combined with the emission factors for each functional type of Guenther et al. (2012) to compute the landscape average emission factors.

\subsubsection{Anthropogenic emissions}

VOC emissions (based on the European Monitoring and Evaluation Programme (EMEP) inventory in this study) are used as in Menut et al. (2013); volatile organic compounds are split into CHIMERE model species according to a speciation database depending on the emission sector.

For primary SVOC emissions, a SVOC/POA factor is applied to convert POA emissions into SVOC emissions. In Couvidat et al. (2012), a SVOC/POA factor of 5 was used on the basis that SVOC primary emissions are underestimated. With this factor, the model was able to simulate the strong concentrations of organic aerosols in winter and to give satisfactory results over most of Europe. Denier van der Gon et al. (2015) has shown that POA emissions are greatly underestimated due to a strong underestimation of residential wood burning emissions by a factor of 3 over Europe (between 1 and 10 depending on the countries) if SVOC emissions are included. This strong underestimation of emissions is due to the use of filters at high temperature (for which SVOCs are mainly present as vapors) for emission factor measurement. This result is confirmed by May et al. (2013) who found that $80 \%$ of SVOCs evaporate at high temperature. By correcting POA emissions and assuming that intermediate-volatility organic compounds (IVOCs) are missing from the inventory (with the assumption that IVOC emissions are 1.5 times the size of POA emissions), Denier van der Gon et al. (2015) obtained satisfactory results in winter but still had an underesti- 
Table 1. Reactions leading to SOA formation ${ }^{\mathrm{a}} . \mathrm{C}_{5} \mathrm{H}_{8}$ refers to isoprene, APINEN to $\alpha$-pinene, BPINEN to $\beta$-pinene, LIMONE to limonene, HUMULE to sesquiterpenes, TOL to toluene, XYL to xylene.

\begin{tabular}{|c|c|}
\hline Reaction & $\begin{array}{l}\text { Kinetic rate parameter } \\
\left(\mathrm{s}^{-1} \text { or molecule }{ }^{-1} \mathrm{~cm}^{3} \mathrm{~s}^{-1}\right)\end{array}$ \\
\hline $\mathrm{C}_{5} \mathrm{H}_{8}+\mathrm{OH} \rightarrow \mathrm{ISOR}+\mathrm{OH}$ & $2.54 \times 10^{-11} \times \exp (408 / T)$ \\
\hline $\mathrm{C}_{5} \mathrm{H}_{8}+\mathrm{NO}_{3} \rightarrow \mathrm{ISON}+\mathrm{NO}_{3}$ & $3.03 \times 10^{-12} \times \exp (-448 / T)$ \\
\hline $\mathrm{ISOR}+\mathrm{HO}_{2} \rightarrow 0.282 \mathrm{BiPER}+0.030 \mathrm{BiDER}+\mathrm{HO}_{2}$ & $2.05 \times 10^{-13} \times \exp (1300 / T)$ \\
\hline $\mathrm{ISOR}+\mathrm{CH}_{3} \mathrm{COO} \rightarrow 0.026 \mathrm{BiMT}+0.219 \mathrm{MACR}+\mathrm{CH}_{3} \mathrm{COO}$ & $8.40 \times 10^{-14} \times \exp (221 / T)$ \\
\hline $\mathrm{ISOR}+\mathrm{CH}_{3} \mathrm{O}_{2} \rightarrow 0.026 \mathrm{BiMT}+0.219 \mathrm{MACR}+\mathrm{CH}_{3} \mathrm{O}_{2}$ & $3.40 \times 10^{-14} \times \exp (221 / T)$ \\
\hline $\mathrm{ISOR}+\mathrm{NO} \rightarrow 0.418 \mathrm{MACR}+0.046 \mathrm{ISON}+\mathrm{NO}$ & $2.43 \times 10^{-12} \times \exp (360 / T)$ \\
\hline $\mathrm{ISOR}+\mathrm{NO}_{3} \rightarrow 0.438 \mathrm{MACR}+\mathrm{NO}_{3}$ & $1.20 \times 10^{-12}$ \\
\hline $\mathrm{ISON}+\mathrm{OH} \rightarrow \mathrm{OH}$ & $1.30 \times 10^{-11}$ \\
\hline $\mathrm{ISON}+\mathrm{NO}_{3} \rightarrow 0.074 \mathrm{BiNIT} 3+\mathrm{NO}_{3}$ & $6.61 \times 10^{-13}$ \\
\hline $\mathrm{MACR}+\mathrm{NO} \rightarrow \mathrm{NO}$ & $2.54 \times 10^{-12} \times \exp (360 / T)$ \\
\hline $\mathrm{MACR}+\mathrm{HO}_{2} \rightarrow \mathrm{HO}_{2}$ & $1.82 \times 10^{-13} \times \exp (1300 / T)$ \\
\hline $\mathrm{MACR}+\mathrm{CH}_{3} \mathrm{O}_{2} \rightarrow \mathrm{CH}_{3} \mathrm{O}_{2}$ & $3.40 \times 10^{-14} \times \exp (221 / T)$ \\
\hline $\mathrm{MACR}+\mathrm{NO}_{2} \rightarrow \mathrm{MPAN}+\mathrm{NO}_{2}$ & $2.80 \times 10^{-12} \times \exp (181 / T)$ \\
\hline $\mathrm{MPAN} \rightarrow \mathrm{MACR}$ & $1.60 \times 10^{16} \times \exp (-13486 / T)$ \\
\hline $\mathrm{MPAN}+\mathrm{OH} \rightarrow 0.067 \mathrm{BiMGA}+0.047 \mathrm{BiNGA}+\mathrm{OH}$ & $3.20 \times 10^{-11}$ \\
\hline $\mathrm{MPAN}+\mathrm{NO}_{3} \rightarrow 0.067 \mathrm{BiMGA}+0.047 \mathrm{BiNGA}+\mathrm{NO}_{3}$ & $3.20 \times 10^{-11}$ \\
\hline $\mathrm{BiPER}+\mathrm{h} v \rightarrow$ Degradation products & $k=50 \times$ kinetic of photolysis of $\mathrm{H}_{2} \mathrm{O}_{2}$ \\
\hline $\mathrm{APINEN}+\mathrm{OH} \rightarrow 0.30 \mathrm{BiA} 0 \mathrm{D}+0.17 \mathrm{BiA} 1 \mathrm{D}+0.10 \mathrm{BiA} 2 \mathrm{D}+\mathrm{OH}$ & $1.21 \times 10^{-11} \times \exp (440 / T)$ \\
\hline APINEN $+\mathrm{O}_{3} \rightarrow 0.18 \mathrm{BiA} 0 \mathrm{D}+0.16 \mathrm{BiA} 1 \mathrm{D}+0.05 \mathrm{BiA} 2 \mathrm{D}+\mathrm{O}_{3}$ & $5.00 \times 10^{-16} \times \exp (-530 / T)$ \\
\hline $\mathrm{APINEN}+\mathrm{NO}_{3} \rightarrow 0.70 \mathrm{BiA0D}+0.10 \mathrm{BiNIT}+\mathrm{NO}_{3}$ & $1.19 \times 10^{-12} \times \exp (-490 / T)$ \\
\hline $\mathrm{BPINEN}+\mathrm{OH} \rightarrow 0.07 \mathrm{BiA} 0 \mathrm{D}+0.08 \mathrm{BiA} 1 \mathrm{D}+0.06 \mathrm{BiA} 2 \mathrm{D}+\mathrm{OH}$ & $2.38 \times 10^{-11} \times \exp (357 / T)$ \\
\hline $\mathrm{BPINEN}+\mathrm{O}_{3} \rightarrow 0.09 \mathrm{BiA} 0 \mathrm{D}+0.13 \mathrm{BiA} 1 \mathrm{D}+0.04 \mathrm{BiA} 2 \mathrm{D}+\mathrm{O}_{3}$ & $1.50 \times 10^{-17}$ \\
\hline $\mathrm{BPINEN}+\mathrm{NO}_{3} \rightarrow 0.02 \mathrm{BiA} 0 \mathrm{D}+0.63 \mathrm{BiNIT}+\mathrm{NO}_{3}$ & $2.51 \times 10^{-12}$ \\
\hline $\mathrm{LIMONE}+\mathrm{OH} \rightarrow 0.35 \mathrm{BiA} 0 \mathrm{D}+0.20 \mathrm{BiA} 1 \mathrm{D}+0.0035 \mathrm{BiA} 2 \mathrm{D}+\mathrm{OH}$ & $4.20 \times 10^{-11} \times \exp (401 / T)$ \\
\hline $\mathrm{LIMONE}+\mathrm{O}_{3} \rightarrow 0.09 \mathrm{BiA} 0 \mathrm{D}+0.10 \mathrm{BiA} 1 \mathrm{D}+\mathrm{O}_{3}$ & $2.95 \times 10^{-15} \times \exp (783 / T)$ \\
\hline $\mathrm{LIMONE}+\mathrm{NO}_{3} \rightarrow 0.69 \mathrm{BiA} 0 \mathrm{D}+0.27 \mathrm{BiNIT}+\mathrm{NO}_{3}$ & $1.22 \times 10^{-11}$ \\
\hline $\mathrm{HUMULE}+\mathrm{OH} \rightarrow 0.74 \mathrm{BiBmP}+0.26 \mathrm{BiBlP}+\mathrm{OH}$ & $2.93 \times 10^{-10}$ \\
\hline $\mathrm{TOL}+\mathrm{OH} \rightarrow \ldots+0.25 \mathrm{TOLP}$ & $1.80 \times 10^{-12} \times \exp (355 / T)$ \\
\hline $\mathrm{TOLP}+\mathrm{HO}_{2} \rightarrow 0.78 \mathrm{AnClP}+\mathrm{HO}_{2}$ & $3.75 \times 10^{-13} \times \exp (980 / T)$ \\
\hline $\mathrm{TOLP}+\mathrm{CH}_{3} \mathrm{COO} \rightarrow 0.78 \mathrm{AnClP}+\mathrm{CH}_{3} \mathrm{COO}$ & $7.40 \times 10^{-13} \times \exp (765 / T)$ \\
\hline $\mathrm{TOLP}+\mathrm{CH}_{3} \mathrm{O}_{2} \rightarrow 0.78 \mathrm{AnClP}+\mathrm{CH}_{3} \mathrm{O}_{2}$ & $3.56 \times 10^{-14} \times \exp (708 / T)$ \\
\hline $\mathrm{TOLP}+\mathrm{NO} \rightarrow 0.097 \mathrm{AnBlP}+0.748 \mathrm{AnBmP}+\mathrm{NO}$ & $2.70 \times 10^{-12} \times \exp (360 / T)$ \\
\hline $\mathrm{TOLP}+\mathrm{NO}_{3} \rightarrow 0.097 \mathrm{AnBlP}+0.748 \mathrm{AnBmP}+\mathrm{NO}_{3}$ & $1.2 \times 10^{-12}$ \\
\hline $\mathrm{XYL}+\mathrm{OH} \rightarrow \ldots+0.274 \mathrm{XYLP}$ & $1.70 \times 10^{-11} \times \exp (116 / T)$ \\
\hline $\mathrm{XYLP}+\mathrm{HO}_{2} \rightarrow 0.71 \mathrm{AnClP}+\mathrm{HO}_{2}$ & $3.75 \times 10^{-13} \times \exp (980 / T)$ \\
\hline $\mathrm{XYLP}+\mathrm{CH}_{3} \mathrm{COO} \rightarrow 0.71 \mathrm{AnClP}+\mathrm{CH}_{3} \mathrm{COO}$ & $7.40 \times 10^{-13} \times \exp (765 / T)$ \\
\hline $\mathrm{XYLP}+\mathrm{CH}_{3} \mathrm{O}_{2} \rightarrow 0.71 \mathrm{AnClP}+\mathrm{CH}_{3} \mathrm{O}_{2}$ & $3.56 \times 10^{-14} \times \exp (708 / T)$ \\
\hline $\mathrm{XYLP}+\mathrm{NO} \rightarrow 0.063 \mathrm{AnBlP}+0.424 \mathrm{AnBmP}+\mathrm{NO}$ & $2.70 \times 10^{-12} \times \exp (360 / T)$ \\
\hline $\mathrm{XYLP}+\mathrm{NO}_{3} \rightarrow 0.063 \mathrm{AnBlP}+0.424 \mathrm{AnBmP}+\mathrm{NO}_{3}$ & $1.2 \times 10^{-12}$ \\
\hline
\end{tabular}

a Oxidants may be present as both reactants and products so that a reaction added to the mechanism will not affect the original photochemical oxidant concentrations.

mation of OM from biomass burning. The authors therefore used a total (IVOC + SVOC)/POA factor of 7.5.

In this study, POAs are transformed into SVOC emissions: a SVOC/POA ratio of 5 is used for residential emissions (without adding IVOC emissions and assuming that POA emissions only account for $20 \%$ of emissions) and 1 for the other sectors (assuming therefore that no SVOC emissions from other sectors are missing). For each sector, emissions of SVOC are split into emissions of POAIP (25\% of emissions), POAmP (32\% of emissions) and POAhP (43\% of 
emissions) to follow the dilution curve of POA in Robinson et al. (2007). A sensitivity analysis of the SVOC/POA ratio was already performed by Couvidat et al. (2012).

However, IVOCs are not taken into account because of the large uncertainties on their emissions and their oxidation mechanism. Pye and Seinfeld (2010) used naphthalene as a surrogate for IVOC and used the yields from smog chamber experiments (Chan et al., 2009; Kautzman et al., 2010) to develop a mechanism of IVOC oxidation. The authors found that only minor concentrations of SOA are formed from IVOC (only $5 \%$ of total OM), whereas Zhao et al. (2016a) simulated strong concentrations of SOA from IVOC contributing to half the OM over China. However, Pye and Seinfeld (2010) argued that naphthalene may not be an appropriate choice for the surrogate species. Platt et al. (2013) investigated the SOA formation from gasoline vehicles in an environmental reaction chamber and found that only a small part of SOA could be explained by the oxidation of aromatic compounds, and therefore most of the SOA formation could be attributed to the oxidation of IVOC. This result is however contradicted by Nordin et al. (2013) who found that most of the SOA formation is due to the oxidation of aromatic compounds.

\subsubsection{Thermodynamic of secondary organic and inorganic aerosols}

Two thermodynamic modules are implemented inside CHIMERE to take into account the formation of secondary aerosols: ISORROPIA v2.1 (Fountoukis and Nenes, 2007) for inorganic aerosols and SOAP (Couvidat and Sartelet, 2015) for organic aerosols. Due to the lack of information on the dust composition, crustal elements are not taken into account for the partitioning, as they can strongly impact the formation of ammonium nitrate (Ansari and Pandis, 1999; Moya et al., 2002). However, a simple reaction (described in Sect. 2.1.8) is added to CHIMERE to take into account the formation of calcium nitrate as done by Hodzic et al. (2006).

SOAP computes the partitioning of organic compounds between the gas and particle phases according to the complexity required by the user. It uses the molecular surrogate approach in which surrogate compounds are associated with molecular structures to estimate several properties and parameters (hygroscopicity, absorption into the aqueous phase of particles, activity coefficients and phase separation). Each surrogate can be hydrophilic (condense only into the aqueous phase of particles), hydrophobic (condense only into the organic phases of particles) or both. Activity coefficients are computed with the UNIFAC (UNIversal Functional group Activity Coefficient; Fredenslund et al., 1975) thermodynamic model for short-range interactions and with the Aerosol Inorganic-Organic Mixtures Functional groups Activity Coefficients (AIOMFAC) parameterization for medium- and long-range interactions between electrolytes and organic compounds (Zuend et al., 2008, 2011; Zuend and Seinfeld, 2012; Ganbavale et al., 2015).

SOAP can simulate SOA formation with either an equilibrium representation or a dynamic representation of organic aerosol condensation processes. The dynamic representation takes into account the condensation/evaporation kinetic of organic compounds and their diffusion in the particle by dividing the organic particle into several layers. However, this method requires a lot of computing time. Therefore, in a first approach, the equilibrium approach of SOAP is used.

As in the hydrophilic/hydrophobic organic $\mathrm{H}^{2} \mathrm{O}$ mechanism (Couvidat et al., 2012), SOA surrogate compounds are assumed to be either hydrophilic or hydrophobic and the impact of medium-range and long-range interactions on activity coefficients are not taken into account. For hydrophilic acids, SOAP takes into account the dissociation of organic acids at high $\mathrm{pH}$ as a function of their dissociation constant. Moreover, Pun and Seigneur (2007) developed a parameterization to take into account the impact of $\mathrm{pH}$ on the oligomerization of aldehyde compounds by computing an effective Henry's law constant:

$H_{\mathrm{eff}}=H\left(1+0.1\left(\frac{a\left(H^{+}\right)}{10^{-6}}\right)^{1.91}\right)$,

where $H_{\mathrm{eff}}$ is the effective Henry's law constant of BiA0D (surrogate species of the $\mathrm{H}^{2} \mathrm{O}$ mechanism for aldehydes formed from the oxidation of monoterpenes), $H$ is the monomer Henry's law constant of BiA0D and $a\left(\mathrm{H}^{+}\right)$is the activity of protons in the aqueous phase.

Thermodynamic properties of biogenic and anthropogenic species are shown in Table 2. Table 3 shows the properties of primary SVOC compounds (POAlP, POAmP, POAhP) and their aging products.

\subsubsection{Computation of the wet diameter and the wet density of particles}

Several parameterizations (condensation/evaporation, coagulation, particle deposition) depend on the particle diameter $D_{\mathrm{p} \text {, wet }}$ which is different from the dry diameter (without water) $D_{\mathrm{p} \text {, dry }}$. Similarly, dry deposition of particles depends on the wet density $d_{\mathrm{w}}$ of particles.

To compute the wet diameter $D_{\mathrm{p}}$, wet and the wet density $d_{\mathrm{w}}$, ISORROPIA is used to compute the amount of water absorbed by each size bin as a function of the composition and the relative humidity. The method of Semmler et al. (2006) is used to compute the density of the liquid aqueous phase $d_{1}$. The volume of the whole particle is computed with

$V_{\text {tot }}=V_{\text {solid }}+V_{\text {liq, inorg }}+V_{\text {org }}$,

with $V_{\text {tot }}$ the volume of the whole particle, $V_{\text {solid }}$ the volume of the solid part of the particle (including dust, black carbon),

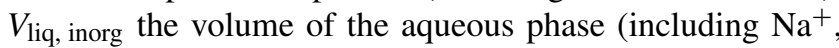
$\mathrm{Cl}^{-}, \mathrm{SO}_{4}^{2-}, \mathrm{NH}_{4}^{+}, \mathrm{NO}_{3}^{-}$and $\mathrm{H}_{2} \mathrm{O}$ ) and $V_{\text {org }}$ the volume of the 
Table 2. Properties of the surrogate SOA species of $\mathrm{H}^{2} \mathrm{O}$ (Couvidat et al., 2012).

\begin{tabular}{llrrrl}
\hline Surrogate & Type & $H^{\mathrm{a}}$ & $P^{0 \mathrm{~b}}$ & $\Delta H_{\mathrm{vap}}{ }^{\mathrm{c}}$ & Comments \\
\hline BiMT & hydrophilic & $3.3 \times 10^{10}$ & $1.45 \times 10^{-6}$ & 38.4 & - \\
BiPER & hydrophilic & $8.1 \times 10^{9}$ & $2.61 \times 10^{-6}$ & 38.4 & - \\
BiDER & hydrophilic & $8.91 \times 10^{10}$ & $4.10 \times 10^{-7}$ & 38.4 & - \\
BiMGA & hydrophilic & $5.25 \times 10^{8}$ & $1.4 \times 10^{-5}$ & 43.2 & $\mathrm{p} K_{\mathrm{a}}=4.0$ \\
BiNGA & hydrophobic & - & $1.4 \times 10^{-5}$ & 43.2 & $K_{\mathrm{p}, \mathrm{eff}}=K_{\mathrm{p}}\left(1+K_{\text {oligo }}\right)^{\mathrm{d}}$ \\
BiNIT3 & hydrophobic & - & $1.45 \times 10^{-6}$ & 38.4 & - \\
\hline BiA0D & hydrophilic & $1.98 \times 10^{6}$ & $2.70 \times 10^{6}$ & 50 & See Eq. $(8)$ \\
BiA1D & hydrophilic & $1.12 \times 10^{8}$ & $2.17 \times 10^{-7}$ & 50 & $\mathrm{p} K_{\mathrm{a}}=3.2$ \\
BiA2D & hydrophilic & $2.67 \times 10^{8}$ & $1.43 \times 10^{-7}$ & 50 & $\mathrm{p} K_{\mathrm{a} 1}=3.4, \mathrm{p} K_{\mathrm{a} 2}=5.1$ \\
BiNIT & hydrophobic & - & $2.5 \times 10^{-6}$ & 109 & - \\
\hline BiB1P & hydrophobic & - & $6.0 \times 10^{-10}$ & 175 & - \\
BiBmP & hydrophobic & - & $3.0 \times 10^{-7}$ & 175 & - \\
\hline AnBlP & hydrophobic & - & $6.8 \times 10^{-8}$ & 50 & - \\
AnBmP & hydrophobic & - & $8.4 \times 10^{-6}$ & 50 & - \\
AnClP & hydrophobic & - & & non-volatile & - \\
\hline
\end{tabular}

${ }^{\mathrm{a}}$ Henry's law constant $\left(\mathrm{ML}^{-1} \mathrm{~atm}^{-1}\right){ }^{\mathrm{b}}$ Saturation vapor pressure (torr). ${ }^{\mathrm{c}}$ Enthalpy of vaporization $\left(\mathrm{kJ} \mathrm{mol}^{-1}\right) .{ }^{\mathrm{d}} K_{\mathrm{Oligo}}(\mathrm{equal}$ to 64.2 ) is used to take into account the formation of oligomers (Couvidat et al., 2012). $K_{\mathrm{p} \text {,eff }}$ is the effective partitioning constant and $K_{\mathrm{p}}$ is the partitioning constant calculated as in Pankow (1994).

Table 3. Properties of primary and aged SVOCs.

\begin{tabular}{|c|c|c|c|}
\hline Surrogate & $\mathrm{MW}^{\mathrm{a}}$ & $K_{\mathrm{p}}^{\mathrm{b}}$ & $\Delta H_{\mathrm{vap}}{ }^{\mathrm{c}}$ \\
\hline POAIP & 280 & 1.1 & 106 \\
\hline POAmP & 280 & 0.0116 & 91 \\
\hline POAhP & 280 & 0.00031 & 79 \\
\hline SOAlP & 392 & 110 & 106 \\
\hline SOAmP & 392 & 1.16 & 91 \\
\hline SOAhP & 392 & 0.031 & 79 \\
\hline
\end{tabular}

organic phase of particles. For simplification purposes, the organic phase density is assumed to be equal to $1300 \mathrm{~kg} \mathrm{~m}^{-3}$ and the density of the aqueous phase is assumed to be not influenced by hydrophilic organic compounds.

Using the density of the solid phase $d_{\text {solid }}$ (assumed to be equal to $2200 \mathrm{~kg} \mathrm{~m}^{-3}$ ), the density of the liquid aqueous phase $d_{1}$ and the density of the organic phase $d_{\text {org }}$, Eq. (9) leads to

$d_{\mathrm{w}}=\left(\frac{w_{\text {solid }}}{d_{\text {solid }}}+\frac{w_{\text {liq, inorg }}}{d_{1}}+\frac{w_{\text {org }}}{d_{\text {org }}}\right)^{-1}$,

with $w_{\text {solid }}, w_{\text {liq, inorg }}$ and $w_{\text {org }}$ the mass fractions inside the particle of, respectively, the solid phase, the aqueous phase and the organic phase.

The wet diameter can be computed with the following equation given by the ratio of the volume of the wet parti- cle to the volume of the dry particle:

$$
\frac{D_{\mathrm{p}, \text { wet }}^{3}}{D_{\mathrm{p}, \text { dry }}^{3}}=\frac{1}{1-w_{\mathrm{H}_{2} \mathrm{O}}} \frac{d_{\mathrm{dry}}}{d_{\mathrm{wet}}},
$$

with $w_{\mathrm{H}_{2} \mathrm{O}}$ the mass fraction of water in the particle and $d_{\mathrm{dry}}$ the dry density of the particle which can be computed with Semmler et al. (2006) and Eq. (9) without taking into account the mass of water.

\subsubsection{Dry deposition of particles and semi-volatile organic species}

Dry deposition is parameterized via a downward flux $\left(F_{\mathrm{dry}, i}\right)$ such that

$F_{\mathrm{dry}, i}=-v_{\mathrm{d}, i} * C_{i}$,

with $v_{\mathrm{d}}$ the deposition velocity and $C_{i}$ the concentration. The deposition velocity is represented via the resistance analogy of Wesely (1989). For each gaseous species $i, v_{\mathrm{d}, i}$ is calculated with

$v_{\mathrm{d}, i}=\frac{1}{R_{a}+R_{\mathrm{b}, i}+R_{\mathrm{c}, i}}$,

with $R_{a}$ the aerodynamic resistance associated with turbulent transport in the atmosphere, $R_{\mathrm{b}, i}$ the quasi-laminar resistance and $R_{\mathrm{c}, i}$ the surface resistance.

The surface resistance depends on the nature of the surface and is generally divided into three categories: water, ground 
and vegetation. For the deposition of gases to water and vegetation, the parameterizations depend on the Henry's law constants of compounds $i$.

For SVOC, Bessagnet et al. (2010) showed that not taking into account dry deposition of gas-phase SVOC could lead to an overestimation of SOA by $50 \%$. As done by Bessagnet et al. (2010), Henry's law constants $H_{i}$ of SVOC are used to take into account their deposition. Henry's law constants of hydrophilic species are taken from Couvidat et al. (2012). For hydrophobic species, they are calculated using the activity coefficients at infinite dilution as in Couvidat and Seigneur (2011), by using the saturation vapor pressure $\mathrm{P}^{0}$ and the activity coefficient of compound $i$ at infinite dilution computed with UNIFAC $\gamma_{i}^{\infty}$ such that

$H_{i}=\lim _{C_{i} \rightarrow 0}\left(\frac{C_{i}}{P_{i}}\right)=\frac{\rho_{\mathrm{water}}}{M_{\mathrm{water}} \times \gamma_{i}^{\infty} \times P_{i}^{0}}$,

with $\rho_{\text {water }}$ the density of water, $M_{\text {water }}$ the molar mass of water, $M$ the primary SVOC (POAlP, POAmP and POAhP), Henry's law constant of $0.01 \mathrm{~mol} \mathrm{~L}^{-1} \mathrm{~atm}^{-1}$ is used (similar to Henry's law constant of alkanes). For their aging products and Henry's law constant of $3000 \mathrm{~mol} \mathrm{~L}^{-1} \mathrm{~atm}^{-1}$ (for a slightly oxidized molecule). Table 4 shows effective Henry's law constants used in this study. For SVOC, Henry's law parameters for wet and dry deposition are computed for a $\mathrm{pH}$ of 5.6 ( $\mathrm{pH}$ of water in the presence of $\mathrm{CO}_{2}$ ).

For dry deposition of particles, the parameterizations of Menut et al. (2013) are used. However, the wet diameter and the wet density are used instead of the dry values.

\subsubsection{Wet deposition of particles and semi-volatile species}

In-cloud scavenging for both gases and aerosols is represented by the parameterization of Croft et al. (2010), assuming that wet deposition by in-cloud scavenging is proportional to the amount of cloud water lost by precipitations such that

$\frac{\mathrm{d} C}{\mathrm{~d} t}_{\text {incl }}=\frac{\zeta_{1} f_{1} p_{\mathrm{r}}}{w_{1} h} C$,

with $p_{\mathrm{r}}$ the precipitation rate (in $\mathrm{g} \mathrm{cm}^{-2} \mathrm{~s}^{-1}$ ), $w_{1}$ the liquid water content of clouds (in $\mathrm{g} \mathrm{cm}^{-3}$ ), $C$ the concentration and $h$ the height of the cell (in centimeters). $f_{1}$ is the fraction of the compound present in the cloud and $\zeta_{1}$ an empirical uptake coefficient chosen equal to 1 .

For gases, $f_{1}$ is computed with the effective Henry's law constant and the liquid water content. For particles, $f_{1}$ is taken as 1 except for particles with a diameter lower than a dry critical radius (chosen equal to $0.1 \mu \mathrm{m}$ ) which are assumed to be too small to form clouds due to the Kelvin effect.

For the below-cloud scavenging of gases and particles, deposition is described by a scavenging coefficient $\lambda$ (in $s^{-1}$ )
Table 4. Effective Henry's law constants used for dry and wet deposition. High numerical values were used for $\mathrm{HNO}_{3}$ and for gaseous $\mathrm{H}_{2} \mathrm{SO}_{4}$ to take into account their hydrophilic properties.

\begin{tabular}{lr}
\hline Compound & $H\left(\mathrm{molL}^{-1} \mathrm{~atm}^{-1}\right)$ \\
\hline $\mathrm{O}_{3}$ & 0.01 \\
$\mathrm{SO}_{2}$ & $10^{5}$ \\
$\mathrm{NO}_{2}$ & 0.01 \\
$\mathrm{NO}$ & $2 \times 10^{-3}$ \\
$\mathrm{NH}_{3}$ & $10^{5}$ \\
$\mathrm{BiA0D}$ & $1.8 \times 10^{6}$ \\
$\mathrm{BiA} 1 \mathrm{D}$ & $2.92 \times 10^{10}$ \\
$\mathrm{BiA} 2 \mathrm{D}$ & $4.23 \times 10^{10}$ \\
$\mathrm{BiMT}$ & $3.3 \times 10^{10}$ \\
$\mathrm{BiPER}$ & $8.1 \times 10^{9}$ \\
$\mathrm{BiDER}$ & $8.91 \times 10^{10}$ \\
$\mathrm{BiMGA}$ & $2.15 \times 10^{10}$ \\
$\mathrm{AnB1P}$ & 0.01 \\
$\mathrm{AnBmP}$ & 0.01 \\
$\mathrm{BiBlP}$ & $1.17 \times 10^{8}$ \\
$\mathrm{BiBmP}$ & $3.05 \times 10^{5}$ \\
AnClP & 0.01 \\
$\mathrm{BiNGA}$ & $2.71 \times 10^{9}$ \\
$\mathrm{BiNIT3}$ & $4.75 \times 10^{6}$ \\
$\mathrm{BiNIT}$ & $7.66 \times 10^{4}$ \\
POAlP & 0.01 \\
POAmP & 0.01 \\
POAhP & 0.01 \\
SOAlP & 3000 \\
SOAmP & 3000 \\
SOAhP & 3000 \\
\hline &
\end{tabular}

such that

$\frac{\mathrm{d} C}{\mathrm{~d} t}=-\lambda C$

For gases, the scavenging coefficient $\lambda_{\mathrm{g}}$ can be calculated with the following equation assuming an irreversible scavenging (Seinfeld and Pandis, 1998):

$\lambda_{\mathrm{g}}=\int_{0}^{\infty} 2 \pi D_{\mathrm{dif}} \operatorname{ShRN}(R) \mathrm{d} R$,

with $R$ the radius of the droplet colliding with the gas, $D_{\mathrm{dif}}$ the molecular diffusion coefficient of the deposited compound, Sh the Sherwood number describing the transfer of gases from air towards a raindrop and $N(R)$ the number of rain droplets in the distribution function.

For particles, the scavenging coefficient is expressed by (Seinfeld and Pandis, 1998)

$\lambda_{\mathrm{g}}=\int_{0}^{\infty} \pi R^{2} U_{\mathrm{t}} E\left(R, R_{\mathrm{p}}\right) N(R) \mathrm{d} R$, 
where $U_{\mathrm{t}}$ is the terminal velocity of the droplet (in $\mathrm{m} \mathrm{s}^{-1}$ ) and $E\left(R, R_{\mathrm{p}}\right)$ is the collision efficiency between a droplet of radius $R$ and a particle of radius $R_{\mathrm{p}}$.

Following Henzing et al. (2006), the rain droplet velocity parameterization of Mätzler (2002) and the rain droplet size distribution parameterizations of de Wolf (1999) are used:

$$
\begin{aligned}
U_{\mathrm{t}}= & 0 \quad R<0.015 \mathrm{~mm} \\
= & 4.323(R-0.015) \quad 0.015 \leq R \leq 0.3 \mathrm{~mm} \\
= & 9.65-10.3 \exp (-0.3 R) \quad R>0.3 \mathrm{~mm} \\
N(R)= & \left(1.047-0.0436 \cdot \ln (P)+0.00734 \cdot(\ln P)^{2}\right) \\
& \times 1.98 \times 10^{-5} P^{-0.384} R^{2.93} \\
& \exp \left(-5.38 P^{-0.186 R}\right),
\end{aligned}
$$

with $P$ the precipitation rate in $\mathrm{mmh}^{-1}$.

\subsubsection{Condensation/evaporation}

Absorption is described by the "bulk equilibrium" approach of Pandis et al. (1993). In this approach, all the bins for which condensation is very fast are merged into a "bulk particulate phase". Following Debry et al. (2007), a cutting diameter of $1.25 \mu \mathrm{m}$ is used to separate bins which are inside the "bulk particle" (with a diameter lower than the cutting diameter) from bins for which condensation/evaporation is represented with a dynamic method. Thermodynamic models are used to compute the partitioning between the gas and particle phases and estimate the gas-phase concentrations at equilibrium. The equilibrium concentration $G_{\mathrm{eq}}$ is calculated by the thermodynamic module ISORROPIA for inorganic semivolatile compounds and by SOAP for SVOC.

The mass of compounds condensing onto particles $\left(\Delta A_{\mathrm{p}}\right)$ is redistributed over bins according to the kinetic of condensation into each bin, whereas the mass of compounds evaporating from each bin is proportional to the amount of the compounds in the bins. If the variation of particulate bulk concentration of compound $i \Delta A_{\mathrm{p}, \mathrm{i}}>0$,

$\Delta A_{\mathrm{p}, \mathrm{i}}^{\mathrm{bin}}=\frac{k_{i}^{\mathrm{bin}}}{\sum_{j} k_{i}^{j}} \Delta A_{\mathrm{p}, \mathrm{i}}$,

with $k_{i}^{\text {bin }}$ the kinetic of condensation of compound $i$ onto the bin and $\Delta A_{\mathrm{p}, \mathrm{i}}^{\mathrm{bin}}$ the concentration of compound $i$ inside the bin. The kinetic is given by Seinfeld and Pandis (1998):

$k_{i}^{\text {bin }}=$ Number $^{\text {bin }} \frac{2 \pi D_{\mathrm{p}, \text { wet }}^{\text {bin }} D_{i} M_{i}}{R T} f(K n, \alpha)$,

with Number ${ }^{\text {bin }}$ the number of particles inside the bin, $D_{\mathrm{p}, \text { wet }}^{\text {bin }}$ the mean wet diameter of the bin, $D_{i}$ the diffusion coefficient for species $i$ in air, $M_{i}$ its molecular weight, $R$ the gas constant, $T$ the temperature and $f(K n, \alpha)$ the correction due to non-continuum effects and imperfect surface accommodation with $K n$ the Knudsen number and $\alpha$ the accommodation coefficient.

If the variation of particulate bulk concentration of compound $i \Delta A_{\mathrm{p}, \mathrm{i}}<0$,

$\Delta A_{\mathrm{p}, \mathrm{i}}^{\mathrm{bin}}=\frac{A_{\mathrm{p}, \mathrm{i}}^{\mathrm{bin}}}{\sum_{j} A_{\mathrm{p}, \mathrm{i}}^{j}} \Delta A_{\mathrm{p}, \mathrm{i}}$.

The absorption flux $J\left(\mu \mathrm{g} \mathrm{m}^{-3} \mathrm{~s}^{-1}\right)$ of a semi-volatile inorganic or organic species onto a bin is computed with

$J=\frac{1}{\tau} \Delta A_{\mathrm{p}, \mathrm{i}}^{\mathrm{bin}}$,

with $\tau$ the time to reach equilibrium (chosen equal to the time step of integration).

For particle with a diameter above the cutting diameter, absorption/evaporation is represented by solving the equation of condensation/evaporation (Seinfeld and Pandis, 1998):

$\frac{\mathrm{d} A_{p, i}^{\mathrm{bin}}}{\mathrm{d} t}=k_{i}^{\mathrm{bin}}\left(p_{i}-p_{\mathrm{eq}, i}^{\mathrm{bin}}\right)$,

with $p_{i}$ the vapor pressure of $i$ and $p_{\mathrm{eq}, i}^{\mathrm{bin}}$ the vapor pressure of $i$ at equilibrium with the particle-phase concentration of $i$ inside the bin. $p_{\mathrm{eq}, i}^{\mathrm{bin}}$ is computed with the reverse mode of ISORROPIA for inorganics. However, the condensation of SVOC onto coarse particle is not taken into account.

The gas to particle conversion of $\mathrm{HNO}_{3}$ onto dust and sea salt is also taken into account. $\mathrm{HNO}_{3}$ can indeed react with calcite $\mathrm{CaCO}_{3}$ in dust to form calcium nitrate $\mathrm{Ca}\left(\mathrm{NO}_{3}\right)_{2}$. $\mathrm{HNO}_{3}$ can also react with dolomite $\left(\mathrm{MgCa}\left(\mathrm{CO}_{3}\right)_{2}\right)$, but only the reaction with calcite is taken into account. Formenti et al. (2008) found a mass fraction of $\mathrm{Ca}^{2+}$ in dust between 4 and $9 \%$. A calcium fraction of $6 \%$ is used. In sea salt, $\mathrm{HNO}_{3}$ can replace the $\mathrm{Cl}^{-}$present in sea salt and leads to the volatilization of $\mathrm{HCl}$. Both reactions are assumed to be limited by the condensation kinetic of $\mathrm{HNO}_{3}$ onto particles as in Hodzic et al. (2006).

\subsubsection{Coagulation}

The flux of coagulation $J_{\text {coag } i}^{b}$ of a compound $i$ inside a bin $b$ is computed with the size binning method of Jacobson and Turco (1994):

$$
\begin{aligned}
J_{\text {coag }, i}^{b}= & \sum_{j=1}^{b} \sum_{k=1}^{b} f_{j, k}^{b} K_{j, l} A_{p, i}^{j} \text { Number }^{k} \\
& -A_{p, i}^{b} \sum_{j=1}^{\text {Nbins }} K_{\text {bin }, j} \text { Number }^{k},
\end{aligned}
$$

with $K_{j, k}$ the coagulation kernel coefficient between bins $i$ and $j, A_{p, i}^{j}$ the particle-phase concentration of compound $i$ 
into bins $j$, Nbins the number of bins and $f_{j, k}^{b}$ the partition coefficient (the fraction of the particle created from the coagulation of bins $j$ and $k$ which is redistributed inside bin $b$ ). The coagulation kernel and the partition coefficient are calculated as in Debry et al. (2007).

\subsection{Nucleation}

Following Menut et al. (2013), the parameterization of Kulmala and Pirjola (1998) for sulfuric acid nucleation is used. This process, favored by cold, humid atmospheric conditions, affects the number of ultrafine particles. The nucleated flux is added to the smallest bin in the sectional distribution. Since the sulfuric acid nucleation process competes with absorption processes, it is expected to occur in weakly particle polluted conditions.

\subsection{Simulation setup}

CHIMERE $2017 \beta$ was run to simulate the concentrations of particles and their composition in 2013 over Europe with a resolution of $0.25^{\circ} \times 0.25^{\circ}$ and $9 \sigma$ levels up to $500 \mathrm{hPa}$. Meteorology was obtained from the operational analysis of the Integrated Forecasting System (IFS) model of the European Centre for Medium-Range Weather Forecasts (ECMWF). The meteorology was evaluated in Bessagnet et al. (2016) for $2 \mathrm{~m}$ temperature, $10 \mathrm{~m}$ wind speed and the planetary boundary layer (PBL) for the model intercomparison project EURODELTA III. The authors reported high correlations for temperature (between 0.88 and 0.94 ) over the whole domain and a slight underestimation of temperature (between -0.3 and $-0.7 \mathrm{~K}$ ), an overestimation of the wind speed from 0.1 to $0.9 \mathrm{~m} \mathrm{~s}^{-1}$ and an underestimation of the PBL height of around $-100 \mathrm{~m}$ (although ECMWF in the EURODELTA III project was shown to be one of the models with the lowest RMSE). Annual anthropogenic emissions of gases and particles were taken from the EMEP inventory. Methodology is described by Vestreng (2003). Temporalization of emissions is done according to temporal factors for each country provided by GENEMIS (Ebel et al., 1997). Boundary conditions were generated from the results of the Model for OZone And Related chemical Tracers (MOZART v4.0; Emmons et al., 2010) available online at https://www.acom.ucar. edu/wrf-chem/mozart.shtml. Sea-salt emissions were computed according to Monahan et al. (1986). The MELCHIOR 2 (Derognat et al., 2003) mechanism was used to simulate the gas-phase chemistry.

For $\mathrm{PM}_{2.5}, \mathrm{PM}_{10}$ and each component of PM, several statistics were computed: root mean square error (RMSE), the correlation coefficient, the mean fractional error (MFE) and the mean fractional bias (MFB). Boylan and Russell (2006) defined two criteria to estimate the performance of the model. The model performance criteria (described as the level of accuracy that is considered to be acceptable for modeling applications) are reached when MFE $\leq 75 \%$ and when
MFB $\leq \pm 50 \%$, whereas the performance goal (described as the level of accuracy that is considered to be close to the best a model can be expected to achieve) is reached when MFE $\leq 50 \%$ and when MFB $\leq \pm 30 \%$. Although these criteria are not recent, they provide a useful basis to evaluate models.

The seasonal evolution of statistics was examined to study the performance of the model for different seasons and to separate the performance over a month from the annual performance. The statistics were also computed by "regions" consisting of countries having similar features. The five regions selected included

- southern Europe consisting of Spain, Portugal and Italy;

- western Europe consisting of Ireland, Great Britain and France;

- central Europe consisting of Germany, Belgium, the Netherlands, Switzerland, Denmark and Austria;

- northern Europe consisting of Norway, Sweden and Finland (characterized by low temperatures and low concentrations of particles); and

- eastern Europe consisting of the other countries in the east of Europe.

Figures S2-S7 in the Supplement show the seasonal evolution of the various statistics (correlation, RMSE, MFB, MFE) for each region.

A map of regions and of the specific stations that are referred to hereafter in the text (mostly stations with measurements of OC) is shown in Fig. 1.

\subsection{Observations}

Results of the model are compared to various measurements $\left(\mathrm{NO}_{3}^{-}, \mathrm{NH}_{4}^{+}, \mathrm{SO}_{4}^{2-}, \mathrm{Na}^{+}, \mathrm{Cl}^{-}, \mathrm{OC}, \mathrm{PM}_{1}, \mathrm{PM}_{2.5}\right.$ and $\left.\mathrm{PM}_{10}\right)$ available in the EBAS database (Tørseth et al., 2012) from various instruments (i.e., filters, tapered element oscillating microbalances, beta ray absorption) for regional background stations. The stations cover most of Europe with the first measurements available beginning in the 1970s. EBAS (http://ebas.nilu.no/) is a database hosting observation data of atmospheric chemical composition and physical properties in support of a number of national and international programs ranging from monitoring activities to research projects. EBAS is developed and operated by the Norwegian Institute for Air Research (NILU). This database is mostly populated by EMEP measurements.

\section{Results}

When not mentioned otherwise, concentrations of components used for the comparison are in the $\mathrm{PM}_{10}$ fraction. 


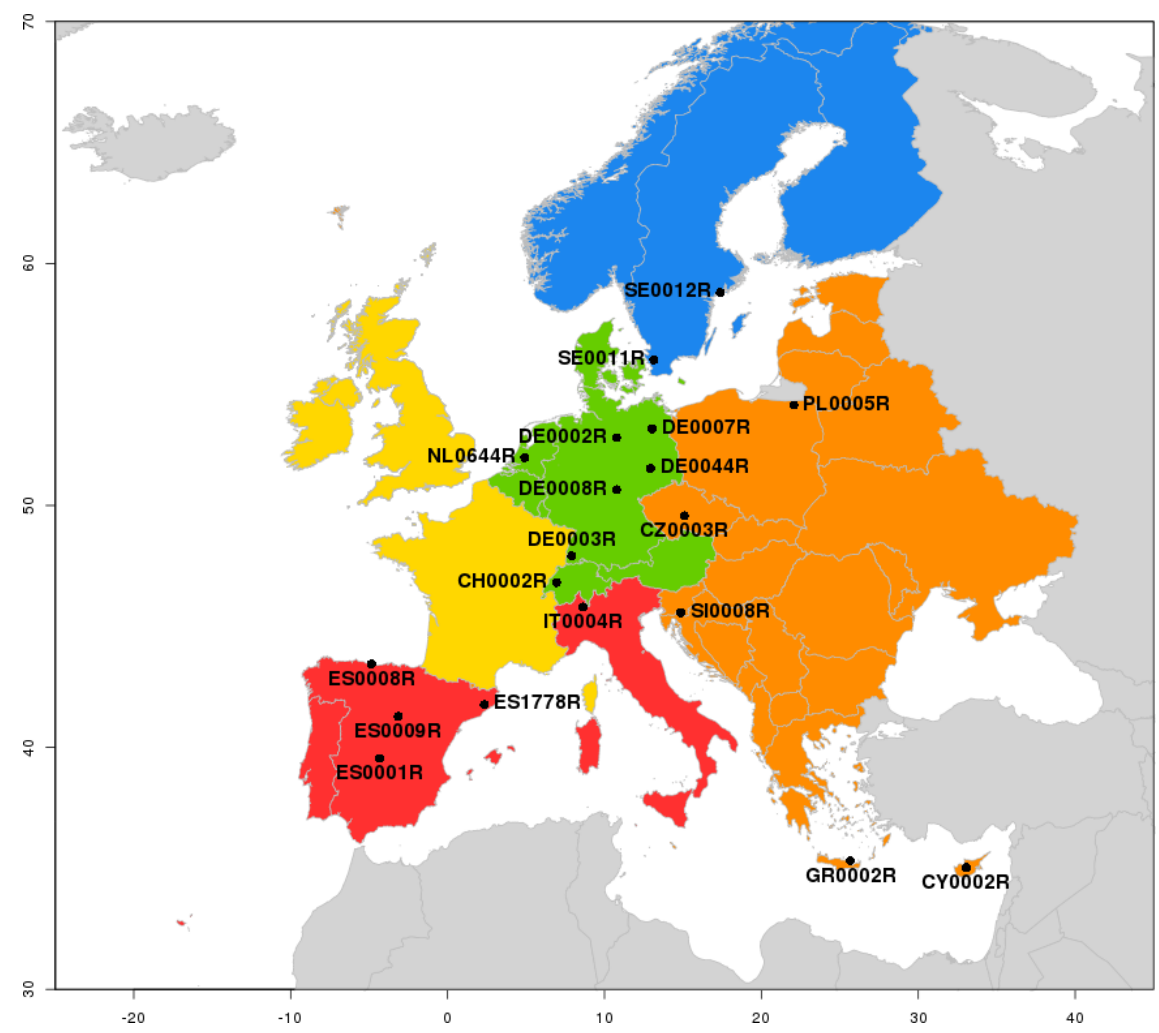

Figure 1. Maps of regions defined in this study and of mentioned stations. The chosen regions are southern Europe (red), western Europe (yellow), central Europe (green), eastern Europe (orange) and northern Europe (blue). Dots represent the specific stations that are referred to in the text (mostly stations with measurements of OC).

Table 5. Annual statistics for the comparison of daily concentrations. Means and RMSEs are in $\mu \mathrm{g} \mathrm{m}^{-3}$. SE: southern Europe. WE: western Europe. CE: central Europe. EE: eastern Europe. NE: northern Europe.

\begin{tabular}{lrrrrrrrrr}
\hline & $\mathrm{PM}_{10}$ & $\mathrm{PM}_{2.5}$ & $\mathrm{NO}_{3}^{-}$ & $\mathrm{NH}_{4}^{+}$ & $\mathrm{SO}_{4}^{2-}$ & $\mathrm{Na}^{+}$ & $\mathrm{Cl}^{-}$ & $\mathrm{TNO}_{3}$ & $\mathrm{TNH}_{4}$ \\
\hline Number of stations & 54 & 39 & 37 & 33 & 55 & 38 & 35 & 42 & 42 \\
Number of stations in SE & 16 & 13 & 15 & 7 & 15 & 6 & 6 & 13 & 13 \\
Number of stations in WE & 9 & 5 & 5 & 5 & 9 & 6 & 6 & 4 & 4 \\
Number of stations in CE & 19 & 12 & 5 & 9 & 11 & 12 & 9 & 8 & 8 \\
Number of stations in EE & 6 & 5 & 4 & 4 & 8 & 2 & 2 & 5 & 5 \\
Number of stations in NE & 4 & 4 & 8 & 8 & 12 & 12 & 12 & 12 & 12 \\
Number of measurements & 18210 & 11640 & 10583 & 7800 & 16564 & 10554 & 7207 & 13249 & 13249 \\
Model mean & 14.42 & 10.54 & 1.99 & 1.29 & 1.66 & 0.67 & 1.28 & 2.55 & 2.16 \\
Measurement mean & 13.51 & 9.06 & 1.46 & 0.89 & 1.6 & 0.69 & 1.17 & 2.07 & 1.49 \\
RMSE & 9.34 & 6.95 & 1.87 & 0.97 & 1.13 & 0.76 & 1.49 & 2.0 & 2.0 \\
Correlation & 0.6 & 0.68 & 0.71 & 0.71 & 0.67 & 0.66 & 0.67 & 0.69 & 0.56 \\
MFB & 0.08 & 0.22 & 0.15 & 0.36 & 0.13 & 0.06 & 0.09 & 0.10 & 0.20 \\
MFE & 0.44 & 0.48 & 0.57 & 0.55 & 0.44 & 0.52 & 0.49 & 0.50 & 0.55 \\
\hline
\end{tabular}

\subsection{Sea salt}

Annual scores for sodium (Na) and chloride $(\mathrm{Cl})$ are given in Table 5. Comparisons are carried out over 38 stations for $\mathrm{Na}^{+}$and 35 stations for $\mathrm{Cl}^{-}$. Scores are very similar between $\mathrm{Na}^{+}$and $\mathrm{Cl}^{-}$. The simulated mean concentrations are close $\left(0.67 \mu \mathrm{g} \mathrm{m}^{-3}\right.$ for $\mathrm{Na}^{+}$and $1.28 \mu \mathrm{g} \mathrm{m}^{-3}$ for $\left.\mathrm{Cl}^{-}\right)$to the measured mean concentrations $\left(0.69 \mu \mathrm{g} \mathrm{m}^{-3}\right.$ for $\mathrm{Na}^{+}$and $1.17 \mu \mathrm{g} \mathrm{m}^{-3}$ for $\mathrm{Cl}^{-}$) and the spatiotemporal correlations are high $\left(0.66\right.$ for $\mathrm{Na}^{+}$and 0.67 for $\left.\mathrm{Cl}^{-}\right)$. MFBs are low $(6 \%$ for $\mathrm{Na}^{+}$and $9 \%$ for $\left.\mathrm{Cl}^{-}\right)$and MFEs $\left(52 \%\right.$ for $\mathrm{Na}^{+}$and $49 \%$ for $\mathrm{Cl}^{-}$) are close to the goal criteria of Boylan and Russell (2006) (MFE $\leq 50 \%$ and MFB $\leq \pm 30 \%)$. Figure 2 
(a) Concentrations
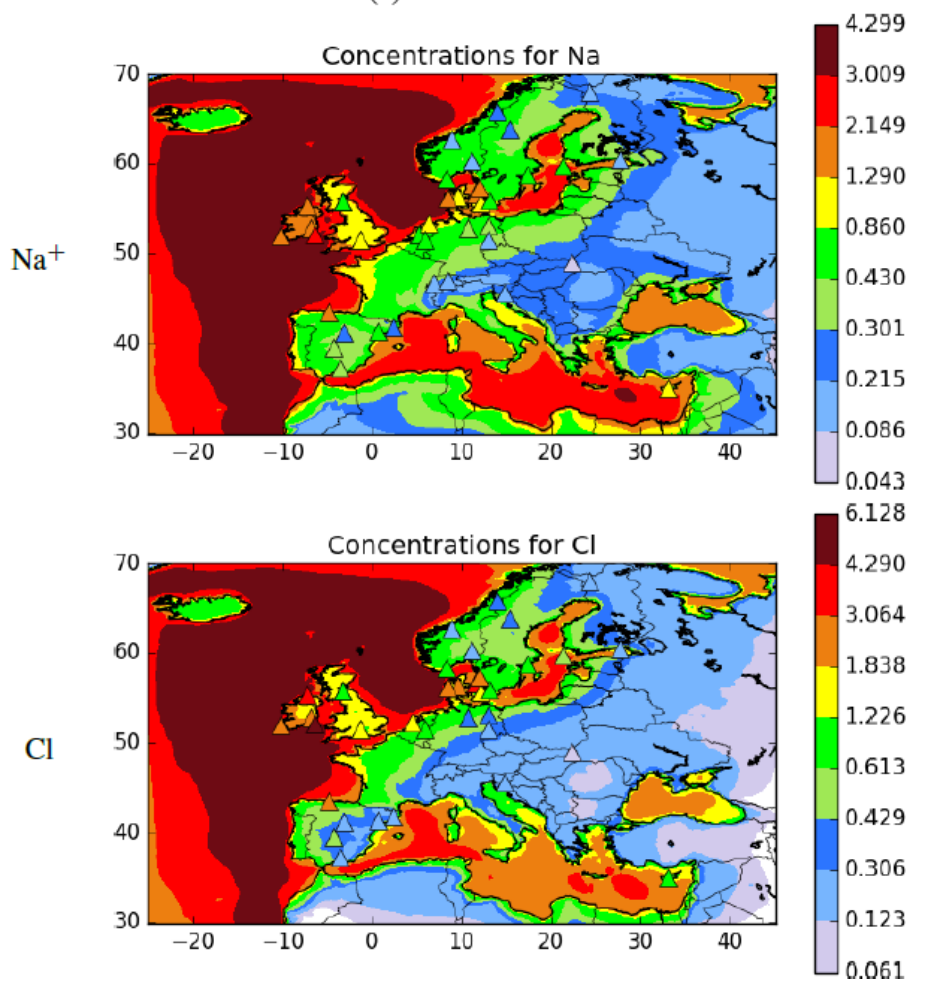

(b) MFB
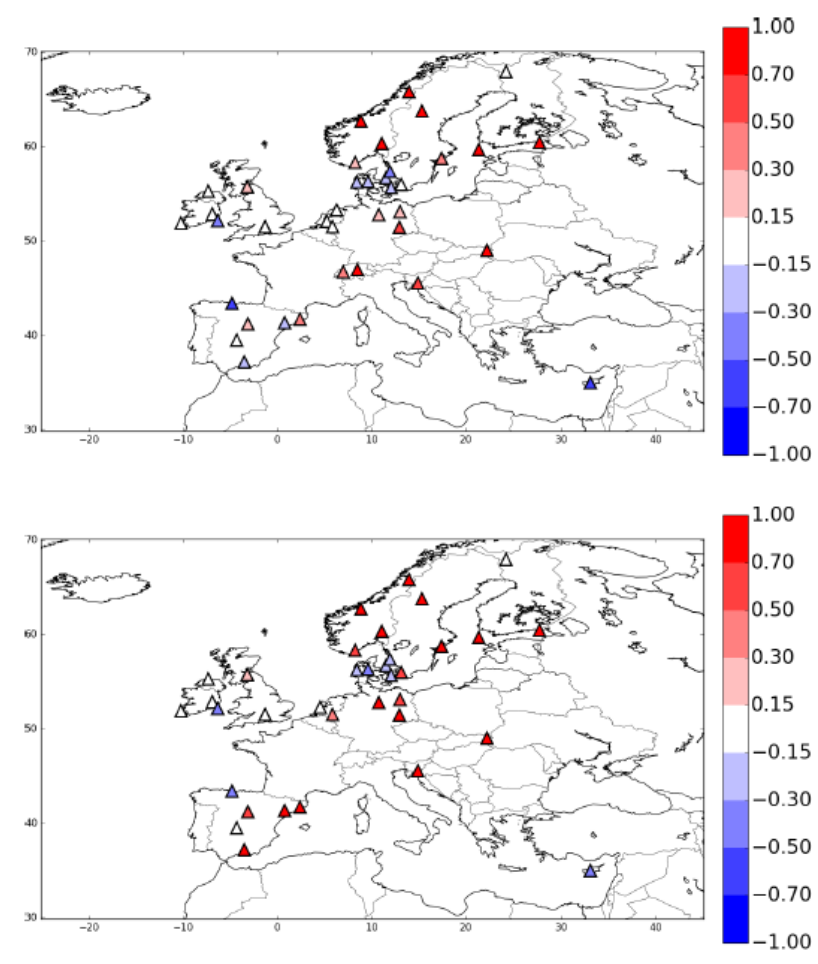

Figure 2. Modeled concentrations (in $\mu \mathrm{g} \mathrm{m}^{-3}$ ) and $\mathrm{MFB}$ for $\mathrm{Na}^{+}$and $\mathrm{Cl}^{-}$in 2013. Triangles correspond to measured concentrations in panel (a) and to the MFB value in panel (b).

shows the annual concentrations and MFBs of $\mathrm{Na}^{+}$and $\mathrm{Cl}^{-}$ at each station. Concentrations for $\mathrm{Na}^{+}$are underestimated significantly for only one station in Spain (along the Bay of Biscay). Most stations in Spain, central Europe and western Europe have a low annual bias for $\mathrm{Na}^{+}$, whereas most stations in northern and eastern Europe seem to have a high MFB with overestimated concentrations. Results are similar for $\mathrm{Cl}^{-}$except in Spain with overestimated concentrations near the Mediterranean Sea and in some stations in central Europe far from the seas.

Figure $\mathrm{S} 2$ shows the seasonal evolution of the statistics by regions. The same behavior was found for $\mathrm{Cl}^{-}$concentrations as for $\mathrm{Na}^{+}$concentrations. $\mathrm{Na}^{+}$concentrations seem to be underestimated for the stations in southern Europe (only stations in Spain for $\mathrm{Na}^{+}$and $\mathrm{Cl}^{-}$) from April to October with MFB reaching $-60 \%$, and the MFE is between 60 to $80 \%$ throughout the whole year. The temporal correlation is high but the spatial correlation is low. However, for station ES0008R along the Bay of Biscay, the model underestimates the concentrations of $\mathrm{Na}^{+}$while strong concentrations are measured at this station (with several peaks higher than $\left.6 \mu \mathrm{g} \mathrm{m}^{-3}\right)$. Temporal evolutions of measured and modeled concentrations are shown in Fig. S1 in the Supplement. It could then be possible that $\mathrm{Na}^{+}$concentrations at this station cannot be reproduced due to the low resolution of the model and the strong evolution of concentrations between the sea and the land. Except from ES0008R, the stations of southern Europe share the same pattern shown in Fig. S2. Concentrations of $\mathrm{Na}^{+}$are overestimated by the model in late autumn and winter (with a MFB from 30 to $60 \%$ ), whereas concentrations are underestimated from June to October with a MFB of $-60 \%$. Measurements give higher concentrations of $\mathrm{Na}^{+}$ in summer and lower concentrations in winter, whereas the model simulates the opposite trend.

For the stations in western and central Europe, the model gives satisfactory results and is able to reproduce the seasonal evolution of $\mathrm{Na}^{+}$concentrations with MFE around $40 \%$ and MFB between +20 and $-20 \%$ except for February in central Europe. Correlations are high (between 50 and $80 \%$ in western Europe around $80 \%$ in central Europe). RMSEs are relatively low for western Europe (between 0.6 and $1.1 \mathrm{\mu g} \mathrm{m}^{-3}$ for concentrations between 0.8 and $1.7 \mu \mathrm{g} \mathrm{m}^{-3}$ ), whereas RMSE for central Europe are of the same range as the measured and modeled concentrations (between 0.4 and $1.6 \mu \mathrm{g} \mathrm{m}^{-3}$ ).

For eastern and northern Europe, the model overestimates concentrations throughout the year with MFB often higher than $50 \%$ for eastern Europe and often higher than $30 \%$ for northern Europe and with high MFE (often higher than 50\% and even exceeding $100 \%$ for some months in eastern Europe). However, if relative errors are high in eastern Europe, absolute errors are low (RMSE lower than $0.35 \mu \mathrm{g} \mathrm{m}^{-3}$ ) be- 

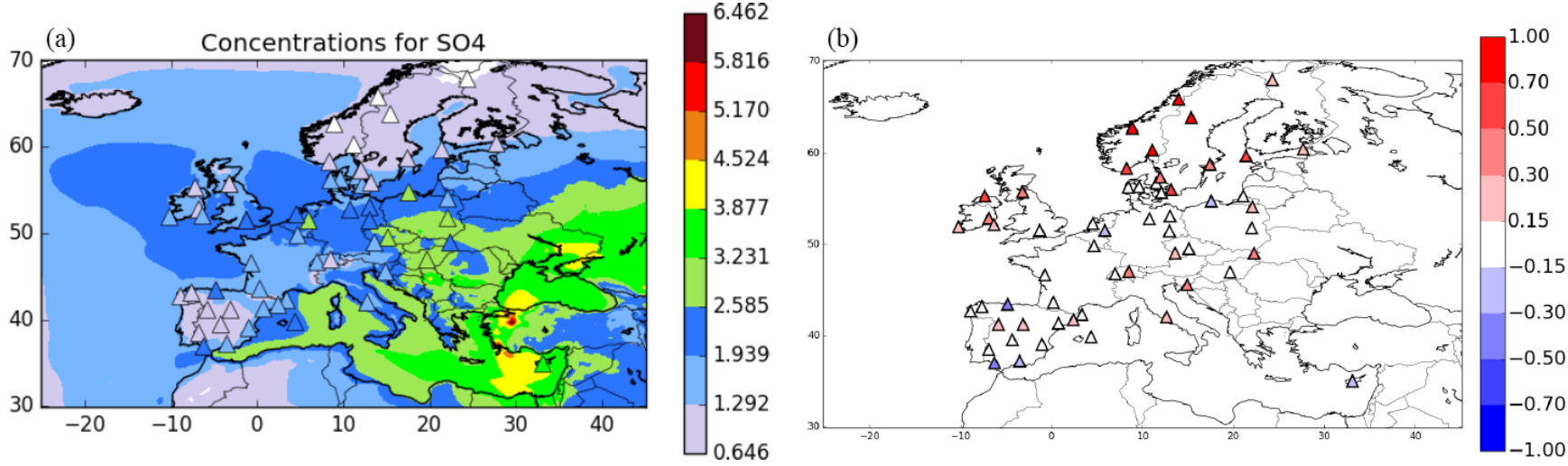

Figure 3. Modeled concentrations (in $\mu \mathrm{g} \mathrm{m}^{-3}$ ) and $\mathrm{MFB}$ for $\mathrm{SO}_{4}^{2-}$ in 2013. Triangles correspond to measured concentrations in panel (a) and to the MFB value in panel (b).

cause concentrations in eastern Europe are very low (mean concentrations lower than $0.12 \mu \mathrm{g} \mathrm{m}^{-3}$ and modeled concentrations between 0.09 and $0.35 \mu \mathrm{g} \mathrm{m}^{-3}$ ). This overestimation could be due to a lack of sea salt deposition in the model which becomes significant for low concentrations far from seas. Such an underestimation of deposition was reported in Tsyro et al. (2011) and Neumann et al. (2016).

\subsection{Sulfate}

Annual scores for $\mathrm{SO}_{4}^{2-}$ are given in Table 5. Comparisons are carried out over 56 stations. The simulated mean concentrations $\left(1.66 \mu \mathrm{g} \mathrm{m}^{-3}\right)$ and the measured mean concentrations $\left(1.60 \mu \mathrm{g} \mathrm{m}^{-3}\right)$ are very close. The spatiotemporal correlation is high (0.67). MFB is low (13\%) but indicates a slight relative overestimation. MFE is below $50 \%(44 \%)$, and therefore the goal criteria of Boylan and Russell (2006) are respected for sulfate. The RMSE is equal to $1.13 \mu \mathrm{g} \mathrm{m}^{-3}$. Figure 3 shows the annual concentrations and MFB of $\mathrm{SO}_{4}^{2-}$ at each station. Most stations give satisfactory results; 41 stations have a MFB between $\pm 30 \%$ and 33 stations respect the goal criteria. The model gives no stations where $\mathrm{SO}_{4}^{2-}$ concentrations would be significantly underestimated (MFB $<-30 \%$ ) but results at some stations are significantly overestimated, especially in the north of Europe. This overestimation is similar to the overestimation of sea salt in northern Europe. However, the contribution of sulfate from sea salt in the model $(7.68 \%)$ is not enough to explain the overestimation of sulfate in northern Europe. However, it may be due to an overestimation of northern boundary conditions (as the stations in northern Europe are close to the limit of the domain), a lack of deposition or errors on meteorological data that create the same overestimation as for sea salt.

Figure $\mathrm{S} 3$ shows the seasonal evolution of the statistics for $\mathrm{SO}_{4}^{2-}$ by regions.

Like $\mathrm{Na}^{+}, \mathrm{SO}_{4}^{2-}$ concentrations seem to be underestimated for the stations in southern Europe (mostly stations in Spain) in summer and overestimated in winter and late autumn with a MFB between -30 and $40 \%$. However, this behavior is probably not due to sulfate from sea salt (due to the low contribution of sea salt to sulfate, only a small part of sulfate would be originating from sea salt). In western, central and eastern Europe, the model succeeds in reproducing the seasonal evolution with a MFB generally between $\pm 30 \%$ and MFE below $50 \%$, except for western Europe in late autumn where MFB exceeds $50 \%$ and central Europe in November where MFB reaches $40 \%$. $\mathrm{SO}_{4}^{2-}$ concentrations seem to be slightly relatively overestimated with a MFB $>0$ in eastern Europe, whereas MFB is $\pm 30 \%$ for central and western Europe. In northern Europe, like sea salt, concentrations of $\mathrm{SO}_{4}^{2-}$ are overestimated with a MFB higher than $30 \%$ and reaching $90 \%$.

\subsection{Ammonium and nitrate}

Annual scores for $\mathrm{NO}_{3}^{-}$and $\mathrm{NH}_{4}^{+}$are given in Table 5 . Comparisons of $\mathrm{NO}_{3}^{-}$and $\mathrm{NH}_{4}^{+}$are carried out over 37 and 33 stations, respectively. The model gives higher mean values than measurements $\left(1.99 \mathrm{\mu g} \mathrm{m}^{-3}\right.$ against $1.46 \mu \mathrm{g} \mathrm{m}^{-3}$ for $\mathrm{NO}_{3}^{-}$and $1.29 \mu \mathrm{g} \mathrm{m}^{-3}$ against $0.89 \mu \mathrm{g} \mathrm{m}^{-3}$ for $\mathrm{NH}_{4}^{+}$. This kind of overestimation has been reported for numerous models (Bessagnet et al., 2014; Lecœur and Seigneur, 2013). RMSEs are higher than mean measured concentrations (1.87 and $0.97 \mu \mathrm{g} \mathrm{m}^{-3}$ ) due to the high bias. The performance criteria are respected, but the goal criteria for both $\mathrm{NO}_{3}^{-}$ $(\mathrm{MFB}=15 \%$ and $\mathrm{MFE}=57 \%)$ and $\mathrm{NH}_{4}^{+}(\mathrm{MFB}=36 \%$ and $\mathrm{MFE}=55 \%$ ) are not. However, the spatiotemporal correlation is rather high $\left(0.71\right.$ for $\mathrm{NO}_{3}^{-}$and 0.71 for $\left.\mathrm{NH}_{4}^{+}\right)$. Figure 4 shows the annual concentrations and MFBs of $\mathrm{NO}_{3}^{-}$and $\mathrm{NH}_{4}^{+}$at each station. Both $\mathrm{NO}_{3}^{-}$and $\mathrm{NH}_{4}^{+}$are overestimated at some stations in Germany, one station near Barcelona and two stations in eastern Europe, indicating there may be too much ammonium nitrate at these stations. $\mathrm{NH}_{4}^{+}$is strongly overestimated in northern Europe, which may be linked to the overestimation of sulfate and the formation of ammo- 
(a) Concentrations
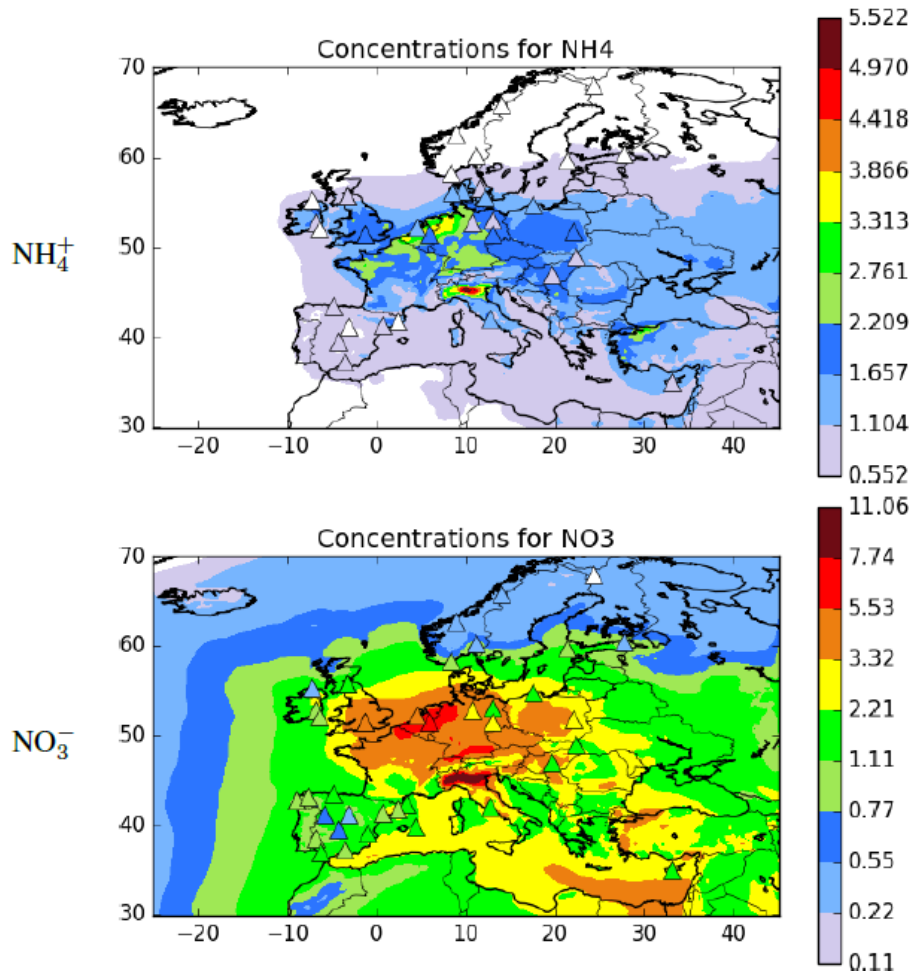

(b) MFB
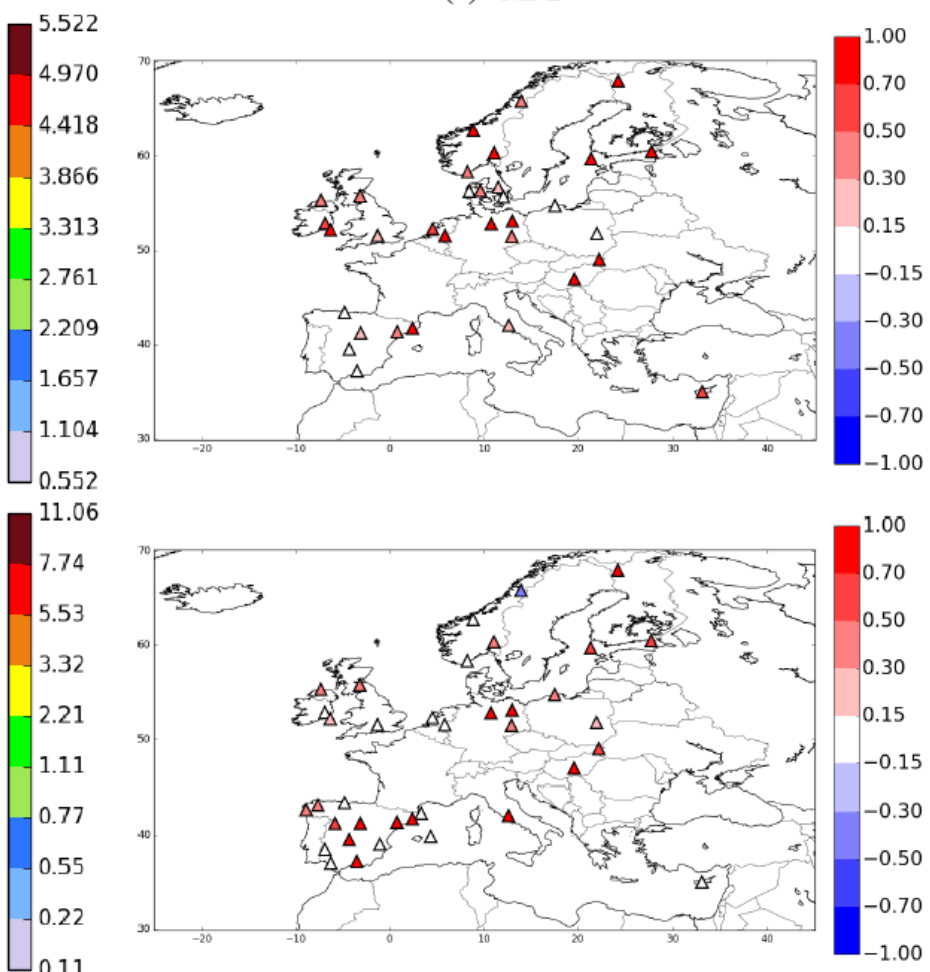

Figure 4. Modeled concentrations (in $\mu \mathrm{g} \mathrm{m}^{-3}$ ) and MFB for $\mathrm{NH}_{4}^{+}$and $\mathrm{NO}_{3}^{-}$in 2013. Triangles correspond to measured concentrations in panel (a) and to the MFB value in panel (b).

nium sulfate over this region, whereas $\mathrm{NO}_{3}^{-}$is overestimated at some stations in southern Europe.

Figures S4 and S5 show the seasonal evolution of the statistics for $\mathrm{NO}_{3}^{-}$and $\mathrm{NH}_{4}^{+}$by regions.

For southern Europe, both $\mathrm{NO}_{3}^{-}$and $\mathrm{NH}_{4}^{+}$concentrations are overestimated significantly in NovemberDecember 2013 with MFBs exceeding $40 \%$ for $\mathrm{NO}_{3}^{-}$and $60 \%$ for $\mathrm{NH}_{4}^{+}$. Concentrations of $\mathrm{NH}_{4}^{+}$are also overestimated from January to May with a MFB higher than $40 \%$, whereas $\mathrm{NO}_{3}^{-}$is overestimated to a smaller extent. $\mathrm{NO}_{3}^{-}$is also a bit underestimated from June to August. These results may indicate the formation of too-high ammonium nitrate concentrations at the end of the year. For $\mathrm{NH}_{4}^{+}$, errors on concentrations seem related to the errors on $\mathrm{SO}_{4}^{2-}$ concentrations, indicating that $\mathrm{NH}_{4}^{+}$may be better represented with a better representation of sulfates. Part of the errors may be also due to errors on $\mathrm{NO}_{3}^{-}$and $\mathrm{HNO}_{3}$ concentrations. Monthly correlations are low for $\mathrm{NH}_{4}^{+}$(lower than 0.4) and slightly higher for $\mathrm{NO}_{3}^{-}$(between 0.4 and 0.6 ).

For western Europe, results for $\mathrm{NO}_{3}^{-}$are very similar to the results for $\mathrm{NH}_{4}^{+}$, with an overestimation of both $\mathrm{NO}_{3}^{-}$and $\mathrm{NH}_{4}^{+}$in November and December (MFB higher than $40 \%$ for $\mathrm{NO}_{3}^{-}$and higher than $60 \%$ for $\mathrm{NH}_{4}^{+}$) and a slight overestimation for the peak in March (MFB around $30 \%$ for both $\mathrm{NO}_{3}^{-}$and $\mathrm{NH}_{4}^{+}$). All together, the MFB for $\mathrm{NH}_{4}^{+}$is higher than the MFB for $\mathrm{NO}_{3}^{-}$which may be due to the slight over- estimation of $\mathrm{SO}_{4}^{2-}$ (and therefore the overestimation of ammonium sulfate). Monthly correlations are a bit higher for $\mathrm{NO}_{3}^{-}$(higher than 0.8 for most of the year) than for $\mathrm{NH}_{4}^{+}$ (between 0.6 and 0.8 for most of the year).

Over central Europe, $\mathrm{NO}_{3}^{-}$and $\mathrm{NH}_{4}^{+}$concentrations are strongly overestimated at the end of the year where high concentrations are simulated. $\mathrm{NH}_{4}^{+}$is also slightly overestimated at the beginning of the year with a MFB higher than $30 \%$. Monthly correlations are high (between 0.6 and 0.8 ) for $\mathrm{NO}_{3}^{-}$, whereas monthly correlations are lower for $\mathrm{NH}_{4}^{+}$ in summer (below 0.5).

The results over eastern Europe are similar to the results of central Europe; however, $\mathrm{NO}_{3}^{-}$concentrations are overestimated at the beginning of the year and underestimated in summer.

For northern Europe, $\mathrm{NH}_{4}^{+}$concentrations are overestimated throughout the year with a MFB around $40 \%$ in May to August and up to $120 \%$ at the end of the year. These results are very similar to the results for $\mathrm{SO}_{4}^{2-}$. $\mathrm{NO}_{3}^{-}$concentrations are underestimated in summer and are strongly overestimated for the rest of the year (especially in February with a MFB close to $100 \%$ ).

Generally, statistics for $\mathrm{SO}_{4}^{2-}$ and $\mathrm{NO}_{3}^{-}$seem better than the statistics for $\mathrm{NH}_{4}^{+}$; this may be due to the cumulative errors on ammonium nitrate and ammonium sulfate. To investigate the highlighted results on ammonium and nitrate, scores 
were computed for total nitrate $\mathrm{TNO}_{3}$ (particulate $\mathrm{NO}_{3}^{-}$and gaseous $\mathrm{HNO}_{3}$ ) and for total ammonium $\mathrm{TNH}_{4}$ (particulate $\mathrm{NH}_{4}^{+}$and gaseous $\mathrm{NH}_{3}$ ). The performance is close to the goal criteria with a slight overestimation of concentrations. The mean seasonal evolutions of $\mathrm{TNO}_{3}$ and $\mathrm{TNH}_{4}$ are plotted in Fig. 6. Annual scores for $\mathrm{TNO}_{3}$ and $\mathrm{TNH}_{4}$ are given in Table 5 .

$\mathrm{TNO}_{3}$ and $\mathrm{TNH}_{4}$ share the same pattern with a slight underestimation of concentrations in summer and an overestimation of concentrations in autumn and winter.

This feature could be explained by

- An overestimation of the gas-particle conversion of $\mathrm{HNO}_{3}$ and $\mathrm{NH}_{3}$ can affect total concentrations. Indeed, Peters and Bruckner-Schatt (1995) measured higher deposition velocity of $\mathrm{HNO}_{3}$ and $\mathrm{NH}_{3}$ over spruce stand and Seinfeld and Pandis (1998) reported higher deposition velocity for gases than for particles lower than $2.5 \mu \mathrm{m}$ over water surfaces. An overestimation of the partitioning can therefore lead to an overestimation of total concentrations because the deposition velocities of these gases are generally higher than those of particles (Peters and Bruckner-Schatt, 1995).

- An underestimation of the deposition velocity would lead to a lack of compound removal.

- An overestimation of $\mathrm{HNO}_{3}$ production rate by the gasphase mechanism MELCHIOR 2 can lead to an overestimation of the partitioning of $\mathrm{NH}_{3}$ and $\mathrm{HNO}_{3}$ toward the particle phase and therefore lead to an overestimation of both $\mathrm{TNO}_{3}$ and $\mathrm{TNH}_{4}$.

- An overestimation of $\mathrm{NH}_{3}$ emissions in winter and autumn and an underestimation of $\mathrm{NH}_{3}$ emissions in summer as an overestimation of $\mathrm{NH}_{3}$ would lead to an overestimation of the partitioning of $\mathrm{NH}_{3}$ and $\mathrm{HNO}_{3}$ toward the particle phase and therefore lead to an overestimation of both $\mathrm{TNO}_{3}$ and $\mathrm{TNH}_{4}$ because the deposition velocities of these gases are generally higher than those of particles (Peters and Bruckner-Schatt, 1995).

The last assumption seems to be supported by the shape of the seasonal profile of $\mathrm{NH}_{3}$ emissions used in CHIMERE illustrated in Fig. 7 which gives high emissions in NovemberDecember, whereas Skjøth et al. (2011) (who developed a dynamical method to estimate $\mathrm{NH}_{3}$ emissions based on the different types of agriculture) estimated very low emissions during this period. Using dynamical emissions may give a better representation of $\mathrm{NH}_{3}$ and $\mathrm{NO}_{3}^{-}$concentrations. Moreover, in some countries from northern Europe like Sweden, $\mathrm{NH}_{3}$ emissions are mainly due to livestock (87\% of ammonia emissions in Sweden), whereas the temporal profile for Sweden is similar to the one of other countries with two peaks of emissions (one in March-April and one in OctoberNovember) corresponding to the application of fertilizers in spring and autumn. It could explain why, for northern $\mathrm{Eu}-$ rope, $\mathrm{NO}_{3}^{-}$is significantly underestimated in summer and significantly overestimated at the beginning and the end of the year.

Coarse $\mathrm{NO}_{3}^{-}$modeled concentrations and biases are shown in Fig. 5. Coarse $\mathrm{NO}_{3}^{-}$measurements were estimated by the difference between $\mathrm{PM}_{10}$ and $\mathrm{PM}_{2.5}$ concentrations. Low values should therefore be uncertain due to uncertainties in the two measurements. Concentrations of coarse $\mathrm{NO}_{3}^{-}$ are underestimated over stations ES0008R, CY0002R and DE0044R. Concentrations of coarse $\mathrm{NO}_{3}^{-}$are high over the Mediterranean Sea due to high concentrations of $\mathrm{HNO}_{3}$ (formed the oxidation by high concentrations of $\mathrm{OH}$ of high concentrations of $\mathrm{NO}_{x}$ originating from maritime traffic) combined with high concentrations of dust and sea salt. The high concentrations of coarse $\mathrm{NO}_{3}^{-}$over the Mediterranean Sea are confirmed by measurements in Spain and in Cyprus. High concentrations of coarse $\mathrm{NO}_{3}^{-}$are also simulated over the English Channel and the North Sea due to high concentrations of sea salt and $\mathrm{HNO}_{3}$. However, the model seems to underestimate the high concentrations of coarse $\mathrm{NO}_{3}^{-}$ observed at station DE0044R. This underestimation is not linked to sea salt (which is overestimated at this station) nor to the presence of ammonium nitrate in coarse particles: observed concentrations of coarse ammonium are not enough $\left(0.16 \mu \mathrm{g} \mathrm{m}^{-3}\right.$ in April) to explain observed concentrations of coarse $\mathrm{NO}_{3}^{-}\left(1.44 \mu \mathrm{g} \mathrm{m}^{-3}\right.$ in April). One possibility is that the coarse $\mathrm{NO}_{3}^{-}$observed at this station originates directly from primary coarse PM emission (which is not taken into account in the model). Coarse concentrations seem to be in the right order of magnitude for other stations but temporal correlations at each station were poor (inferior to 0.6 ) possibly due to the uncertainty of the determination of measured concentrations by differences.

\subsubsection{Organic aerosol}

Organic aerosol concentration measurements are not available in the database. However, measurements for organic carbon (OC) concentrations are available. OC is the mass of carbon inside the organic aerosols. For the comparison, $\mathrm{OM} / \mathrm{OC}$ ratios (that depend on the composition of organic aerosols, especially the degree of oxidation of compounds) have to be assumed to estimate OC concentrations from modeled OM concentrations. Turpin and Lim (2001) measured the $\mathrm{OM} / \mathrm{OC}$ ratios at different locations and found ratios between 1.2 and 2.5, and recommended to use a ratio of 2.1 for rural areas. Following Couvidat et al. (2012), modeled OC concentrations were calculated directly from the modeled concentrations of each organic surrogate compound using their molecular structure to estimate the $\mathrm{OM} / \mathrm{OC}$ ratio of the surrogate compounds. Several sensitivity tests were conducted by Couvidat et al. (2012) and has shown that the $\mathrm{OM} / \mathrm{OC}$ ratio simulated by the $\mathrm{H}^{2} \mathrm{O}$ mechanism is generally quite low compared to the $\mathrm{OM} / \mathrm{OC}$ ratio recommended by 

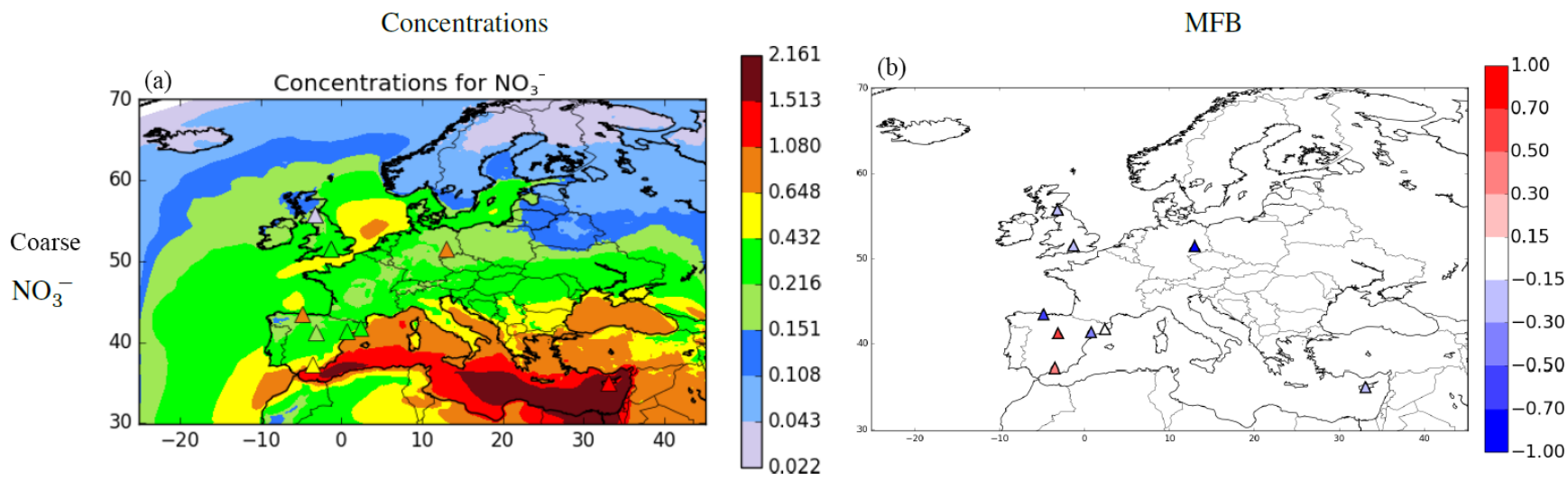

Figure 5. Modeled concentrations (in $\mu \mathrm{g} \mathrm{m}^{-3}$ ) and MFB for coarse $\mathrm{NO}_{3}^{-}$in 2013. Triangles correspond to measured concentrations in panel (a) and to the MFB value in panel (b).
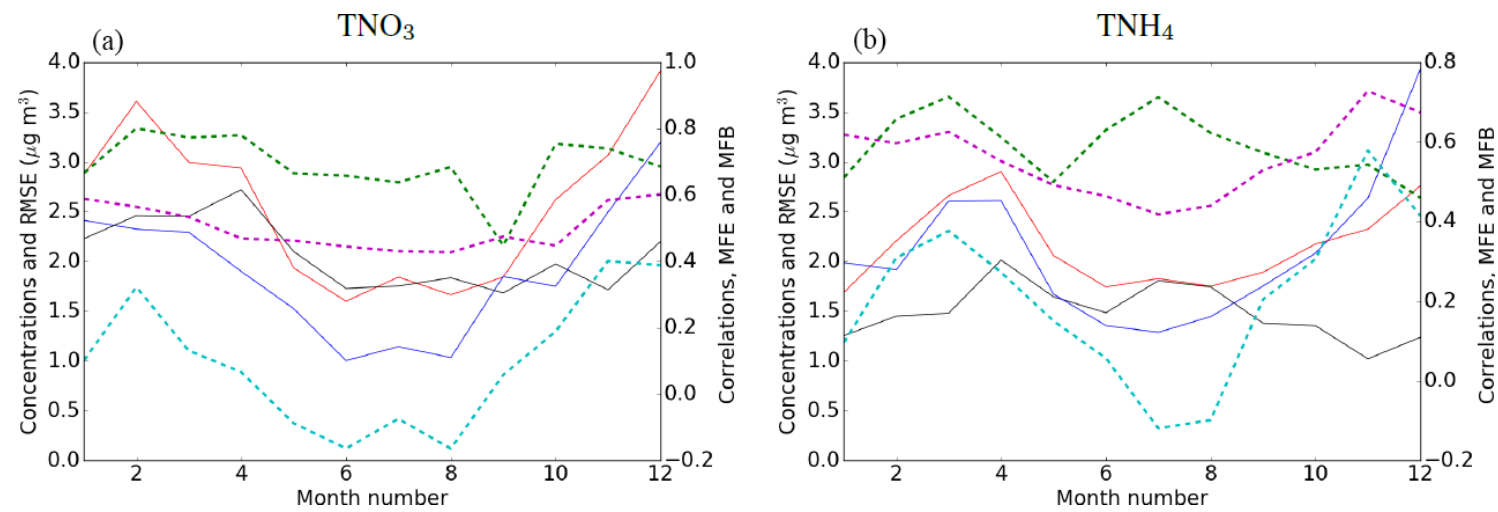

Figure 6. Seasonal evolution of statistics for the all Europe for $\mathrm{TNO}_{3}$ and $\mathrm{TNH}_{4}$ : monthly mean measured concentrations (black), monthly mean modeled concentrations (red), monthly RMSEs (blue), monthly spatiotemporal correlations (green), monthly MFB (cyan) and monthly MFE (magenta).

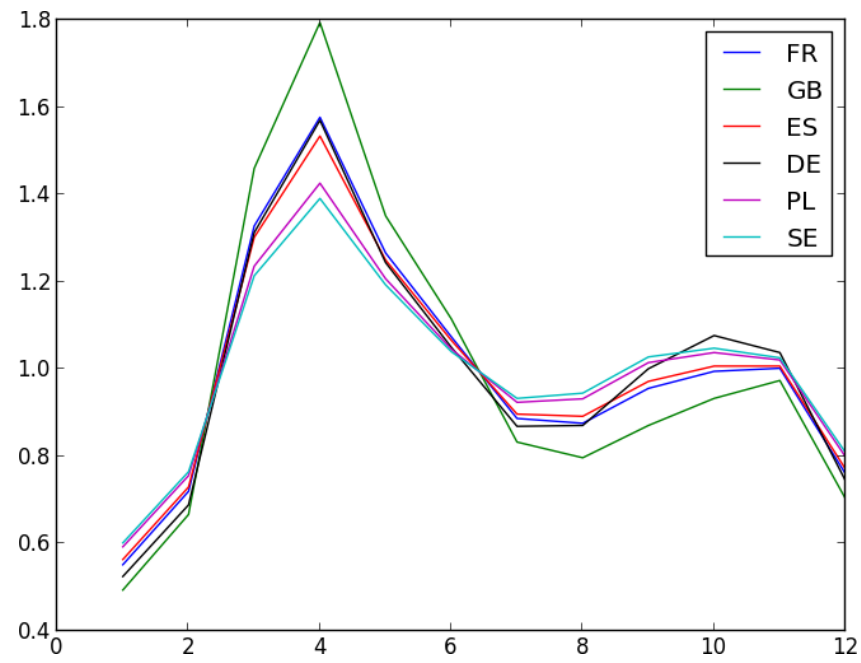

Figure 7. Seasonal factors used in CHIMERE to compute the evolution of $\mathrm{NH}_{3}$ emissions for several countries. The factors originate from GENEMIS (Ebel et al., 1997).
Turpin and Lim (2001). An overestimation of OC concentrations by the model could therefore be due to an underestimation of the $\mathrm{OM} / \mathrm{OC}$ ratio.

Table 6 shows the annual statistics for $\mathrm{OC}$ for each station. Time series of the concentrations for each station are shown in Figs. 9 and 10 for stations in the southern half and northern half of Europe, respectively. Figure 8 shows the maps of OC concentrations over Europe for January and July 2013 as well as the MFB at stations. These figures show for January and July an underestimation of OC concentrations over central Europe.

Annual concentrations at some stations seem to be overestimated (ES1778R, IT0004R and DE0003R) with MFBs between 36 and $40 \%$. However, the performance criteria are respected for these stations. It could also be possible that the overestimation of $\mathrm{OC}$ concentrations at these stations does not correspond to an underestimation of $\mathrm{OC}$ if the $\mathrm{OM} / \mathrm{OC}$ ratio is underestimated. The performance goal is respected for stations $\mathrm{CH} 0002 \mathrm{R}$ and SI0008R, whereas the performance criteria are respected for stations CY0002R, DE0008R, PL0005R and SE0011R. Concentrations are un- 
(a) Concentrations
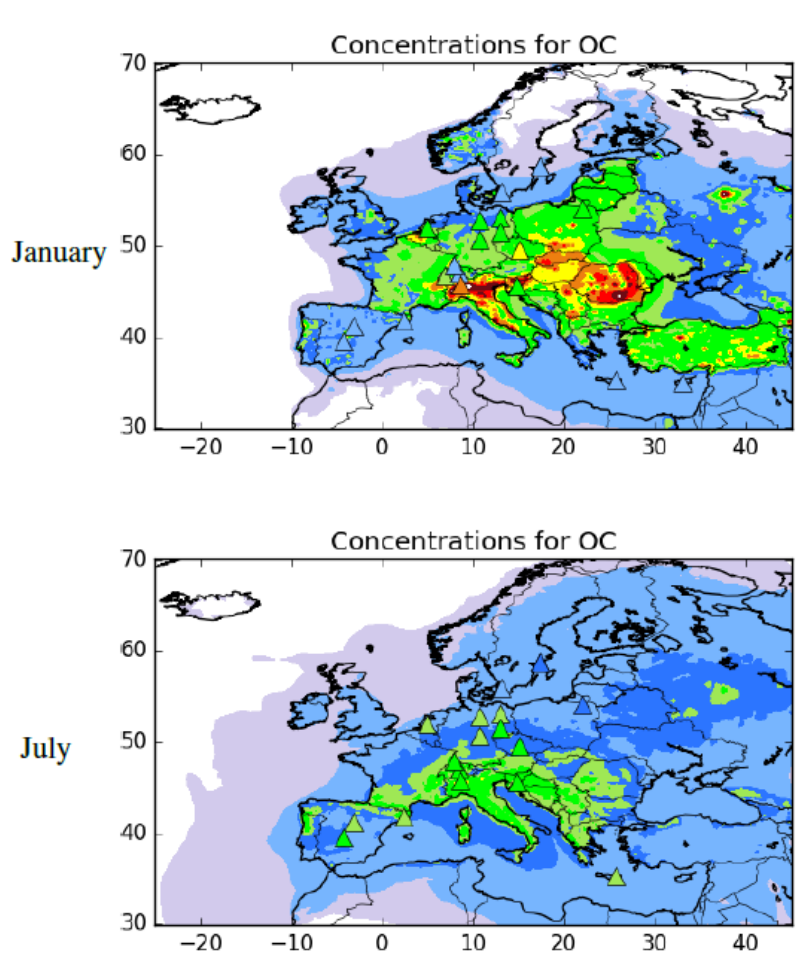

(b) MFB
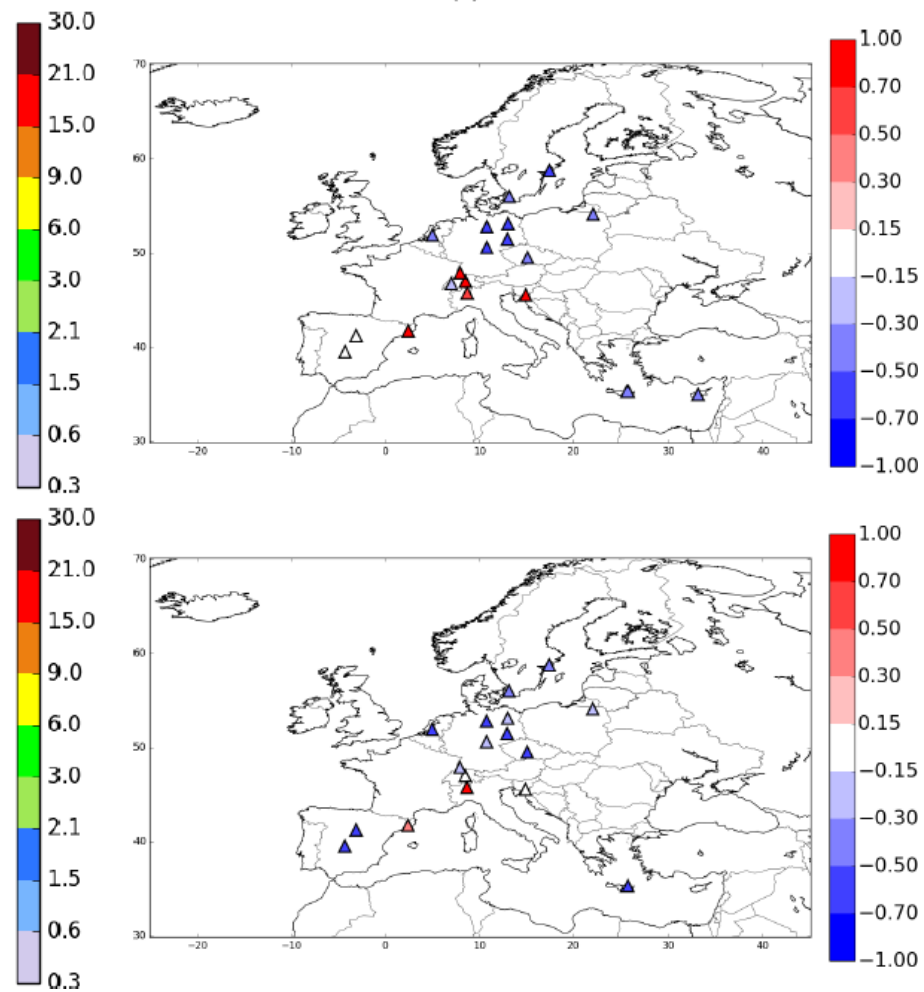

Figure 8. Modeled concentrations (in $\mu \mathrm{g} \mathrm{m}^{-3}$ ) and MFB for OC in January and July 2013. Triangles correspond to measured concentrations in panel (a) and to the MFB value in panel (b).

Table 6. Comparison of modeled concentrations to measured concentrations of OC. Means and RMSEs $\operatorname{are~in~} \mu \mathrm{g} \mathrm{m}{ }^{-3}$.

\begin{tabular}{lrrrrrr}
\hline Station & Modeled mean & Measured mean & RMSE & Correlation & MFB & MFE \\
\hline CH0002R & 2.48 & 3.29 & 1.70 & 0.67 & -0.13 & 0.37 \\
CY0002R & 0.91 & 1.65 & 1.65 & 0.07 & -0.35 & 0.65 \\
CZ0003R & 1.97 & 3.64 & 2.28 & 0.72 & -0.63 & 0.67 \\
DE0002R & 1.20 & 2.40 & 1.79 & 0.40 & -0.68 & 0.75 \\
DE0003R & 1.83 & 1.27 & 1.28 & 0.35 & 0.40 & 0.63 \\
DE0007R & 1.28 & 2.26 & 2.03 & 0.29 & -0.56 & 0.73 \\
DE0008R & 1.49 & 1.73 & 1.18 & 0.49 & -0.03 & 0.54 \\
DE0044R & 1.67 & 3.65 & 2.45 & 0.82 & -0.74 & 0.76 \\
ES0001R & 0.90 & 1.79 & 1.18 & 0.64 & -0.65 & 0.70 \\
ES0009R & 0.69 & 1.79 & 1.87 & 0.07 & -0.77 & 0.87 \\
ES1778R & 1.97 & 1.60 & 1.07 & 0.68 & 0.36 & 0.48 \\
IT0004R & 10.4 & 6.36 & 7.43 & 0.84 & 0.40 & 0.55 \\
NL0644R & 1.21 & 2.57 & 1.53 & 0.84 & -0.87 & 0.87 \\
PL0005R & 1.87 & 3.04 & 2.18 & 0.71 & -0.42 & 0.49 \\
SI0008R & 4.70 & 4.19 & 2.45 & 0.53 & -0.01 & 0.40 \\
GR0002R & 0.82 & 1.78 & 1.42 & 0.19 & -0.65 & 0.72 \\
SE0011R & 0.84 & 1.14 & 0.71 & 0.41 & -0.32 & 0.50 \\
SE0012R & 0.73 & 1.53 & 1.16 & 0.74 & -0.70 & 0.72 \\
\hline
\end{tabular}

derestimated at the other stations with MFBs between -56 and $-87 \%$.

Although OC concentrations are slightly overestimated in ES1778 (near Barcelona, Spain) and IT0004 (in Ispra, Italy), the seasonality of OC concentrations is well captured by the model. Moreover, the overestimation of concentrations could be due to the proximity of high emission sources and the low resolution of the model (ES1778 is only at $50 \mathrm{~km}$ from 
CY0002R

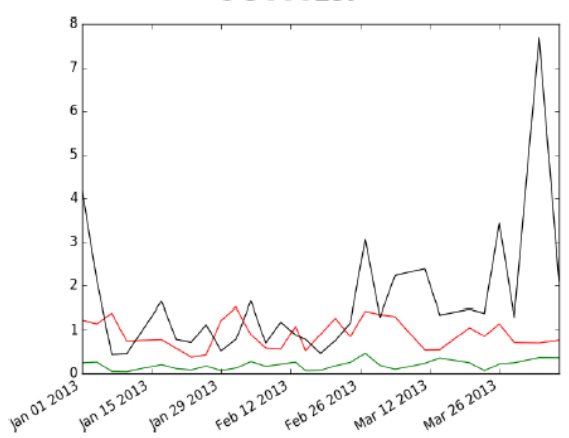

ES1778R

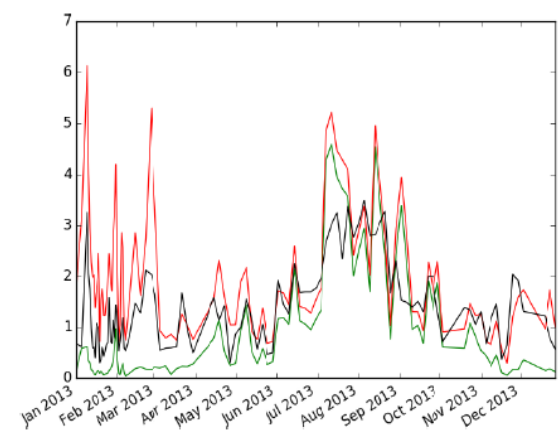

SI0008R

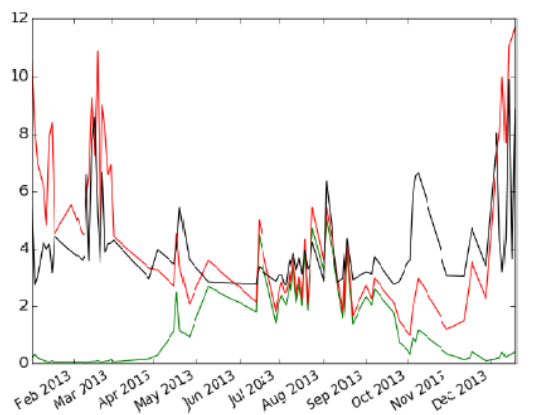

ES0001R

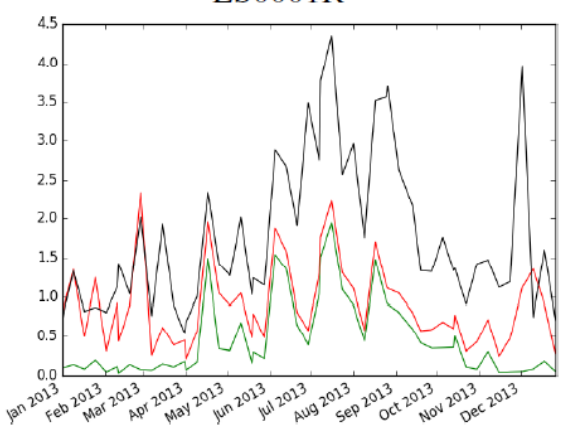

GR0002R

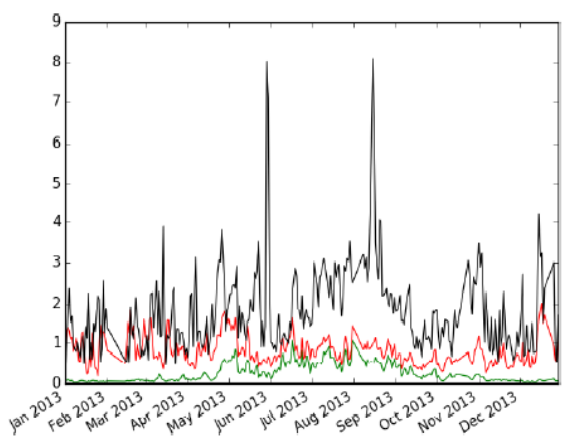

ES0009R

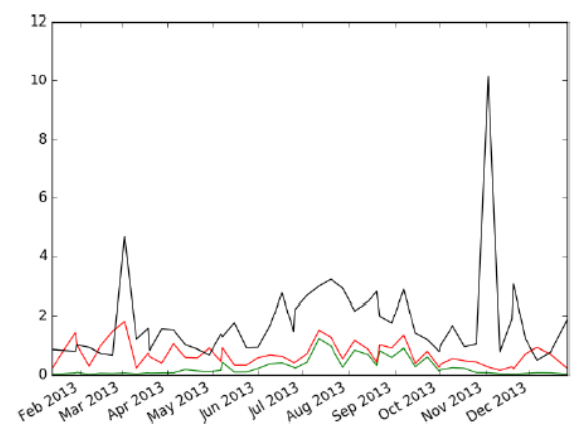

IT0004R

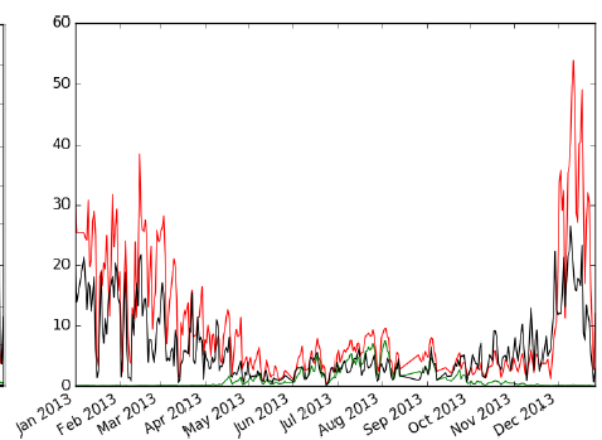

Figure 9. Temporal evolution of modeled (red line) and measured (black line) OC concentrations (in $\mu \mathrm{g} \mathrm{m}^{-3}$ ) for stations in the south of Europe. The green line corresponds to OC from biogenic compounds.

Barcelona, whereas the resolution is only $0.25^{\circ}$ and IT0004 is close to Milan). Concentrations and the seasonal evolution are well reproduced in SI0008 (Iskrba, Slovenia). For the other stations in the south of Europe, summer concentrations are underestimated, whereas the winter concentrations seem to be well reproduced. This may indicate a lack of secondary organic aerosol formation. These stations all have strong modeled concentrations of biogenic SOA in summer and strong modeled concentrations of anthropogenic organic aerosol in winter.

For the northern half of Europe, except for stations DE0003 and CH0005R in Switzerland and PL0005R in Poland which have strong concentrations of modeled biogenic SOA, summer concentrations of organic aerosol are underestimated. Only a peak of organic aerosol (due to biogenic aerosols in the model) at the end of August for sev- eral stations (CZ0003R, DE0002R, DE0007R, DE0008R, DE0044R) is reproduced by the model. These stations correspond to areas with strong anthropogenic emissions. A lack of anthropogenic SOA could therefore explain this pattern. However, this underestimation could be also due to a lack of biogenic emissions over these areas.

During winter, OC is overestimated over a few stations: ES1778R, IT0004R, CH0005R and DE0003R. These four stations under meteorological conditions are difficult to simulate at such a low resolution $(25 \mathrm{~km})$. They are often close to cities: ES1778R is close to Barcelona $(60 \mathrm{~km})$, IT0004R (Ispra) is in the Po Valley (an area with strong anthropogenic emissions) not far from Milan, CH0005 is less than $20 \mathrm{~km}$ from Lucerne (with 205000 inhabitants) and DE0003R is $12 \mathrm{~km}$ from Freiburg (a city of 206000 inhabitants). Moreover, these stations are in mountainous regions with high 
CH0002R

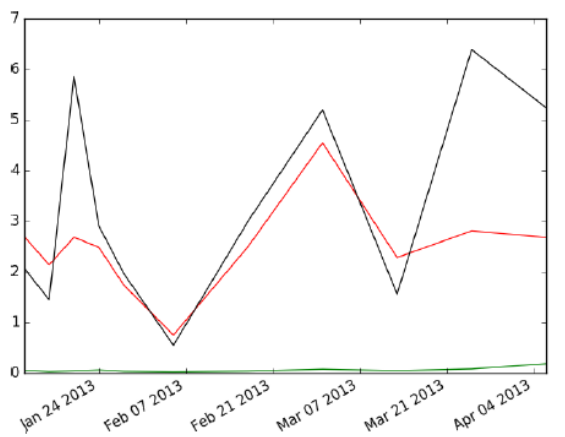

DE0002R

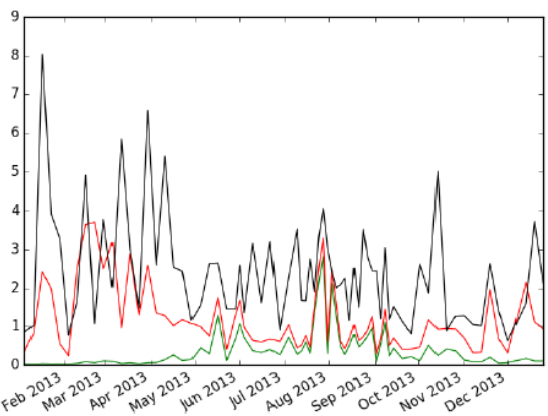

DE0008R

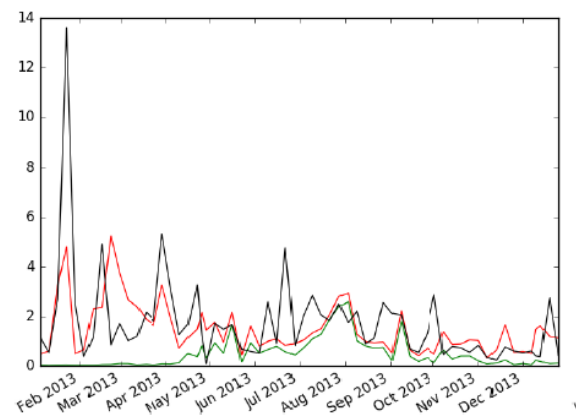

PL0005R

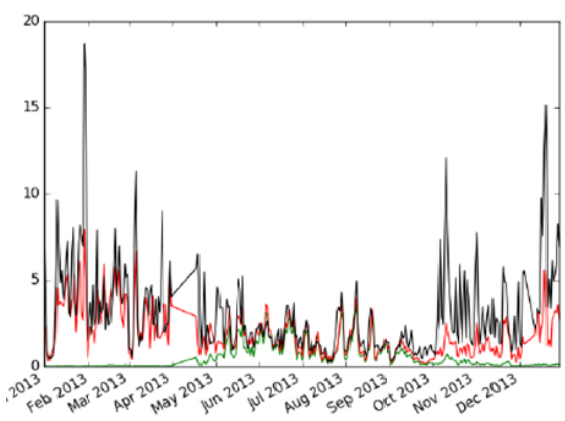

CH0005R

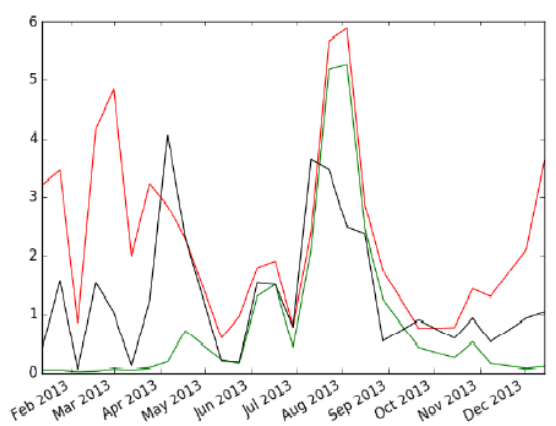

DE0003R

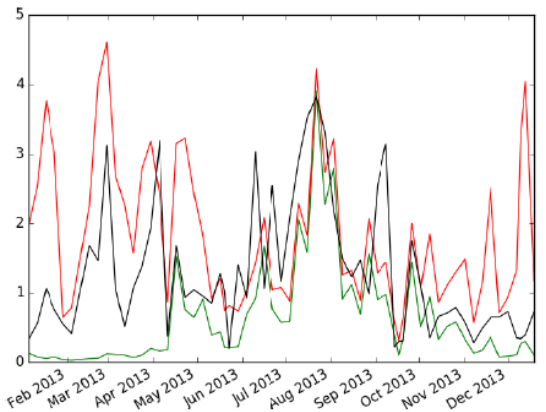

DE0044R

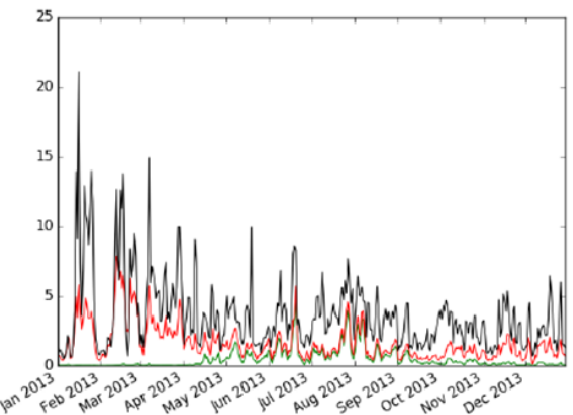

SE0011R

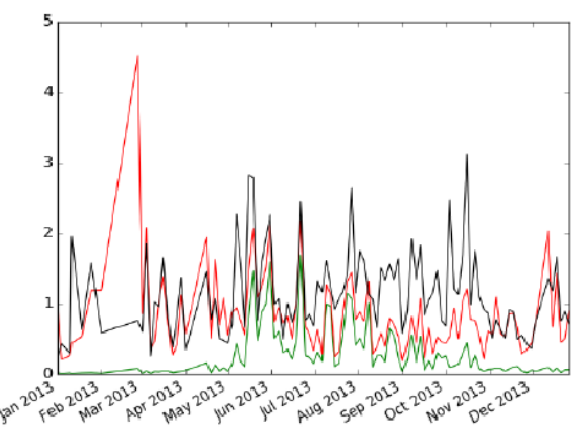

CZ0003R

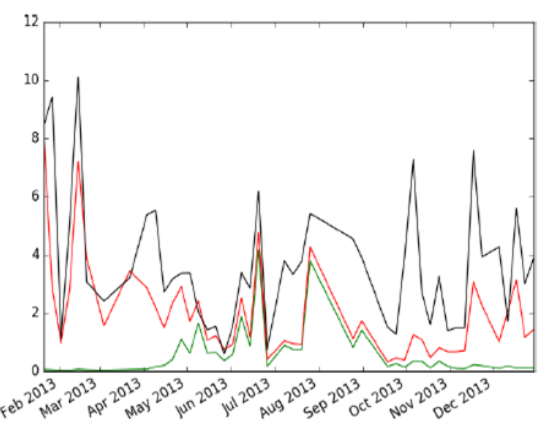

DE0007R

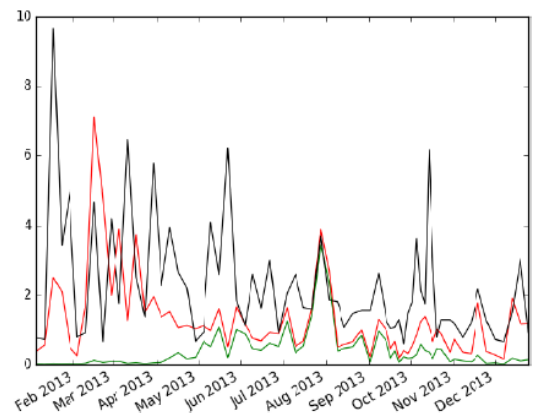

NL0644R

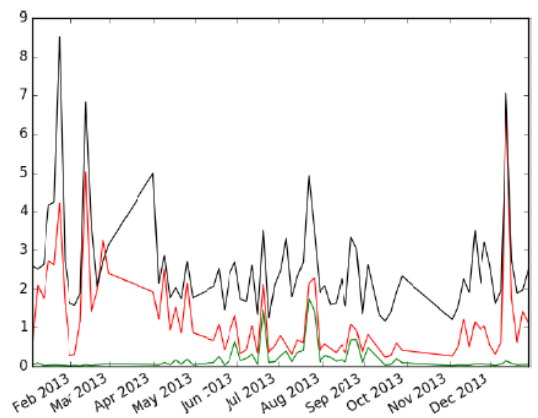

SE0012R

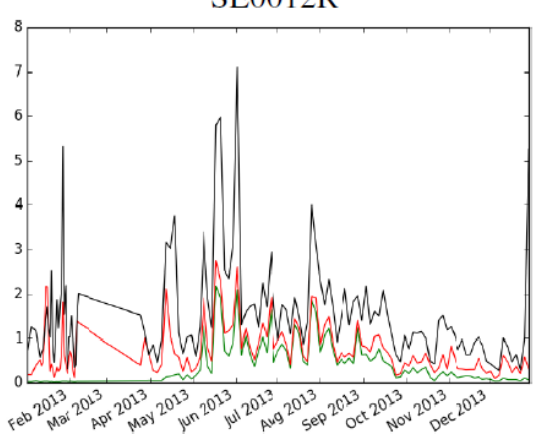

Figure 10. Temporal evolution of modeled (red line) and measured (black line) OC concentrations (in $\mu \mathrm{g} \mathrm{m}^{-3}$ ) for stations in the south of Europe. The green line corresponds to OC from biogenic compounds.

variations of altitude that are difficult to represent at such a resolution. Except for these four stations, concentrations of organic aerosol in winter simulated by the model tend to be underestimated, although reasonable performance could be attained for numerous stations, emphasizing the need to better represent anthropogenic emissions in winter. 
(a) Concentrations
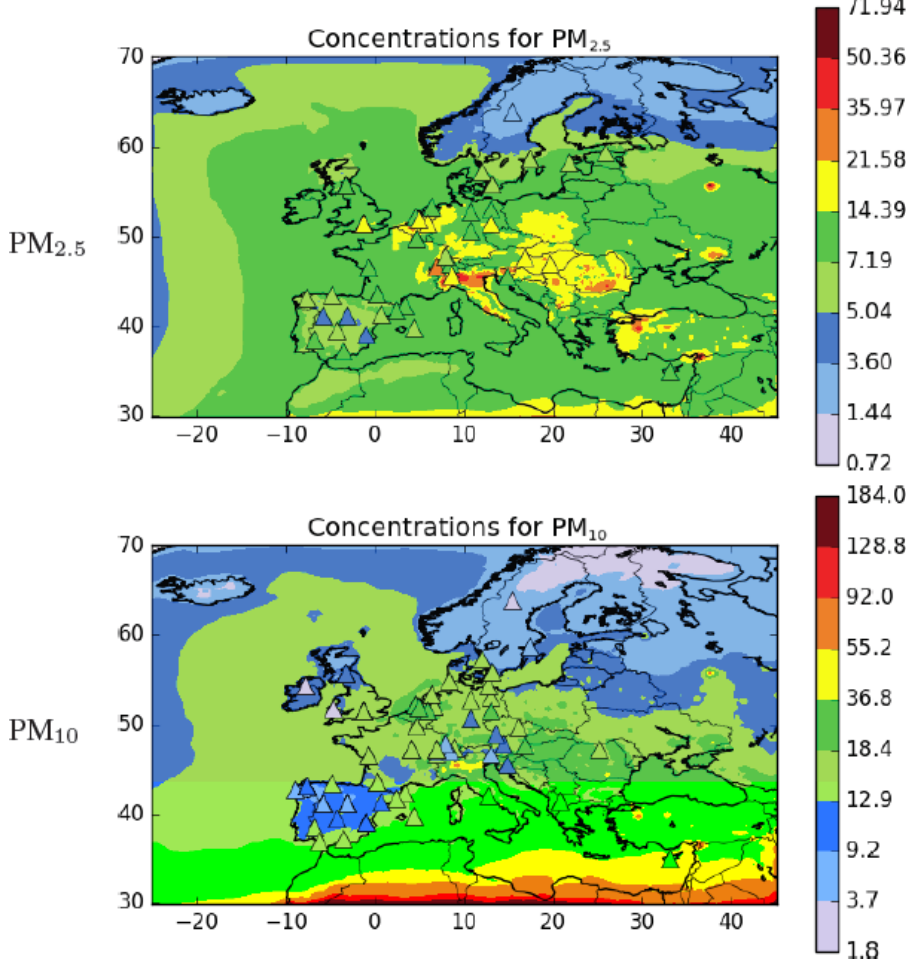

(b) MFB
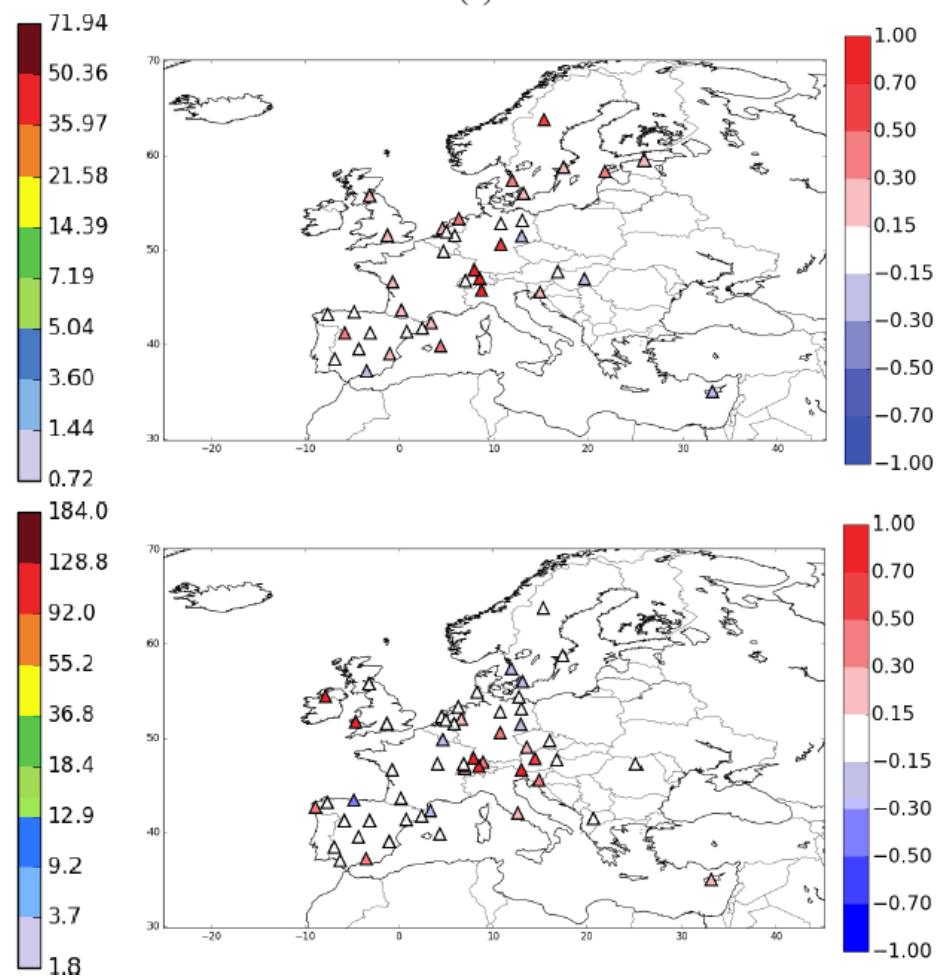

Figure 11. Modeled concentrations (in $\mu \mathrm{g} \mathrm{m}^{-3}$ ) and MFB for $\mathrm{PM}_{2.5}$ and $\mathrm{PM}_{10}$ in 2013. Triangles correspond to measured concentrations in panel (a) and to the MFB value in panel (b).

\subsubsection{PM concentrations}

Annual scores for $\mathrm{PM}_{2.5}$ and $\mathrm{PM}_{10}$ are given in Table 5 . Comparisons are carried out over 41 stations for $\mathrm{PM}_{2.5}$ and 59 stations for $\mathrm{PM}_{10}$. The goal criteria are respected for both $\mathrm{PM}_{2.5}$ and $\mathrm{PM}_{10}$. However, $\mathrm{PM}_{2.5}$ concentrations are slightly overestimated (MFB $=22 \%$ ). The MFB for $\mathrm{PM}_{10}$ is lower $(8 \%)$, indicating that coarse particles may be underestimated. This is confirmed by comparing the modeled coarse particle concentrations with estimated measured coarse concentrations (by subtracting $\mathrm{PM}_{2.5}$ from $\mathrm{PM}_{10}$ ) for the stations with measurements of both $\mathrm{PM}_{2.5}$ and $\mathrm{PM}_{10}$. The comparison gives a MFB of $-25 \%$, confirming that concentrations of coarse particles are underestimated. The underestimation of coarse particles was reported for numerous models in the intercomparison model project AQMEII (Solazzo et al., 2012; Pirovano et al., 2012).

The simulated mean concentrations $\left(10.54 \mu \mathrm{g} \mathrm{m}^{-3}\right.$ for $\mathrm{PM}_{2.5}$ and $14.42 \mu \mathrm{g} \mathrm{m}^{-3}$ for $\left.\mathrm{PM}_{10}\right)$ are close to the measured mean concentrations $\left(9.06 \mu \mathrm{g} \mathrm{m}^{-3}\right.$ for $\mathrm{PM}_{2.5}$ and $13.51 \mu \mathrm{g} \mathrm{m}^{-3}$ for $\left.\mathrm{PM}_{10}\right)$ and the spatiotemporal correlations are high ( 0.68 for $\mathrm{PM}_{2.5}$ and 0.60 for $\mathrm{PM}_{10}$ ).

Figure 11 shows the annual concentrations and MFBs of $\mathrm{PM}_{2.5}$ and $\mathrm{PM}_{10}$ at each station. The model strongly underestimates annual concentrations of $\mathrm{PM}_{10}$ only for the ES0008R station, probably due to the underestimation of sea salt at this station. However, the model overestimates PM concentrations with a MFB above $30 \%$ at several locations: 14 stations for $\mathrm{PM}_{2.5}$ and 12 stations for $\mathrm{PM}_{10}$ especially over the Alps. The overestimation over the Alps is probably due to difficulties in reproducing the complexity of mountainous meteorology for a model with such a coarse resolution.

Figures S6 and S7 show the seasonal evolution of the statistics by regions for $\mathrm{PM}_{2.5}$ and $\mathrm{PM}_{10}$, respectively.

$\mathrm{PM}_{2.5}$ concentrations seem to be underestimated for the stations in southern Europe from June to August and overestimated the rest of the year (especially in March, November and December with MFB reaching 60\%). A similar feature is obtained with $\mathrm{PM}_{10}$ but with lower MFB in March, November and December, which is probably due to some compensation effects and an underestimation of the coarse fraction of PM. Based on these results, this overestimation is probably mainly due to the overestimation of ammonium nitrate observed during these months while the underestimation from June to August is probably due to the underestimation of all PM components.

For western Europe, $\mathrm{PM}_{2.5}$ is overestimated from September to December with a MFB between 40 and $60 \%$ which may be due at least partly to the overestimation of ammonium nitrate. The overestimation could also be due to an overestimation of organic matter observed at some stations 

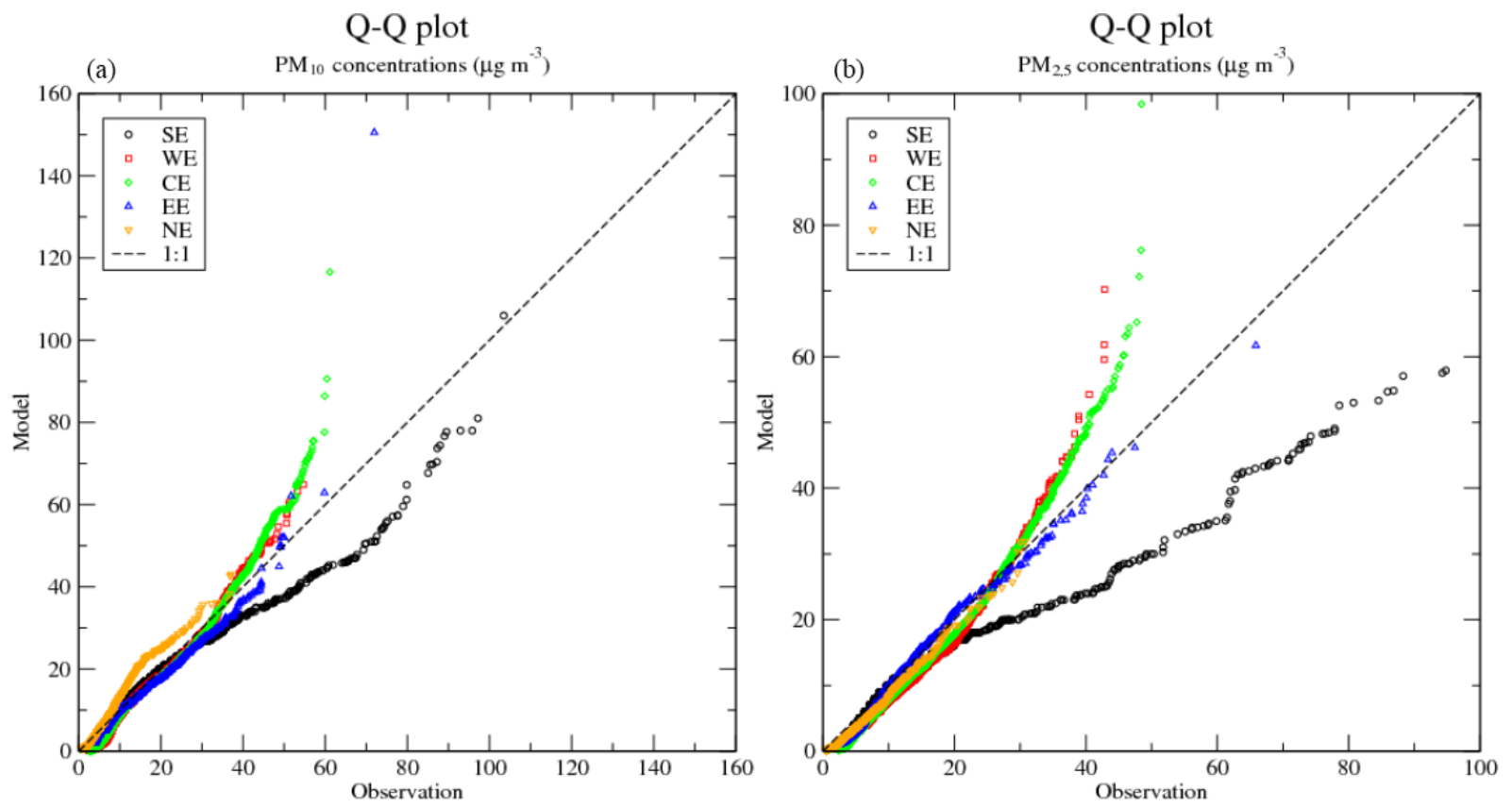

Figure 12. Q-Q plot of $\mathrm{PM}_{10}$ (a) and of $\mathrm{PM}_{2.5}$ (b) modeling results against measurements for the several regions. SE: southern Europe. WE: western Europe. CE: central Europe. EE: eastern Europe. NE: northern Europe.

or to an overestimation of primary particles. Similar results are obtained for $\mathrm{PM}_{10}$.

In central Europe, the model reproduces well the strong concentrations of $\mathrm{PM}_{2.5}$ and $\mathrm{PM}_{10}$ in winter and spring (with a MFE around $40 \%$ ). However, concentrations are slightly underestimated in summer (with a negative MFB reaching $-30 \%$ for $\mathrm{PM}_{2.5}$ and $-40 \%$ for $\left.\mathrm{PM}_{10}\right)$ and are overestimated from October to December with a MFB between 40 and $80 \%$ for $\mathrm{PM}_{2.5}$ (probably due to the strong overestimation of ammonium nitrate) and reaching $50 \%$ for $\mathrm{PM}_{10}$.

For eastern and northern Europe, similar features are obtained. $\mathrm{PM}_{2.5}$ and $\mathrm{PM}_{10}$ are overestimated in winter and autumn (probably due mostly to the overestimation of ammonium nitrate) and underestimated in summer (probably due to the summer underestimation of ammonium nitrate and organic aerosols).

A quantile-quantile (Q-Q) plot of modeling results against measurements for $\mathrm{PM}_{10}$ and $\mathrm{PM}_{2.5}$ is shown in Fig. 12. Q-Q plots can be used to assess the similarity of the distribution of two compared datasets. Figure 12 shows the quantile of modeled concentrations against the corresponding quantile of measured concentrations. For southern Europe, concentrations higher than $40 \mu \mathrm{g} \mathrm{m}^{-3}$ for $\mathrm{PM}_{10}$ and higher than $20 \mu \mathrm{g} \mathrm{m}^{-3}$ for $\mathrm{PM}_{2.5}$ are significantly underestimated, especially for high concentrations of $\mathrm{PM}_{2.5}$. Western and central Europe have a similar distribution of concentrations with a strong overestimation of high concentrations of $\mathrm{PM}_{2.5}$ (higher than $35 \mu \mathrm{g} \mathrm{m}^{-3}$ ) and of $\mathrm{PM}_{10}$ (higher than $55 \mu \mathrm{g} \mathrm{m}^{-3}$ ). This overestimation is probably due to the high overestimation of ammonium nitrate during the late autumn for these regions. For eastern and southern Europe, the distributions of modeled concentrations are similar to the distributions of observed concentrations.

\subsubsection{The case of the Cyprus station}

The Cyprus station (CY0002R) was analyzed due to the specificity of this station close to the boundary conditions, influenced by high concentrations of PM due to mineral dust and high anthropogenic emissions from the Mediterranean maritime traffic. Moreover, numerous measurements were carried out at this station: $\mathrm{PM}_{2.5}$ and $\mathrm{PM}_{10}$ and measurements of speciation (both in the fine fraction and in $\mathrm{PM}_{10}$ ) covering $\mathrm{NO}_{3}, \mathrm{NH}_{4}^{+}, \mathrm{SO}_{4}^{2-}, \mathrm{Na}^{+}, \mathrm{Cl}^{-}$and also $\mathrm{Ca}^{2+}$ (originating mainly from dust). The temporal evolution of $\mathrm{PM}_{2.5}$ and $\mathrm{PM}_{10}, \mathrm{Ca}^{2+}$ (fine fraction and $\mathrm{PM}_{10}$ fraction), $\mathrm{NO}_{3}^{-}$ (fine fraction and $\mathrm{PM}_{10}$ fraction) is shown in Fig. 13 and the temporal evolution of $\mathrm{Na}^{+}, \mathrm{Cl}^{-}, \mathrm{NH}_{4}$ and $\mathrm{SO}_{4}$ is shown in Fig. 14. The temporal evolution of $\mathrm{OC}$ concentrations is shown in Fig. 9.

The model gives at this station good performances for the simulation of $\mathrm{PM}_{2.5}$ (correlation $=0.54, \mathrm{MFB}=-10 \%$, $\mathrm{MFE}=35 \%)$ and $\mathrm{PM}_{10}$ (correlation $=0.64, \mathrm{MFB}=26 \%$, $\mathrm{MFE}=39 \%$ ). The temporal evolution of $\mathrm{PM}_{2.5}$ and $\mathrm{PM}_{10}$ are well reproduced by the model. The good results at this station are mainly due to the good representation of dust transport in the simulation (coming here from the boundary conditions taken from MOZART v4.0). Simulated concentrations of $\mathrm{Ca}^{2+}$ (assuming a fraction of $6 \%$ in dust) were compared to the measurements of $\mathrm{Ca}^{2+}$. The model gives 

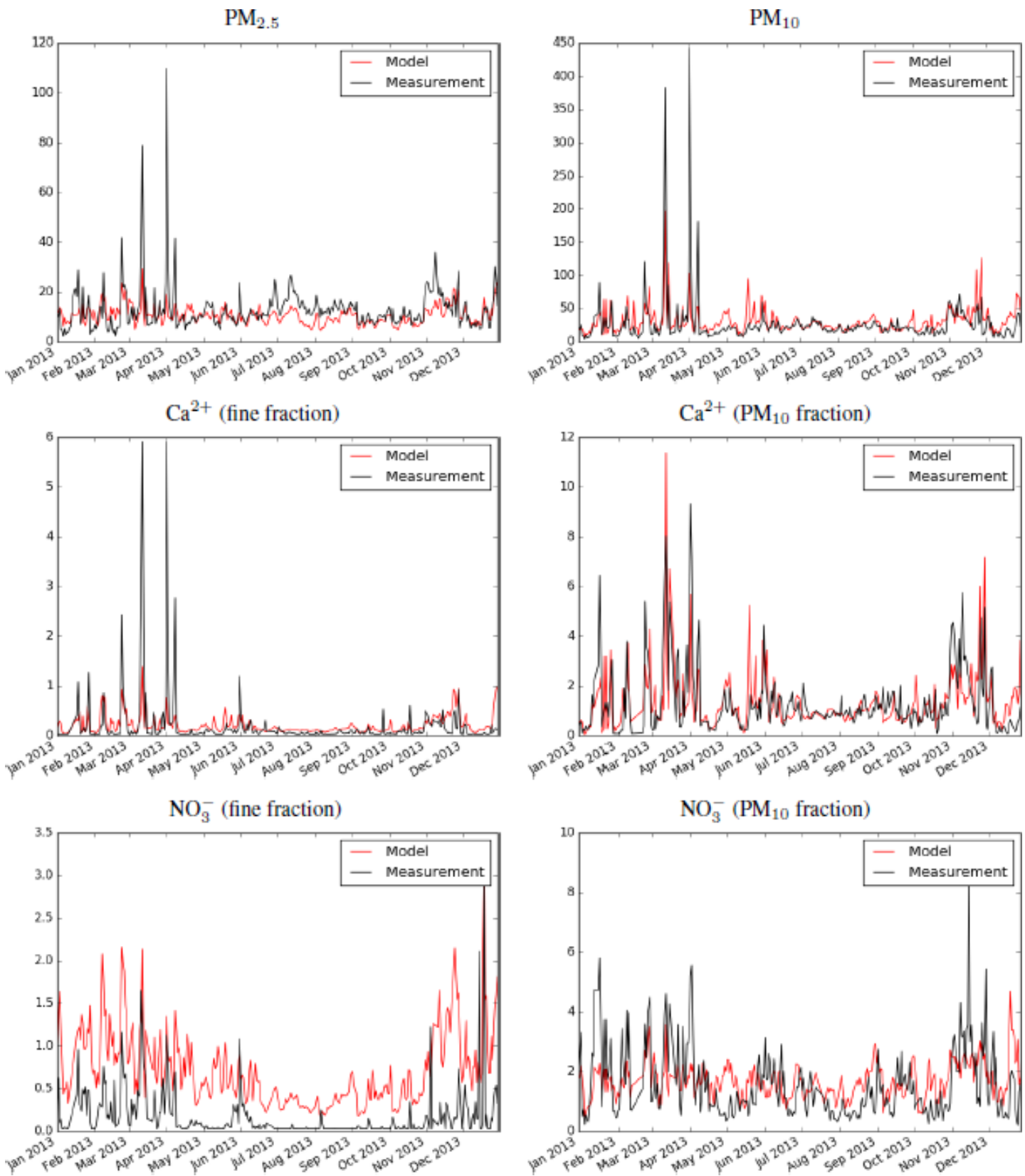

Figure 13. Modeled (red) and measured (black) concentrations of $\mathrm{PM}_{2.5}, \mathrm{PM}_{10}, \mathrm{Ca}^{2+}$ (fine fraction and $\mathrm{PM}_{10}$ fraction) and $\mathrm{NO}_{3}^{-}$(fine fraction and $\mathrm{PM}_{10}$ fraction) in $\mu \mathrm{g} \mathrm{m}^{-3}$ for the Cyprus station (CY0002R).

good results for $\mathrm{Ca}^{2+}$ concentrations in $\mathrm{PM}_{10}$ (correlation $=$ $0.65, \mathrm{MFB}=6 \%$ and MFE $=45 \%)$. However, $\mathrm{Ca}^{2+}$ concentrations in fine particles are overestimated (correlation $=$ $0.53, \mathrm{MFB}=63 \%$ and $\mathrm{MFE}=81 \%$ ) but the concentrations $\left(0.19 \mu \mathrm{g} \mathrm{m}^{-3}\right.$ in measurements) are low compared to $\mathrm{Ca}^{2+}$ in $\mathrm{PM}_{10}\left(1.32 \mu \mathrm{g} \mathrm{m}^{-3}\right.$ in measurements). $\mathrm{Na}^{+}$and $\mathrm{Cl}^{-}$are strongly underestimated (MFB $=-85 \%$ and $\mathrm{MFB}=-40 \%$ for $\mathrm{Cl}^{-}$).

The model almost respects the goal criteria for $\mathrm{NO}_{3}^{-}$ in $\mathrm{PM}_{10}(\mathrm{MFB}=24 \%$ and $\mathrm{MFE}=51 \%)$ but with a low correlation (0.38). The modeled annual mean of $\mathrm{NO}_{3}^{-}$in $\mathrm{PM}_{10}\left(1.66 \mu \mathrm{g} \mathrm{m}^{-3}\right)$ is close to the measured annual mean $\left(1.53 \mu \mathrm{g} \mathrm{m}^{-3}\right)$. However, the modeled annual mean of $\mathrm{NO}_{3}^{-}$ in fine particles is strongly overestimated $\left(0.71 \mu \mathrm{g} \mathrm{m}^{-3}\right.$ against $0.18 \mu \mathrm{g} \mathrm{m}^{-3}$ ). The model seems here to underestimate the coarse fraction of $\mathrm{NO}_{3}^{-}$. Even if the model gives strong $\mathrm{NO}_{3}^{-}$concentrations in the coarse fraction due to the coarse-mode formation with dust, a significant part of $\mathrm{NO}_{3}^{-}$ in the model seems to be due to ammonium nitrate formation in $\mathrm{PM}$, whereas most of $\mathrm{NH}_{4}^{+}$seems to be due to am- 

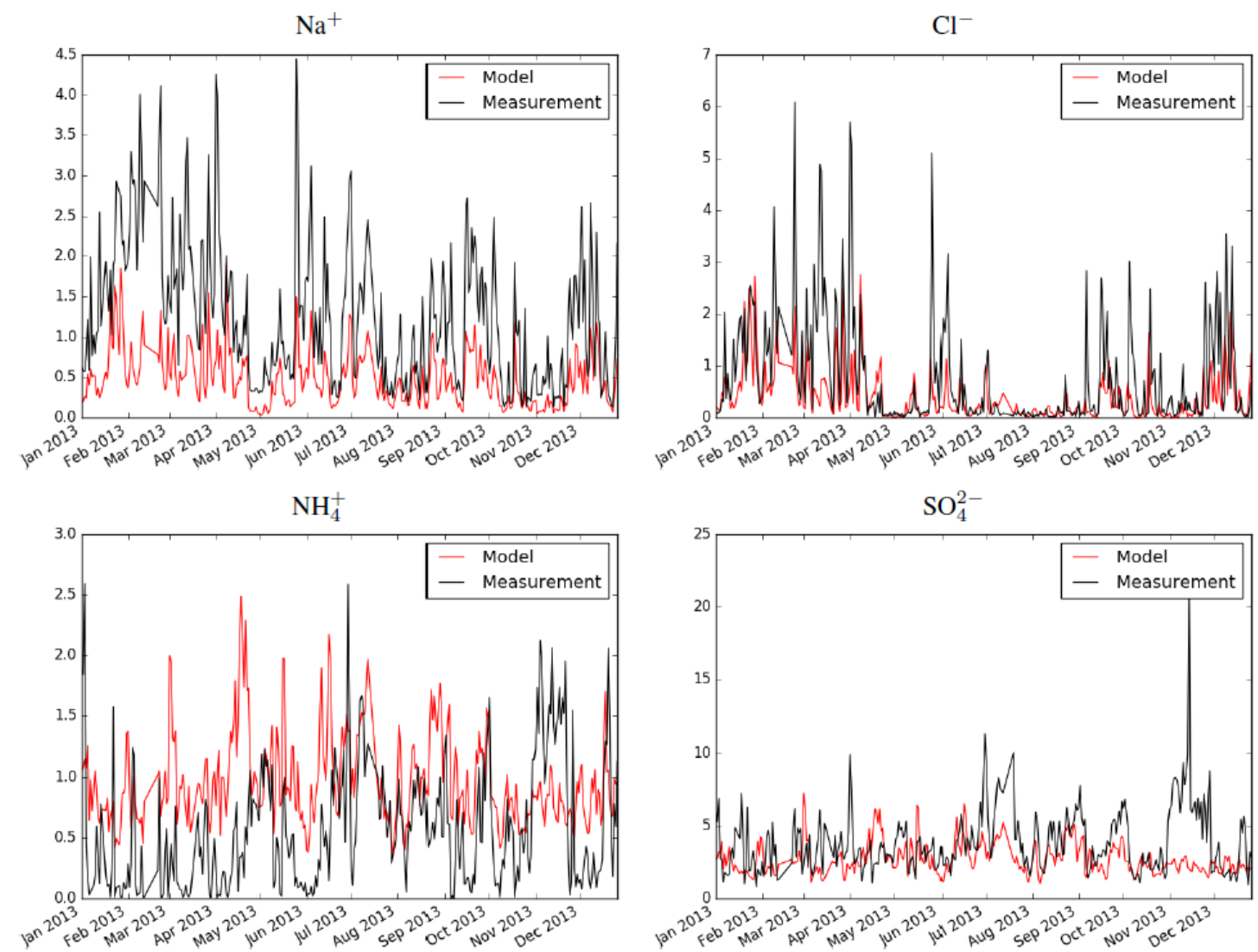

Figure 14. Modeled (red) and measured (black) concentrations of $\mathrm{Na}^{+}, \mathrm{Cl}^{-}, \mathrm{NH}_{4}^{+}$and $\mathrm{SO}_{4}^{2-}$ in $\mu \mathrm{g} \mathrm{m}^{-3}$ for the Cyprus station (CY0002R).

monium sulfate formation (correlation of 0.85 between observed sulfate and ammonium). A similar feature is observed at station ES0008R with a good order of magnitude for $\mathrm{NO}_{3}^{-}$ in $\mathrm{PM}_{10}\left(1.23 \mu \mathrm{g} \mathrm{m}^{-3}\right.$ in the model and $1.19 \mathrm{\mu g} \mathrm{m}^{-3}$ in measurements) but with an overestimation of $\mathrm{NO}_{3}^{-}$in the fine fraction $\left(1.22 \mu \mathrm{g} \mathrm{m}^{-3}\right.$ in the model and $0.38 \mu \mathrm{g} \mathrm{m}^{-3}$ in measurements). These results may be partly due to a lack of $\mathrm{HNO}_{3}$ condensing onto dust but the underestimation is probably mainly due to sea salt which is underestimated at these two stations.

$\mathrm{NH}_{4}^{+}$concentrations are overestimated with a MFB of $49 \%$. This overestimation of ammonium nitrate is likely due to the lack of $\mathrm{HNO}_{3}$ condensing onto dust and sea salt (with more $\mathrm{HNO}_{3}$ condensing onto dust and sea salt, less $\mathrm{HNO}_{3}$ will be available to form ammonium nitrate). $\mathrm{SO}_{4}^{2-}$ concentrations are underestimated (MFB $=-0.29 \%$ ) especially in July and November 2013 where the model is not able to reproduce the high concentrations of sulfate. Correlation are very low $\left(0.23\right.$ for $\mathrm{NH}_{4}^{+}$and 0.13 for $\left.\mathrm{SO}_{4}^{2-}\right)$.

\subsubsection{The case of the Melpitz station (Germany)}

Numerous simultaneous types of measurements were also carried out at the Melpitz station (DE0044R) in Germany. The temporal evolution of $\mathrm{PM}_{2.5}$ and $\mathrm{PM}_{10}, \mathrm{Ca}^{2+}$ (fine frac- tion and $\mathrm{PM}_{10}$ fraction) and $\mathrm{NO}_{3}^{-}$(fine fraction and $\mathrm{PM}_{10}$ fraction) is shown in Fig. 15 and the temporal evolution of $\mathrm{Na}^{+}, \mathrm{Cl}^{-}, \mathrm{NH}_{4}, \mathrm{SO}_{4}$ and EC is shown in Fig. 16. The temporal evolution of OC concentrations is shown in Fig. 10.

At this station, $\mathrm{PM}_{2.5}$ and $\mathrm{PM}_{10}$ share a similar pattern. For $\mathrm{PM}_{2.5}$, annual concentrations are underestimated by the model $\left(13.2 \mu \mathrm{g} \mathrm{m}^{-3}\right.$ against $17.8 \mu \mathrm{g} \mathrm{m}^{-3}$ in measurements) especially in summer with an underestimation ranging from 7 to $11 \mu \mathrm{g} \mathrm{m}^{-3}$ from June to August and a monthly MFB between -65 and $-95 \%$, and at a lesser extent in winter (except in February) with an underestimation of about $7 \mu \mathrm{g} \mathrm{m}^{-3}$. For $\mathrm{PM}_{10}$, the underestimation is stronger $\left(15.7 \mu \mathrm{g} \mathrm{m}^{-3}\right.$ against $22.1 \mathrm{\mu g} \mathrm{m}^{-3}$ ) especially between April and August with an underestimation between 10 and $15 \mu \mathrm{g} \mathrm{m}^{-3}$.

Concentrations of $\mathrm{SO}_{4}^{2-}$ are well reproduced by the model with a high correlation (0.83) and low MFB and MFE (0.12 and $0.35 \%$ ). The model succeeds in capturing the high concentrations of $\mathrm{SO}_{4}^{2-}$ in winter. $\mathrm{NO}_{3}^{-}$concentrations and $\mathrm{NH}_{4}^{+}$ concentrations are also well reproduced by the model except at the end of the year where concentrations are strongly overestimated. The high concentrations of $\mathrm{NO}_{3}^{-}$in February and March are well reproduced by the model (temporal correlation of 0.91 and 0.73 , MFE $=30$ and $40 \%$ ). The low concentrations of $\mathrm{Na}^{+}$and $\mathrm{Cl}^{-}$are a bit overestimated. The overes- 

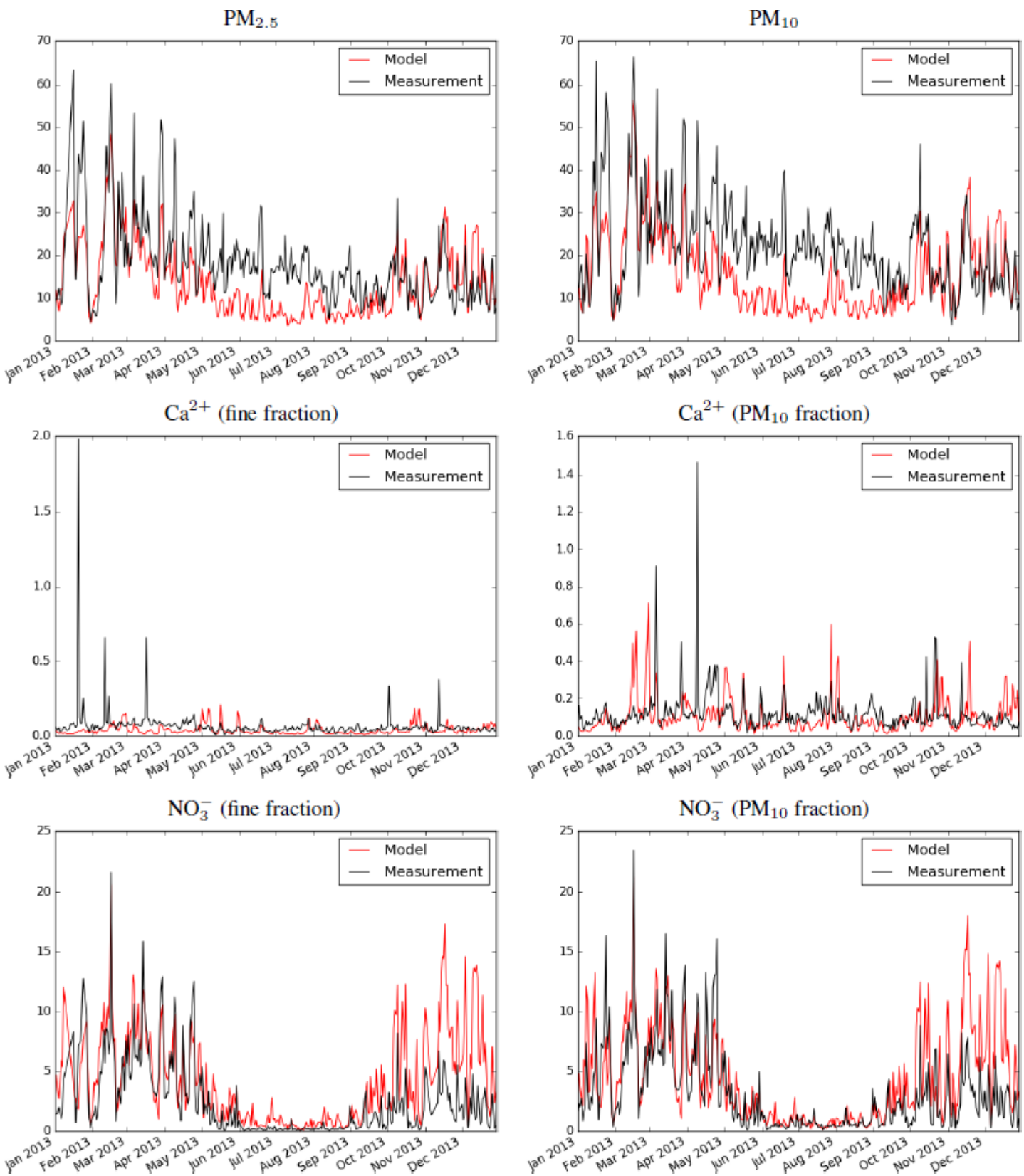

Figure 15. Modeled (red) and measured (black) concentrations of $\mathrm{PM}_{2.5}, \mathrm{PM}_{10}, \mathrm{Ca}^{2+}$ (fine fraction and total) and $\mathrm{NO}_{3}^{-}$(fine fraction and total) in $\mu \mathrm{g} \mathrm{m}{ }^{-3}$ for station DE0044R (Germany).

timation reaches $0.34 \mu \mathrm{g} \mathrm{m}^{-3}$ for $\mathrm{Na}^{+}$and $0.41 \mu \mathrm{g} \mathrm{m}{ }^{-3}$ for $\mathrm{Cl}^{-}$in January.

Most of the underestimation of $\mathrm{PM}_{2.5}$ concentrations is probably due to the underestimation of organic aerosols at this station. Indeed, OC concentrations are underestimated by $2.9 \mu \mathrm{g} \mathrm{m}^{-3}$ from June to August. Using the $\mathrm{OM} / \mathrm{OC}$ ratio of 2.1 measured by Turpin and Lim (2001) for rural areas, the underestimation of organic aerosol could explain most of the differences between modeled and measured $\mathrm{PM}_{2.5}$. However, in June, the underestimation of OC concentrations is only of $3.3 \mu \mathrm{g} \mathrm{m}^{-3}$, which would correspond to an underestimation of $\mathrm{OM}$ of $7 \mu \mathrm{g} \mathrm{m}^{-3}$, whereas $\mathrm{PM}_{2.5}$ concentrations are underestimated by $11 \mu \mathrm{g} \mathrm{m}^{-3}$. It appears difficult that, in June, the underestimation alone of organic aerosols could explain all the underestimation of PM. The remaining underestimation in June cannot be explained by $\mathrm{SO}_{4}^{2-}$, $\mathrm{NO}_{3}^{-}, \mathrm{NH}_{4}^{+}, \mathrm{Na}^{+}$or $\mathrm{Cl}^{-}$. The sum of these concentrations is $4.0 \mu \mathrm{g} \mathrm{m}^{-3}$ for the model and $3.0 \mu \mathrm{g} \mathrm{m}^{-3}$ for measurements. The fine fraction of $\mathrm{Ca}^{2+}$ is a bit underestimated by the model $\left(0.08 \mu \mathrm{g} \mathrm{m}^{-3}\right.$ against $0.11 \mu \mathrm{g} \mathrm{m}^{-3}$ in measurements $)$, 

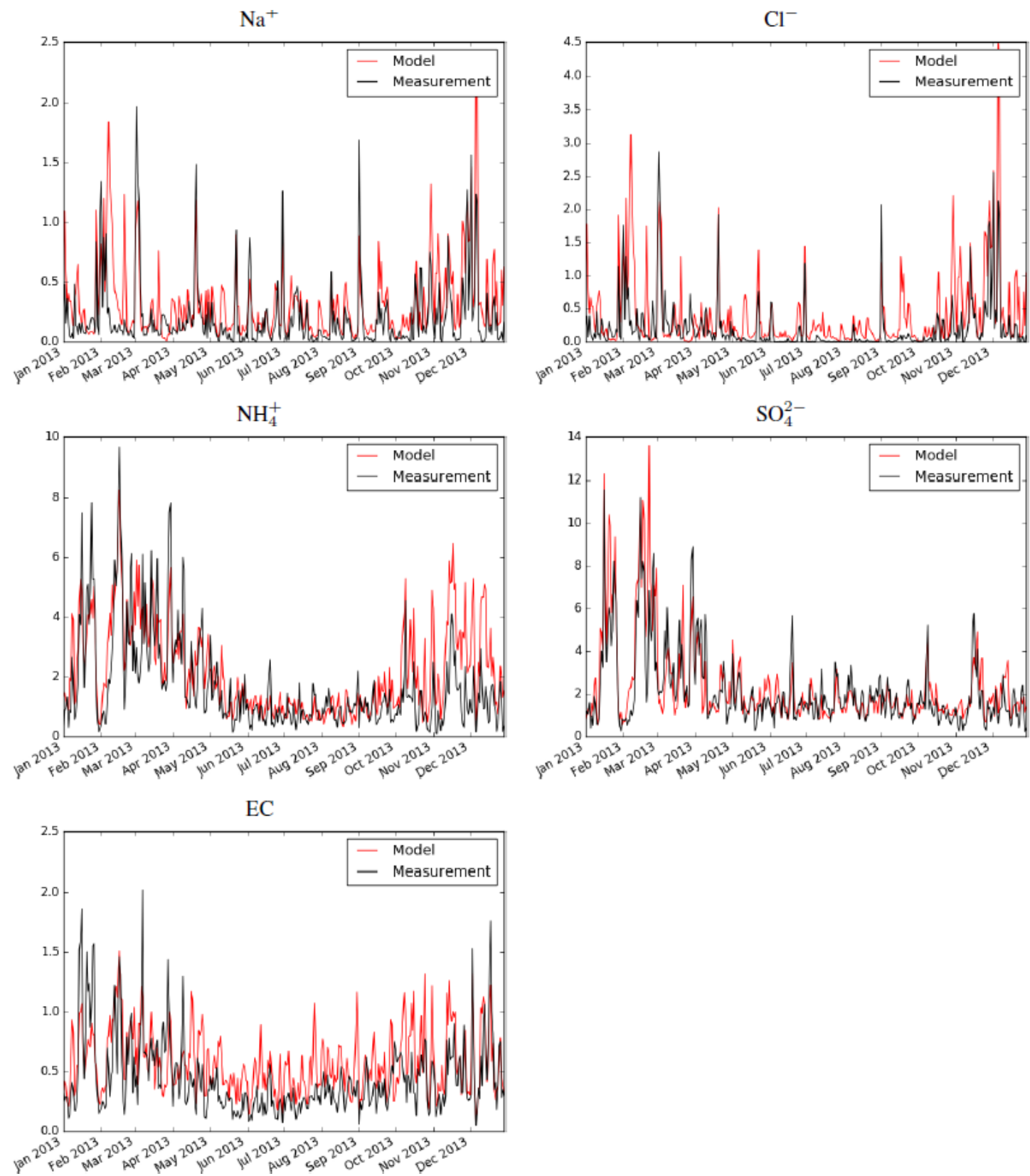

Figure 16. Modeled (red) and measured (black) concentrations of $\mathrm{Na}^{+}, \mathrm{Cl}^{-}, \mathrm{NH}_{4}^{+}, \mathrm{SO}_{4}^{2-}$ and $\mathrm{EC}$ in $\mu \mathrm{g} \mathrm{m}^{-3}$ for station $\mathrm{DE} 0044 \mathrm{R}(\mathrm{Ger}-$ many).

which could explain an underestimation of $0.75 \mathrm{\mu g} \mathrm{m}^{-3}$ (assuming that there is $4 \%$ of $\mathrm{Ca}^{2+}$ in dust) which is just enough to compensate the overestimation by the model of inorganic aerosols. The remaining underestimation in June could be explained by an underestimation of primary aerosols. However, EC concentrations are well reproduced by the model (annual correlation of $0.62, \mathrm{MFB}=0.34 \%$ and $\mathrm{MFE}=47 \%$ ) and are slightly overestimated by the model $\left(0.42 \mu \mathrm{g} \mathrm{m}^{-3}\right.$ against $0.22 \mu \mathrm{g} \mathrm{m}^{-3}$ in measurements).

\section{Perspectives on model improvement}

The following list provides a list of possible developments that may be addressed in the future:

- The formation of ammonium nitrate in the model for which the strongest errors were obtained needs to be improved. As $\mathrm{NH}_{3}$ emissions are a key element, implementing a dynamic method to improve the spatial and temporal evolution of $\mathrm{NH}_{3}$ emissions from agriculture, like the method described in Skjøth et al. (2011), de- 
pending on temperature and wind speed could be a major improvement.

- The formation of anthropogenic SOA has to be better represented in the model. For that, SVOC and IVOC emissions should be better represented. The inventory of Denier van der Gon et al. (2015) could be used to better estimate SVOC from residential biomass burning. More generally, to take into account IVOC emissions, emission inventories by volatility classes should be developed based, for example, on the method developed by Zhao et al. (2016b). Moreover, mechanisms of formation of SOA from IVOC oxidation and the aging of SVOC have to be better understood. Bruns et al. (2016) showed that the formation of SOA from SOA precursors traditionally taken into account in models (like toluene, xylene, alkanes) only accounts for a small amount of SOA (between 3 and $27 \%$ of SOA formed) from biomass burning and that most of the SOA is due to non-traditional SOA precursors (phenol, naphthalene, benzaldehyde, etc.). These precursors should be added into the SOA mechanism. Aging has also a major impact on SOA formation (Donahue et al., 2012; Zhao et al., 2016a) and should be studied in greater detail.

- The influence of the gas-phase mechanism on PM formation should be tested within CHIMERE. Indeed, Sarwar et al. (2013) found significant differences over the United States between CB05 (Sarwar et al., 2008) and RACM2 (Goliff et al., 2013) in $\mathrm{OH}$ concentrations (46\% in $\mathrm{OH}$ concentrations) and PM components (10\% in sulfate, $6 \%$ in nitrate, $10 \%$ in ammonium, $42 \%$ in anthropogenic SOA and $5 \%$ in biogenic SOA). The strong differences in radical concentrations may strongly affect the aging of SVOC compounds and the seasonal evolution of PM components. It may also be important to compare the results of the MELCHIOR 2 mechanisms with more recent gas-phase mechanisms.

- The formation of inorganic aerosol could be integrated in the SOAP thermodynamic model. SOAP would then be able to simulate both inorganic and organic aerosols and take into account the influence between inorganic and organic aerosols which can affect the partitioning of compounds and the hygroscopicity of the aerosol (Jing et al., 2016). It could also be important to take into account the formation of some acid organics/ammonium salt which can be in competition with ammonium nitrate formation. Some organonitrogen compounds were also found by condensation of ammonia onto organic aerosols (Liu et al., 2015).

- Interactions of dust with inorganic aerosols could be better represented in the model. The interactions could, for example, be simulated by taking into account the mineralogy of dust within CHIMERE, by emitting dust particles with different composition depending on the location of emissions.

- Some recent experimental studies emphasize the need to account for dynamical aspects of the organic aerosol formation rather than assuming thermodynamic equilibrium with the gas phase because organic aerosols can be highly viscous (Virtanen et al., 2010; Cappa and Wilson, 2011; Pfrang et al., 2011; Shiraiwa et al., 2011; Vaden et al., 2011; Shiraiwa and Seinfeld, 2012; Abramson et al., 2013). To our knowledge, this phenomenon was never investigated inside a 3-D air quality model. However, a dynamic method for SOA formation that takes into account the diffusion inside a few layers was developed in the thermodynamic model SOAP. This method could be used to test the influence of the organic-phase viscosity on SOA formation inside a 3-D air quality model.

- The aqueous-phase chemical mechanism can be extensively improved. Several studies highlight the importance of aqueous-phase chemistry for SOA formation from isoprene. An isoprene-derived epoxidiol (IEPOX) has been shown to form methyltetrols and $\mathrm{C}_{5}$-alkene triols in the aqueous phase of particles and droplets by hydrolysis as well as organosulfates by reaction with sulfate or bisulfate ions and oligomers (Surratt et al., 2010). Froyd et al. (2010) found very high concentrations of SOA $\left(910 \mathrm{ng} \mathrm{m}^{-3}\right)$ formed from IEPOX in Atlanta, USA, due to a very acidic aerosol. The formation of SOA from IEPOX was investigated in a previous study (Couvidat et al., 2013). Using a Henry's law constant of IEPOX of $2 \times 10^{7} \mathrm{Matm}^{-1}$ and a mechanism based on available information, the model could simulate concentrations of SOA from IEPOX in the right order of magnitude and simulate concentrations of SOA from IEPOX in summer that could reach $1 \mu \mathrm{g} \mathrm{m}^{-3}$ over some regions and could give strong peaks of SOA. Nguyen et al. (2014) found a Henry's law constant of $3 \times 10^{7} \mathrm{Matm}^{-1}$. However, this modeling study did not take into account interactions with inorganic aerosol. Aqueous-phase processing of glyoxal (which is formed from the oxidation of toluene and isoprene) was also found to be possibly a significant source of SOA as it can form oxalic acid via reaction in clouds (Griffin et al., 2003) and could form oligomers or form SOA in particles via reaction with the hydroxyl radical or from reactions catalyzed by ammonium (Knote et al., 2014) which could be important to take into account. Implementing a complete cloud chemical mechanism should be tested. A mechanism similar to Leriche et al. (2013) could be implemented to improve the representation of the cloud chemistry inside the model.

- The number of particles has also an effect on health, especially in urban areas (Jing et al., 2001). To prop- 
erly estimate the effects of particles on health in urban areas, more complete parameterization of nucleation should be implemented (for example, the impact of organic compounds; Lupascu et al., 2015) and model results should be compared to available data on European megacities (Pikridas et al., 2015).

- The possibility to take into account the mixing state, as done by Zhu et al. (2015, 2016a, b), should be added to the model as it can impact the aerosol formation and composition and their optical and hygroscopic properties.

\section{Conclusions}

Concentrations were compared to available information on PM concentrations and composition thanks to the EBAS database. Whereas the model gives satisfactory results with regard to the criteria defined by Boylan and Russell (2006), results could be improved in terms of seasonality and PM composition. Strongest errors were found to be probably due to ammonium nitrate which is often overestimated especially in late autumn (probably due to an overestimation of $\mathrm{NH}_{3}$ emissions during this period). Only in summer, concentrations of ammonium nitrate could be underestimated. Strong errors were also found on OC concentrations in summer (especially over the northern half of Europe) indicating that strong concentrations of anthropogenic SOA could be missing from the models. The underestimation could also be due to a lack of biogenic emissions over the northern half of Europe. Sea-salt concentrations were properly simulated at most stations but were overestimated over regions with low concentrations and underestimated for regions with very strong concentrations (which could lead to an underestimation of $\mathrm{HNO}_{3}$ condensation onto coarse particles).

However, the model has good performance in general and respects the goal criteria for both $\mathrm{PM}_{2.5}$ and $\mathrm{PM}_{10}$. For sea salt, the model almost respects the goal criteria of Boylan and Russell (2006) and succeeds in reproducing the seasonal evolution of concentrations for western and central Europe. For sulfate, except for an overestimation of sulfate in northern Europe, modeled concentrations are close to observations with a good seasonal evolution of concentrations. For organic aerosol, the model performs well for stations with strong modeled biogenic SOA concentrations.

Several improvements should be tested. Taking into account the dynamics of $\mathrm{NH}_{3}$ emissions could greatly improve the results of the model in simulating ammonium nitrate. Taking into account SOA formation from missing SVOC/IVOC emissions probably has an important impact on SOA formation and could probably improve results on SOA concentrations. Moreover, the impact of inorganic-organic interactions and the effect of aqueous-phase chemistry on SOA formation should be investigated.
Code availability. CHIMERE $2017 \beta$ is a version of CHIMERE developed for research on aerosol modeling. It is available on request by contacting the authors.

\section{The Supplement related to this article is available online at https://doi.org/10.5194/gmd-11-165-2018-supplement.}

Competing interests. The authors declare that they have no conflict of interest.

Acknowledgements. This work was funded by the French Ministry of the Environment, Energy and Marine Affairs. Simulations were performed using the TGCC-CCRT supercomputers under the GENCI time allocation gen7485. Measurements were extracted from the EBAS database. The EBAS database has largely been funded by the UN-ECE CLRTAP (EMEP), AMAP and through Norwegian Institute for Air Research (NILU) internal resources.

Edited by: Samuel Remy

Reviewed by: three anonymous referees

\section{References}

Abramson, E., Imre, D., Beránek, J., Wilson, J., and Zelenyuk, A.: Experimental determination of chemical diffusion with secondary organic aerosol particles, Phys. Chem. Chem. Phys., 15, 2983-2991, https://doi.org/10.1039/C2CP44013J, 2013.

Ansari, A. S. and Pandis, S. N.: Prediction of multicomponent inorganic atmospheric aerosol behavior, Atmos. Environ., 33, 745757, https://doi.org/10.1016/S1352-2310(98)00221-0, 1999.

Bessagnet, B., Seigneur, C., and Menut, L.: Impact of dry deposition of semi-volatile organic compounds on secondary organic aerosols, Atmos. Environ., 44, 1781-1787, https://doi.org/10.1016/j.atmosenv.2010.01.027, 2010.

Bessagnet, B., Colette, A., Meleux, F., Rouîl, L., Ung, A., Favez, O., Thunis, P., Cuvelier, C., Tsyro, S., Stern, R., Manders, A., Kranenburg, R., Aulinger, A., Bieser, J., Mircea, M., Briganti, G., Cappelletti, A., Calori, G., Finardi, S., Silibello, C., Ciarelli, G., Aksoyoglu, S., Prévot, A., Pay, M.-T., Baldasano, J., García Vivanco, M., Garrido, J. L., Palomino, I., Martín, F., Pirovano, G., Roberts, P., Gonzalez, L., White, L., Menut, L., Dupont, J.-C., Carnevale, C., and Pederzoli, A.: The EURODELTA III exercise - model evaluation with observations issued from the 2009 EMEP intensive period and standard measurements in Feb/Mar 2009, Tech. Rep., EMEP, 2014.

Bessagnet, B., Pirovano, G., Mircea, M., Cuvelier, C., Aulinger, A., Calori, G., Ciarelli, G., Manders, A., Stern, R., Tsyro, S., García Vivanco, M., Thunis, P., Pay, M.-T., Colette, A., Couvidat, F., Meleux, F., Rouïl, L., Ung, A., Aksoyoglu, S., Baldasano, J. M., Bieser, J., Briganti, G., Cappelletti, A., D’Isidoro, M., Finardi, S., Kranenburg, R., Silibello, C., Carnevale, C., Aas, W., Dupont, J.-C., Fagerli, H., Gonzalez, L., Menut, L., Prévôt, A. S. H., Roberts, P., and White, L.: Presentation of the EURODELTA 
III intercomparison exercise - evaluation of the chemistry transport models' performance on criteria pollutants and joint analysis with meteorology, Atmos. Chem. Phys., 16, 12667-12701, https://doi.org/10.5194/acp-16-12667-2016, 2016.

Boylan, J. W. and Russell, A. G.: PM and light extinction model performance metrics, goals, and criteria for threedimensional air quality models, Atmos. Environ., 40, 49464959, https://doi.org/10.1016/j.atmosenv.2005.09.087, 2006.

Bruns, E. A., El Haddad, I., Slowik, J. G., Kilic, D., Klein, F., Baltensperger, U., and Prévôt, A. S. H.: Identification of significant precursor gases of secondary organic aerosols from residential wood combustion, Sci. Rep.-UK, 6, 27881, https://doi.org/10.1038/srep27881, 2016.

Cappa, C. D. and Wilson, K. R.: Evolution of organic aerosol mass spectra upon heating: implications for OA phase and partitioning behavior, Atmos. Chem. Phys., 11, 1895-1911, https://doi.org/10.5194/acp-11-1895-2011, 2011.

Carlton, A. G., Bhave, P. V., Napelenok, S. L., Edney, E. O., Sarwar, G., Pinder, R. W., Pouliot, G. A., and Houyoux, M.: Model representation of secondary organic aerosol in CMAQv4.7, Environ. Sci. Technol., 44, 8553-8560, https://doi.org/10.1021/es100636q, 2010.

Chan, A. W. H., Kautzman, K. E., Chhabra, P. S., Surratt, J. D., Chan, M. N., Crounse, J. D., Kürten, A., Wennberg, P. O., Flagan, R. C., and Seinfeld, J. H.: Secondary organic aerosol formation from photooxidation of naphthalene and alkylnaphthalenes: implications for oxidation of intermediate volatility organic compounds (IVOCs), Atmos. Chem. Phys., 9, 3049-3060, https://doi.org/10.5194/acp-9-3049-2009, 2009.

Couvidat, F. and Sartelet, K.: The Secondary Organic Aerosol Processor (SOAP v1.0) model: a unified model with different ranges of complexity based on the molecular surrogate approach, Geosci. Model Dev., 8, 1111-1138, https://doi.org/10.5194/gmd8-1111-2015, 2015.

Couvidat, F. and Seigneur, C.: Modeling secondary organic aerosol formation from isoprene oxidation under dry and humid conditions, Atmos. Chem. Phys., 11, 893-909, https://doi.org/10.5194/acp-11-893-2011, 2011.

Couvidat, F., Debry, É., Sartelet, K., and Seigneur, C.: A Hydrophilic/Hydrophobic Organic $\left(\mathrm{H}^{2} \mathrm{O}\right)$ model: model development, evaluation and sensitivity analysis, J. Geophys. Res.Atmos., 117, D10304, https://doi.org/10.1029/2011JD017214, 2012.

Couvidat, F., Sartelet, K., and Seigneur, C.: Investigating the impact of aqueous-phase chemistry and wet deposition on organic aerosol formation using a molecular surrogate modeling approach, Environ. Sci. Technol., 47, 914-922, https://doi.org/10.1021/es3034318, 2013.

Croft, B., Lohmann, U., Martin, R. V., Stier, P., Wurzler, S., Feichter, J., Hoose, C., Heikkilä, U., van Donkelaar, A., and Ferrachat, S.: Influences of in-cloud aerosol scavenging parameterizations on aerosol concentrations and wet deposition in ECHAM5-HAM, Atmos. Chem. Phys., 10, 1511-1543, https://doi.org/10.5194/acp-10-1511-2010, 2010.

de Wolf, A. D.: On the Laws-Parsons distribution of raindrop sizes, Radio Sci., 36, 639-642, https://doi.org/10.1029/2000RS002369, 1999.

Debry, E., Fahey, K., Sartelet, K., Sportisse, B., and Tombette, M.: Technical Note: A new SIze REsolved Aerosol
Model (SIREAM), Atmos. Chem. Phys., 7, 1537-1547, https://doi.org/10.5194/acp-7-1537-2007, 2007.

Denier van der Gon, H. A. C., Bergström, R., Fountoukis, C., Johansson, C., Pandis, S. N., Simpson, D., and Visschedijk, A. J. H.: Particulate emissions from residential wood combustion in Europe - revised estimates and an evaluation, Atmos. Chem. Phys., 15, 6503-6519, https://doi.org/10.5194/acp15-6503-2015, 2015.

Derognat, C., Beekmann, M., Baeumle, M., Martin, D., and Schmidt, H.: Effect of biogenic volatile organic compound emissions on tropospheric chemistry during the Atmospheric Pollution Over the Paris Area (ESQUIF) campaign in the Ile-de-France region, J. Geophys. Res.-Atmos., 108, 8560, https://doi.org/10.1029/2001JD001421, 2003.

Donahue, N. M., Henry, K. M., Mentel, T. F., Kiendler-Scharr, A., Spindler, C., Bohn, B., Brauers, T., Dorn, H. P., Fuchs, H., Tillmann, R., Wahner, A., Saathoff, H., K.-H., N., Möhler, O., Leisner, T., Müller, L., Reinnig, M.-C., Hoffmann, T., Salo, L., Hallquist, M., Frosch, M., Bilde, M., Tritscher, T., Barmet, P., Praplan, A. P., DeCarlo, P. F., Dommen, J., Prévôt, A. S. H., and Baltensperger, U.: Aging of biogenic secondary organic aerosol via gas-phase $\mathrm{OH}$ radical reactions, P. Natl. Acad. Sci. USA, 109, 13503-13508, https://doi.org/10.1073/pnas.1115186109, 2012.

Ebel, A., Friedrich, R., and Rodhe, H.: Tropospheric Modelling and Emission Estimation. Transport and Chemical Transformation of Pollutants in the Troposphere, chap. GENEMIS: Assessment, Improvement, and Temporal and Spatial Disaggregation of European Emission Data, Springer, Berlin, Germany, 1997.

Emmons, L. K., Walters, S., Hess, P. G., Lamarque, J.-F., Pfister, G. G., Fillmore, D., Granier, C., Guenther, A., Kinnison, D., Laepple, T., Orlando, J., Tie, X., Tyndall, G., Wiedinmyer, C., Baughcum, S. L., and Kloster, S.: Description and evaluation of the Model for Ozone and Related chemical Tracers, version 4 (MOZART-4), Geosci. Model Dev., 3, 43-67, https://doi.org/10.5194/gmd-3-43-2010, 2010.

Formenti, P., Rajot, J. L., Desboeufs, K., Caquineau, S., Chevaillier, S., Nava, S., Gaudichet, A., Journet, E., Triquet, S., Alfaro, S., Chiri, M., Haywood, J., Coe, H., and Highwood, E.: Regional variability of the composition of mineral dust from western Africa: results from the AMMA SOP0/DABEX and DODO field campaigns, J. Geophys. Res.-Atmos., 113, D00C13, https://doi.org/10.1029/2008JD009903, 2008.

Fountoukis, C. and Nenes, A.: ISORROPIA II: a computationally efficient thermodynamic equilibrium model for $\mathrm{K}^{+}-\mathrm{Ca}^{2+}$ $\mathrm{Mg}^{2+}-\mathrm{NH}_{4}^{+}-\mathrm{Na}^{+}-\mathrm{SO}_{4}^{2-}-\mathrm{NO}_{3}^{-}-\mathrm{Cl}^{-}-\mathrm{H}_{2} \mathrm{O}$ aerosols, Atmos. Chem. Phys., 7, 4639-4659, https://doi.org/10.5194/acp-7-46392007, 2007.

Fredenslund, A., Jones, R. L., and Prausnitz, J. M.: Groupcontribution estimation of activity-coefficients in nonideal liquid-mixtures, AIChE J., 21, 1086-1099, 1975.

Froyd, K. D., Murphy, S. M., Murphy, D. M., de Gouw, J. A., Eddingsaas, N. C., and Wennberg, P. O.: Contribution of isoprene-derived organosulfates to free tropospheric aerosol mass, P. Natl. Acad. Sci. USA, 107, 21360-21365, https://doi.org/10.1073/pnas.1012561107, 2010.

Ganbavale, G., Zuend, A., Marcolli, C., and Peter, T.: Improved AIOMFAC model parameterisation of the temperature dependence of activity coefficients for aqueous organic mixtures, At- 
mos. Chem. Phys., 15, 447-493, https://doi.org/10.5194/acp-15447-2015, 2015.

Goliff, W. S., Stockwell, W. R., and Lawson, C. V.: The regional atmospheric chemistry mechanism, Version 2, Atmos. Environ., 68, 174-185, 2013.

Grieshop, A. P., Logue, J. M., Donahue, N. M., and Robinson, A. L.: Laboratory investigation of photochemical oxidation of organic aerosol from wood fires 1: measurement and simulation of organic aerosol evolution, Atmos. Chem. Phys., 9, 1263-1277, https://doi.org/10.5194/acp-9-1263-2009, 2009.

Griffin, R. J., Nguyen, K., Dabdub, D., and Seinfeld, J. H.: A coupled hydrophobic-hydrophilic model for predicting secondary organic aerosol formation, J. Atmos. Chem., 44, 171190, https://doi.org/10.1023/A:1022436813699, 2003.

Guenther, A. B., Jiang, X., Heald, C. L., Sakulyanontvittaya, T., Duhl, T., Emmons, L. K., and Wang, X.: The Model of Emissions of Gases and Aerosols from Nature version 2.1 (MEGAN2.1): an extended and updated framework for modeling biogenic emissions, Geosci. Model Dev., 5, 1471-1492, https://doi.org/10.5194/gmd-5-1471-2012, 2012.

Henzing, J. S., Olivié, D. J. L., and van Velthoven, P. F. J.: A parameterization of size resolved below cloud scavenging of aerosols by rain, Atmos. Chem. Phys., 6, 3363-3375, https://doi.org/10.5194/acp-6-3363-2006, 2006.

Hodzic, A., Bessagnet, B., and Vautard, R.: A model evaluation of coarse-mode nitrate heterogeneous formation on dust particles, Atmos. Environ., 40, 4158-4171, https://doi.org/10.1016/j.atmosenv.2006.02.015, 2006.

Jacobson, M. Z. and Turco, R. P.: Modeling coagulation among particles of different composition and size, Atmos. Environ., 28, 1327-1338, https://doi.org/10.1016/1352-2310(94)90280-1, 1994.

Jing, B., Tong, S., Liu, Q., Li, K., Wang, W., Zhang, Y., and Ge, M.: Number concentration and size of particles in urban air: effects on spirometric lung function in adult asthmatic subjects, Environ. Health Persp., 109, 319-323, 2001.

Jing, B., Tong, S., Liu, Q., Li, K., Wang, W., Zhang, Y., and Ge, M.: Hygroscopic behavior of multicomponent organic aerosols and their internal mixtures with ammonium sulfate, Atmos. Chem. Phys., 16, 4101-4118, https://doi.org/10.5194/acp-164101-2016, 2016.

Kanakidou, M., Seinfeld, J. H., Pandis, S. N., Barnes, I., Dentener, F. J., Facchini, M. C., Van Dingenen, R., Ervens, B., Nenes, A., Nielsen, C. J., Swietlicki, E., Putaud, J. P., Balkanski, Y., Fuzzi, S., Horth, J., Moortgat, G. K., Winterhalter, R., Myhre, C. E. L., Tsigaridis, K., Vignati, E., Stephanou, E. G., and Wilson, J.: Organic aerosol and global climate modelling: a review, Atmos. Chem. Phys., 5, 1053-1123, https://doi.org/10.5194/acp-5-10532005, 2005.

Kautzman, K. E., Surratt, J. D., Chan, M. N., Chan, A. W. H., Hersey, S. P., Chhabra, P. S., Dalleska, N. F., Wennberg, P. O., Flagan, R. C., and Seinfeld, J. H.: Chemical composition of gas- and aerosol-phase products from the photooxidation of naphthalene, J. Phys. Chem. A, 114, 913-934, https://doi.org/10.1021/jp908530s, 2010.

Knote, C., Hodzic, A., Jimenez, J. L., Volkamer, R., Orlando, J. J., Baidar, S., Brioude, J., Fast, J., Gentner, D. R., Goldstein, A. H., Hayes, P. L., Knighton, W. B., Oetjen, H., Setyan, A., Stark, H., Thalman, R., Tyndall, G., Washenfelder, R., Waxman,
E., and Zhang, Q.: Simulation of semi-explicit mechanisms of SOA formation from glyoxal in aerosol in a 3-D model, Atmos. Chem. Phys., 14, 6213-6239, https://doi.org/10.5194/acp14-6213-2014, 2014.

Kulmala, M. A. L. and Pirjola, L.: Parameterization for sulfuric acid/water nucleation rates, J. Geophys. Res.-Atmos., 103, 83018307, https://doi.org/10.1029/97JD03718, 1998.

Lecœur, È. and Seigneur, C.: Dynamic evaluation of a multiyear model simulation of particulate matter concentrations over Europe, Atmos. Chem. Phys., 13, 4319-4337, https://doi.org/10.5194/acp-13-4319-2013, 2013.

Leriche, M., Pinty, J.-P., Mari, C., and Gazen, D.: A cloud chemistry module for the 3-D cloud-resolving mesoscale model Meso-NH with application to idealized cases, Geosci. Model Dev., 6, 12751298, https://doi.org/10.5194/gmd-6-1275-2013, 2013.

Liu, Y., Liggio, J., Staebler, R., and Li, S.-M.: Reactive uptake of ammonia to secondary organic aerosols: kinetics of organonitrogen formation, Atmos. Chem. Phys., 15, 1356913584, https://doi.org/10.5194/acp-15-13569-2015, 2015.

Lupascu, A., Easter, R., Zaveri, R., Shrivastava, M., Pekour, M., Tomlinson, J., Yang, Q., Matsui, H., Hodzic, A., Zhang, Q., and Fast, J. D.: Modeling particle nucleation and growth over northern California during the 2010 CARES campaign, Atmos. Chem. Phys., 15, 12283-12313, https://doi.org/10.5194/acp-15-122832015, 2015.

Mätzler, C.: Drop-Size Distributions and Mie Computations for Rain, Tech. Rep., IAP Research Report, University of Bern, Bern, 2002.

May, A. A., Levin, E. J. T., Hennigan, C. J., Riipinen, I., Lee, T., Collett Jr., J. L., Jimenez, J. L., Kreidenweis, S. M., and Robinson, A. L.: Gas-particle partitioning of primary organic aerosol emissions: 3. Biomass burning, J. Geophys. Res.-Atmos., 118, 11327-11338, https://doi.org/10.1002/jgrd.50828, 2013.

Menut, L., Bessagnet, B., Khvorostyanov, D., Beekmann, M., Blond, N., Colette, A., Coll, I., Curci, G., Foret, G., Hodzic, A., Mailler, S., Meleux, F., Monge, J.-L., Pison, I., Siour, G., Turquety, S., Valari, M., Vautard, R., and Vivanco, M. G.: CHIMERE 2013: a model for regional atmospheric composition modelling, Geosci. Model Dev., 6, 981-1028, https://doi.org/10.5194/gmd-6-981-2013, 2013.

Monahan, E., Spiel, D., and Davidson, K.: Oceanic Whitecaps and Their Role in Air-Sea Exchange Processes, Chap. A Model of Marine Aerosol Generation Via Whitecaps and Wave Disruption, D. Reidel Pub., Dordrecht, 1986.

Moya, M., Pandis, S. N., and Jacobson, M. Z.: Is the size distribution of urban aerosols determined by thermodynamic equilibrium? An application to Southern California, Atmos. Environ., 36, 2349-2365, https://doi.org/10.1016/S1352-2310(01)005490,2002 .

Neumann, D., Matthias, V., Bieser, J., Aulinger, A., and Quante, M.: A comparison of sea salt emission parameterizations in northwestern Europe using a chemistry transport model setup, Atmos. Chem. Phys., 16, 9905-9933, https://doi.org/10.5194/acp16-9905-2016, 2016.

Nguyen, T. B., Coggon, M. M., Bates, K. H., Zhang, X., Schwantes, R. H., Schilling, K. A., Loza, C. L., Flagan, R. C., Wennberg, P. O., and Seinfeld, J. H.: Organic aerosol formation from the reactive uptake of isoprene epoxydiols (IEPOX) onto non- 
acidified inorganic seeds, Atmos. Chem. Phys., 14, 3497-3510, https://doi.org/10.5194/acp-14-3497-2014, 2014.

Nordin, E. Z., Eriksson, A. C., Roldin, P., Nilsson, P. T., Carlsson, J. E., Kajos, M. K., Hellén, H., Wittbom, C., Rissler, J., Löndahl, J., Swietlicki, E., Svenningsson, B., Bohgard, M., Kulmala, M., Hallquist, M., and Pagels, J. H.: Secondary organic aerosol formation from idling gasoline passenger vehicle emissions investigated in a smog chamber, Atmos. Chem. Phys., 13, 6101-6116, https://doi.org/10.5194/acp-13-6101-2013, 2013.

Pandis, S., Wexler, A., and Seinfeld, J.: Secondary organic aerosol formation and transport - II. Predicting the ambient secondary organic aerosol size distribution, Atmos. Environ., 27A, 24032416, https://doi.org/10.1016/0960-1686(93)90408-Q, 1993.

Pankow, J. F.: An absorption model of gas/particle partitioning of organic compounds in the atmosphere, Atmos. Environ., 28A, 185-188, 1994.

Peters, K. and Bruckner-Schatt, G.: The dry deposition of gaseous and participate nitrogen compounds to a spruce stand, Water Air Soil Pollut., 85, 2217-2222, https://doi.org/10.1007/BF01186163, 1995.

Pfrang, C., Shiraiwa, M., and Pöschl, U.: Chemical ageing and transformation of diffusivity in semi-solid multi-component organic aerosol particles, Atmos. Chem. Phys., 11, 7343-7354, https://doi.org/10.5194/acp-11-7343-2011, 2011.

Pikridas, M., Sciare, J., Freutel, F., Crumeyrolle, S., von der Weiden-Reinmüller, S.-L., Borbon, A., Schwarzenboeck, A., Merkel, M., Crippa, M., Kostenidou, E., Psichoudaki, M., Hildebrandt, L., Engelhart, G. J., Petäjä, T., Prévôt, A. S. H., Drewnick, F., Baltensperger, U., Wiedensohler, A., Kulmala, M., Beekmann, M., and Pandis, S. N.: In situ formation and spatial variability of particle number concentration in a European megacity, Atmos. Chem. Phys., 15, 10219-10237, https://doi.org/10.5194/acp-15-10219-2015, 2015.

Pirovano, G., Balzarini, A., Bessagnet, B., Emery, C., Kallos, G., Meleux, F., Mitsakou, C., Nopmongcol, U., M., R. G., and Yarwood, G.: Investigating impacts of chemistry and transport model formulation on model performance at European scale, Atmos. Environ., 53, 1-17, https://doi.org/10.1016/j.atmosenv.2011.12.052, 2012.

Platt, S. M., El Haddad, I., Zardini, A. A., Clairotte, M., Astorga, C., Wolf, R., Slowik, J. G., Temime-Roussel, B., Marchand, N., Ježek, I., Drinovec, L., Močnik, G., Möhler, O., Richter, R., Barmet, P., Bianchi, F., Baltensperger, U., and Prévôt, A. S. H.: Secondary organic aerosol formation from gasoline vehicle emissions in a new mobile environmental reaction chamber, Atmos. Chem. Phys., 13, 9141-9158, https://doi.org/10.5194/acp13-9141-2013, 2013.

Pozzoli, L., Janssens-Maenhout, G., Diehl, T., Bey, I., Schultz, M. G., Feichter, J., Vignati, E., and Dentener, F.: Reanalysis of tropospheric sulfate aerosol and ozone for the period 1980-2005 using the aerosol-chemistry-climate model ECHAM5-HAMMOZ, Atmos. Chem. Phys., 11, 9563-9594, https://doi.org/10.5194/acp-11-9563-2011, 2011.

Pun, B. K. and Seigneur, C.: Investigative modeling of new pathways for secondary organic aerosol formation, Atmos. Chem. Phys., 7, 2199-2216, https://doi.org/10.5194/acp-7-2199-2007, 2007.
Pye, H. O. T. and Seinfeld, J. H.: A global perspective on aerosol from low-volatility organic compounds, Atmos. Chem. Phys., 10, 4377-4401, https://doi.org/10.5194/acp-10-4377-2010, 2010.

Robinson, A. L., Donahue, N. M., Shrivastava, M. K., Weitkamp, E. A., Sage, A. M., Grieshop, A. P., Lane, T. E., Pierce, J. R., and Pandis, S. N.: Rethinking organic aerosols: semivolatile emissions and photochemical aging, Science, 315, 1259-1262, https://doi.org/10.1126/science.1133061, 2007.

Rouill, L., Honoré, C., Bessagnet, B., Malherbe, L., Meleux, F., Vautard, R., Beekmann, M., Flaud, J.-M., Dufour, A., Martin, D., Peuch, A., Peuch, V.-H., Elichegaray, C., Poisson, N., and Menut, L.: Prev'air: an operational forecasting and mapping system for air quality in Europe, B. Am. Meteorol. Soc., 90, 73-83, https://doi.org/10.1175/2008BAMS2390.1, 2009.

Sartelet, K., Debry, E., Fahey, K., Roustan, Y., Tombette, M., and Sportisse, B.: Simulation of aerosols and gas-phase species over Europe with the Polyphemus system. Part I: model-todata comparison for 2001, Atmos. Environ., 41, 6116-6131, https://doi.org/10.1016/j.atmosenv.2007.04.024, 2007.

Sarwar, G., Luecken, D., Yarwood, G., Whitten, G. Z., and Carter, W. P. L.: Impact of an updated carbon bond mechanism on predictions from the CMAQ modeling system: preliminary assessment, J. Appl. Meteor. Clim., 47, 3-14, https://doi.org/10.1175/2007JAMC1393.1, 2008.

Sarwar, G., Godowitch, J., Henderson, B. H., Fahey, K., Pouliot, G., Hutzell, W. T., Mathur, R., Kang, D., Goliff, W. S., and Stockwell, W. R.: A comparison of atmospheric composition using the Carbon Bond and Regional Atmospheric Chemistry Mechanisms, Atmos. Chem. Phys., 13, 9695-9712, https://doi.org/10.5194/acp-13-9695-2013, 2013.

Schucht, S., Colette, A., Rao, S., Holland, M., Schöpp, W., Kolp, P., Klimont, Z., Bessagnet, B., Szopa, S., Vautard, R., Brignon, J.-M., and Rouil, L.: Moving towards ambitious climate policies: Monetised health benefits from improved air quality could offset mitigation costs in Europe, Environ. Sci. Policy, 50, 252-269, https://doi.org/10.1016/j.envsci.2015.03.001, 2015.

Seinfeld, J. H. and Pandis, S. N.: Atmospheric Chemistry and Physics, Wiley-Interscience, New York, USA, 1998.

Semmler, M., Luo, B. P., and Koop, T.: Densities of liquid $\mathrm{H}^{+} / \mathrm{NH}_{4}^{+} / \mathrm{SO}_{4}^{2-} / \mathrm{NO}_{3}^{-} / \mathrm{H}_{2} \mathrm{O}$ solutions at tropospheric temperatures, Atmos. Environ., 40, 467-483, https://doi.org/10.1016/j.atmosenv.2005.09.056, 2006.

Shiraiwa, M. and Seinfeld, J. H.: Equilibration timescale of atmospheric secondary organic aerosol partitioning, Geophys. Res. Lett., 39, L24801, https://doi.org/10.1029/2012GL054008, 2012.

Shiraiwa, M., Ammann, M., Koop, T., and Pöschl, U.: Gas uptake and chemical aging of semisolid organic aerosol particles, P. Natl. Acad. Sci. USA, 108, 11003-11008, https://doi.org/10.1073/pnas.1103045108, 2011.

Simpson, D., Benedictow, A., Berge, H., Bergström, R., Emberson, L. D., Fagerli, H., Flechard, C. R., Hayman, G. D., Gauss, M., Jonson, J. E., Jenkin, M. E., Nyíri, A., Richter, C., Semeena, V. S., Tsyro, S., Tuovinen, J.-P., Valdebenito, Á., and Wind, P.: The EMEP MSC-W chemical transport model - technical description, Atmos. Chem. Phys., 12, 7825-7865, https://doi.org/10.5194/acp-12-7825-2012, 2012.

Skjøth, C. A., Geels, C., Berge, H., Gyldenkærne, S., Fagerli, H., Ellermann, T., Frohn, L. M., Christensen, J., Hansen, K. M., Hansen, K., and Hertel, O.: Spatial and tempo- 
ral variations in ammonia emissions - a freely accessible model code for Europe, Atmos. Chem. Phys., 11, 5221-5236, https://doi.org/10.5194/acp-11-5221-2011, 2011.

Solazzo, E., Bianconi, R., Pirovano, G., Matthias, V., Vautard, R., Moran, M. D., Appel, K. W., Bessagnet, B., Brandt, J., Christensen, J. H., Chemel, C., Coll, I., Ferreira, J., Forkel, R., Francis, X. V., Grell, G., Grossi, P., Hansen, A. B., Miranda, A. I., Nopmongcol, U., Prank, M., Sartelet, K. N., Schaap, M., Silver, J. D., Sokhi, R. S., Vira, J., Werhahn, J., Wolke, R., Yarwood, G., Zhang, J., Rao, S. T., and Galmarini, S.: Operational model evaluation for particulate matter in Europe and North America in the context of AQMEII, Atmos. Environ., 53, 75-92, https://doi.org/10.1016/j.atmosenv.2012.02.045, 2012.

Surratt, J. D., Chan, A. W. H., Eddingsaas, N. C., Chan, M. N., Loza, C. L., Kwan, A. J., Hersery, S. P., Flagan, R. C., Wennberg, P. O., and Seinfeld, J. H.: Reactive intermediates revealed in secondary organic aerosol formation from isoprene, P. Natl. Acad. Sci. USA, 107, 6640-6645, https://doi.org/10.1073/pnas.0911114107, 2010.

Tørseth, K., Aas, W., Breivik, K., Fjæraa, A. M., Fiebig, M., Hjellbrekke, A. G., Lund Myhre, C., Solberg, S., and Yttri, K. E.: Introduction to the European Monitoring and Evaluation Programme (EMEP) and observed atmospheric composition change during 1972-2009, Atmos. Chem. Phys., 12, 5447-5481, https://doi.org/10.5194/acp-12-5447-2012, 2012.

Tsyro, S., Aas, W., Soares, J., Sofiev, M., Berge, H., and Spindler, G.: Modelling of sea salt concentrations over Europe: key uncertainties and comparison with observations, Atmos. Chem. Phys., 11, 10367-10388, https://doi.org/10.5194/acp-11-103672011, 2011.

Turpin, B. J. and Lim, H.-J.: Species contributions to $\mathrm{PM}_{2.5}$ mass concentrations: revisiting common assumptions for estimating organic mass, Aerosol. Sci. Tech., 35, 602-610, https://doi.org/10.1080/02786820119445, 2001.

Vaden, T. D., Imre, D., Berankek, J., Shrivastava, M., and Zelenyuk, A.: Evaporation kinetics and phase of laboratory and ambient secondary organic aerosol, P. Natl. Acad. Sci. USA, 108, 21902195, https://doi.org/10.1073/pnas.1013391108, 2011.

Vestreng, V.: Review and Revision, Emission Data Reported to CLRTAP Tech. Rep., EMEP MSW-W, Tech. Rep., Norwegian Meteorological Institute, Oslo, Norway, 2003.

Virtanen, A., Joutsensaari, J., Koop, T., Kannosto, J., YliPirilä, P., Leskinen, J., Mäkelä, J. M., Holopainen, J. K., Pöschl, U., Kulmala, M., Worsnop, D. R., and Laaksonen, A.: An amorphous solid state of biogenic secondary organic aerosol particles, Nature, 467, 824-827, https://doi.org/10.1038/nature09455, 2010.

Wesely, M.: Parameterization of surface resistances to gaseous dry deposition in regional-scale numerical models, Atmos. Environ., 23, 1293-1304, https://doi.org/10.1016/0004-6981(89)90153-4, 1989.

Yu, S., Bhave, P. V., Dennis, R. L., and Marthur, R.: Seasonal and regional variations of primary and secondary organic aerosols over the Continental United States: Semi-empirical estimates and model evaluation, Environ. Sci. Technol., 41, 4690-4697, https://doi.org/10.1021/es061535g, 2007.

Yuan, H., Dai, Y., Xiao, Z., Ji, D., and Shangguan, W.: Reprocessing the MODIS leaf area index products for land surface and climate modelling, Remote Sensing Environ., 155, 1171-1187, https://doi.org/10.1016/j.rse.2011.01.001, 2011.
Zhang, Q., Jimenez, J. L., Canagaratna, M. R., Allan, J. D., Coe, H., Ulbrich, I., Alfarra, M. R., Takami, A., Middlebrook, A. M., Sun, Y. L., Dzepina, K., Dunlea, E., Docherty, K., DeCarlo, P. F., Salcedo, D., Onasch, T., Jayne, J. T., Miyoshi, T., Shimono, A., Hatakeyama, S., Takegawa, N., Kondo, Y., Schneider, J., Drewnick, F., Borrmann, S., Weimer, S., Demerjian, K., Williams, P., Bower, K., Bahreini, R., Cottrell, L., Griffin, R. J., Rautiainen, J., Sun, J. Y., Zhang, Y. M., and Worsnop, D. R.: Ubiquity and dominance of oxygenated species in organic aerosols in anthropogenically-influence Northern Hemisphere mildlatitudes, Geophys. Res. Lett., 34, L13801, https://doi.org/10.1029/2007GL029979, 2007.

Zhang, Y., Pan, Y., Wang, K., Fast, J. D., and Grell, G. A.: WRF/Chem-MADRID: Incorporation of an aerosol module into WRF/Chem and its initial application to the TexAQS2000 episode, J. Geophys. Res., 115, D18202, https://doi.org/10.1029/2009JD013443, 2010.

Zhao, B., Wang, S., Donahue, N. M., Jathar, S. H., Huang, X., Wu, W., Hao, J., and Robinson, A. L.: Quantifying the effect of organic aerosol aging and intermediate-volatility emissions on regional-scale aerosol pollution in China, Sci. Rep.-UK, 6, 28815, https://doi.org/10.1038/srep28815, 2016a.

Zhao, Y., Nguyen, N. T., Presto, A. A. Hennigan, C. J., May, A. A., and Robinson, A. L.: Intermediate volatility organic compound emissions from on-road gasoline vehicles and small offroad gasoline engines, Environ. Sci. Technol., 50, 4554-5463, https://doi.org/10.1021/acs.est.5b06247, 2016b.

Zhu, S., Sartelet, K. N., and Seigneur, C.: A size-composition resolved aerosol model for simulating the dynamics of externally mixed particles: SCRAM (v 1.0), Geosci. Model Dev., 8, 15951612, https://doi.org/10.5194/gmd-8-1595-2015, 2015.

Zhu, S., Sartelet, K., Healy, R., and Wenger, J.: Simulation of particle diversity and mixing state over Greater Paris: a modelmeasurement inter-comparison, Faraday Discuss., 189, 547-566, https://doi.org/10.1039/C5FD00175G, 2016a.

Zhu, S., Sartelet, K., Zhang, Y., and Nenes, A.: Threedimensional modelling of the mixing state of particles over Greater Paris, J. Geophys. Res.-Atmos., 121, 5930-5947, https://doi.org/10.1002/2015JD024241, 2016b.

Zuend, A. and Seinfeld, J. H.: Modeling the gas-particle partitioning of secondary organic aerosol: the importance of liquidliquid phase separation, Atmos. Chem. Phys., 12, 3857-3882, https://doi.org/10.5194/acp-12-3857-2012, 2012.

Zuend, A., Marcolli, C., Luo, B. P., and Peter, T.: A thermodynamic model of mixed organic-inorganic aerosols to predict activity coefficients, Atmos. Chem. Phys., 8, 4559-4593, https://doi.org/10.5194/acp-8-4559-2008, 2008.

Zuend, A., Marcolli, C., Booth, A. M., Lienhard, D. M., Soonsin, V., Krieger, U. K., Topping, D. O., McFiggans, G., Peter, T., and Seinfeld, J. H.: New and extended parameterization of the thermodynamic model AIOMFAC: calculation of activity coefficients for organic-inorganic mixtures containing carboxyl, hydroxyl, carbonyl, ether, ester, alkenyl, alkyl, and aromatic functional groups, Atmos. Chem. Phys., 11, 9155-9206, https://doi.org/10.5194/acp-11-9155-2011, 2011. 